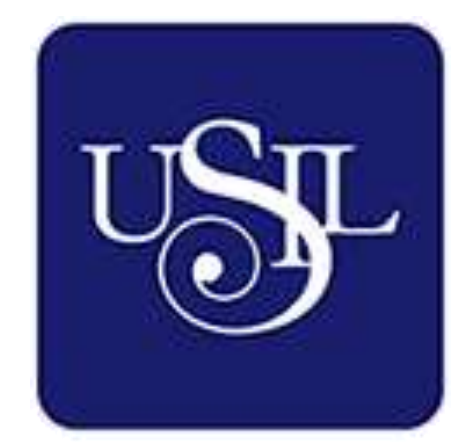

UNIVERSIDAD

SAN IGNACIO

DE LOYOLA

\begin{abstract}
ESCUELA DE POSTGRADO
Maestría en Educación con Mención en Docencia en Educación Superior
\end{abstract}

\title{
ESTRATEGIA METODOLÓGICA PARA DESARROLLAR LA IDENTIDAD MUSICAL NACIONAL EN LOS ESTUDIANTES DE LA ESPECIALIDAD DE CUERDAS DE UN CONSERVATORIO DE LIMA
}

Tesis para optar el grado de Maestro en Educación con mención en Docencia en Educación Superior

\section{LUIS PABLO CONISLLA YAÑEZ}

Asesor:

Félix Fernando Goñi Cruz

Lima -Perú 


\section{Dedicatoria}

A todos aquellos quienes en su existencia y proceder mantienen viva la esencia de nuestra identidad 


\section{Agradecimiento}

A los profesores de post grado de la Universidad San Ignacio de Loyola, quienes con su integridad y profesionalismo son un referente de aspiración personal.

A mi asesor, el Dr. Goñi por su paciencia y dedicación durante toda la Maestría.

A Dios, a mi familia por su apoyo y aliento constante, a mis compañeros de maestría y a las instituciones que me brindaron su apoyo en esta investigación. 


\section{Índice}

Índice

Lista de tablas

Lista de figuras

Resumen

Abstract

Introducción

Planteamiento del problema $\quad 1$

Objetivos de la investigación $\quad 4$

Enfoque, tipo y diseño de investigación $\quad 4$

Enfoque de investigación $\quad 5$

Tipo de investigación $\quad 5$

Diseño de investigación $\quad 6$

Población y muestra $\quad 6$

Muestreo no probabilístico $\quad 6$

$\begin{array}{ll}\text { Unidad de análisis } & 6\end{array}$

Métodos teóricos, empíricos y estadísticos o matemáticos 7

Técnicas e instrumentos de recogida de datos $\quad 10$

Validación de los instrumentos $\quad 11$

Categorías y subcategorías apriorísticas $\quad 11$

$\begin{array}{ll}\text { Estructura de la tesis } & 14\end{array}$

$\begin{array}{ll}\text { Capítulo I } & 15\end{array}$

Marco teórico $\quad 15$

$\begin{array}{ll}\text { Antecedentes de investigación } & 15\end{array}$

Fundamentos teóricos de la identidad musical 20

$\begin{array}{ll}\text { Estudio histórico de la identidad } & 20\end{array}$

Teoría sociocultural de Vygotsky $\quad 39$

Fundamentos teóricos de estrategia metodológica $\quad 41$

Clasificación de las estrategias metodológicas $\quad 44$

Capitulo II $\quad 50$

Diagnostico o trabajo de campo $\quad 50$

Análisis, interpretación y discusión de los hallazgos por técnicas e instrumentos $\quad 50$

Análisis e interpretación de las categorías emergentes y las apriorísticas $\quad 58$

$\begin{array}{ll}\text { Conclusiones aproximativas } & 75\end{array}$

$\begin{array}{ll}\text { Capitulo III } & 79\end{array}$

$\begin{array}{ll}\text { Modelación de la propuesta } & 79\end{array}$ 
Propósito

Justificación

Fundamentación teórico científico

Diseño de la propuesta

Desarrollo e implementación de la propuesta

Ejecución de la estrategia

Validación de la propuesta

Conclusiones aproximativas de los análisis y resultados de la propuesta y su validación teórica/practica

Conclusiones

Recomendaciones

Referencias

Anexos

Anexo $\mathrm{N}^{\circ}$ 1: Matriz Metodológica

Anexo $\mathrm{N}^{\circ}$ 2: Matriz de Categorización

Anexo $\mathrm{N}^{\circ}$ 3: Instrumentos de recolección de datos

Anexo $\mathrm{N}^{\circ}$ 4: Certificado de validez de los instrumentos de recolección de datos

Anexo $\mathrm{N}^{\circ}$ 5: Certificados de validez de la propuesta

Anexo $\mathrm{N}^{\circ}$ 6: Resultados estadísticos del cuestionario aplicado a los estudiantes

Anexo $\mathrm{N}^{\circ}$ 7: Resultados estadísticos de la prueba pedagógica aplicada a los estudiantes

Anexo $\mathrm{N}^{\circ}$ 8: Transcripción de las entrevistas y observación de clase 


\section{Lista de tablas}

Tabla 1. Categorías y subcategorías apriorísticas 11

Tabla 2. Fases de implementación de la propuesta 91

Tabla 3. Taller metodológico de preparación docente 94

Tabla 4. Referentes musicales de la música tradicional 96

Tabla 5. Especialista de la validación 106

Tabla 6. Validez interna por juicio de expertos 107

$\begin{array}{ll}\text { Tabla 7. Validez externa por juicio de expertos } & 108\end{array}$

Tabla 8. Escala de valoración 109

Tabla 9. Valoración interna y externa por criterio de jueces 109 


\section{Lista de figuras}

Figura 1. Presentación de las categorías apriorísticas y emergentes $\quad 60$

Figura 2. Categoría emergente 66

$\begin{array}{ll}\text { Figura 3. Categoría emergente } & 67\end{array}$

$\begin{array}{ll}\text { Figura 4. Categoría emergente } & 69\end{array}$

$\begin{array}{ll}\text { Figura 5. Categoría emergente } & 70\end{array}$

$\begin{array}{ll}\text { Figura 6. Categoría emergente } & 72\end{array}$

$\begin{array}{ll}\text { Figura 7. Categoría emergente } & 73\end{array}$

$\begin{array}{ll}\text { Figura 8. Categoría emergente } & 74\end{array}$

Figura 9. Diseño gráfico funcional de la propuesta 85

Figura 10. Taller Metodológico, Componente Académico 97

Figura 11. Taller metodológico, Componente Investigativo 98

Figura 12. Taller Metodológico, Componente Laboral 99

Figura 13. Taller Metodológico, Componente Extensionista 100

Figura 14. Valoración interna y externa por criterio de jueces 109 


\section{Resumen}

La investigación propone una estrategia metodológica para desarrollar la identidad musical nacional en los estudiantes de cuerdas de un conservatorio de Lima. La presente investigación se enmarca dentro del paradigma sociocrítico e interpretativo, tiene un enfoque cualitativo, con diseño no experimental de corte transversal descriptivo y corresponde a una investigación educacional de tipo aplicada. El muestreo fue no probabilístico a criterio del investigador, conformada por una muestra de dos docentes y 31 estudiantes. Entre las técnicas aplicadas están la encuesta a estudiantes, observación de clase y entrevista a docentes. El diagnostico puso en evidencia un conocimiento superficial referido a los componentes de la música tradicional en los estudiantes, como también la falta de material pedagógico y recursos académicos sistematizados de la música tradicional. Como conclusión se propone una estrategia metodológica que permita desarrollar la identidad musical nacional en los estudiantes con un modelo dinámico y vivencial enfocado a la interacción de los participantes con los componentes académicos, técnicos y socioculturales de la música tradicional con el objetivo de conocer estos potenciales recursos e integrarlos no solo en la formación académica, sino también en su formación como persona que aprecia, investiga, reconoce, valora y difunde su cultura y reafirma su identidad.

Palabras clave: identidad musical, elementos identitarios de la música, estrategia metodológica, socio constructivismo, música tradicional. 


\begin{abstract}
The present investigation proposes a methodological strategy to develop the national musical identity in the string students of a conservatory in Lima. This research is framed within the socio-critical and interpretive paradigm, it has a qualitative approach, it has a non-experimental descriptive cross-sectional design and it corresponds to an applied educational research. The sampling was non-probabilistic at the researcher's discretion, made up of a sample of two teachers and 31 students. Among the techniques applied are the student survey, class observation and teacher interview. The diagnosis revealed superficial knowledge regarding the components of traditional music in students, as well as the lack of pedagogical material and systematized academic resources of traditional music. In conclusion, a methodological strategy is proposed that allows developing the national musical identity in students with a dynamic and experiential model focused on the interaction of the participants with the academic, technical and sociocultural components of traditional music with the aim of knowing these resources and integrate them not only in academic training but also in their training as a person who appreciates, investigates, recognizes, values and disseminates their culture and reaffirms their identity.
\end{abstract}

Key words: musical identity, identity elements of music, methodological strategy, socio constructivism, traditional music. 


\section{Introducción}

\section{Planteamiento del problema}

El desvanecimiento de las fronteras, así como la instauración por parte de la tecnología en un mundo interconectado y ágil que es regido por el consumismo, la globalización y el mercado internacional infringe un certero golpe a las culturas regionales y nacionales, a sus tradiciones, manifestaciones, costumbres, rituales y formas de interactuar que determinan la identidad de cada pueblo o país. La Organización de las Naciones Unidas para la Educación, la Ciencia y la Cultura (Unesco, 2001) sostiene que la protección eficaz del patrimonio de los pueblos indígenas redunda en beneficio de toda la humanidad, la diversidad cultural contribuye a la adaptabilidad y creatividad de toda la especie humana.

Es por ello que el análisis de la identidad cultural en América Latina ha sido uno de los temas más polémicos y álgidos tratados en diversos escenarios, ya sea por su relevancia histórica o por el desarrollo intercultural que ha venido afianzándose desde hace décadas en las diversas naciones del nuevo mundo.

En Latinoamérica la universidad desde su inicio fue estructurada curricularmente por planes de estudio europeos que luego se replican en América Latina. La presencia de expertos en la música centroeuropea en los currículos de formación superior es importante e influyente en la población estudiantil tanto por sus conocimientos, trayectoria y experiencia, así como por su amplio repertorio musical. Esta influencia se puede apreciar en el sistema tonal y la implicancia de las formas estructurales de armonía y contrapunto, la peculiaridad sonora, timbre de los instrumentos entre otros. En base a ello, podemos reconocer que somos producto de la tradición europea con ricos elementos, lógicas y contenidos para crear música, que sin duda se manifiesta enriqueciendo el repertorio artístico y la intuición musical del estudiante.

La influencia académica de siglos en la formación profesional artístico musical se evidencia en el repertorio y la gran cantidad de métodos y materiales pedagógicos en la 
estructura curricular de la carrera, así como la metodología implantada en gran parte por profesores extranjeros o formados en el exterior priorizando los principios y conceptos de escuelas europeas o norteamericana ajenas a las necesidades y realidades de cada región. Álvarez (2015) menciona: “la música local no aparece registrada en materiales de estudio". (pp. 14). Entendemos que en muchos países latinoamericanos no se trabajan los contenidos del repertorio musical local partiendo de las tradiciones y manifestaciones costumbristas. Este repertorio no es considerado dentro de los criterios académico formativo o por lo menos no ha sido adaptado a la metodología de enseñanza-aprendizaje. Todo este acervo musical a la larga termina diluyéndose y mezclándose con otras formas y nuevos estilos comerciales perdiendo su autenticidad.

Sí se traslada esa realidad a nuestro país, específicamente en las instituciones de formación superior en donde esperamos que el concepto de identidad musical nacional cobre mayor fuerza y relevancia notamos que no está afianzada o tiene un bajo desarrollo en los estudiantes de interpretación musical. Son pocos los trabajos de investigación con un enfoque pedagógico y didáctico orientado al tratamiento de los procesos de identidad musical, las investigaciones realizadas con carácter histórico musical desde una visión técnico formativa no han sido esquematizadas ni su estructuración corresponde o se adapta a la realidad de cada región, existe una gran variedad de elementos identitarios en la música nacional que narran nuestra historia, ponen en manifiesto las costumbres, tradiciones y folklore, estos signan nuestra identidad como peruanos y deben ser considerados como objeto de investigación en el contexto pedagógico y formar parte de los contenidos del currículo.

El Perú es un país pluricultural dotado de una gran cantidad de riqueza en sus variadas y diversas manifestaciones culturales, que no se difunden ni explotan apropiadamente en las instituciones líderes en la formación de profesionales quienes deberían estar inmersas en este recurso. 
Por esa razón, nuestros estudiantes al ser ellos prospectos de grandes intérpretes o educadores, carecen de las estrategias herramientas y recursos que los ayuden a desarrollar esta identidad musical nacional. Continuar restándole importancia y olvidando el repertorio musical tradicional, las manifestaciones culturales plasmadas en danzas, rituales, o pasacalles ocurriría la desvalorización y rezago de la identidad innata en cada uno de los entes partícipes del proceso educativo, dando prioridad a los conceptos, ideologías y lineamientos extranjeros que si bien son base para la formación técnico musical profesional, no deben desplazar los principios ni los fundamentos artístico culturales del estudiante.

Actualmente, la necesidad de consolidar el principio de identidad en el ejercicio de la profesión artística y docente, es la visión que debemos tener, para ello es necesario establecer estrategias metodológicas con enfoques multiculturales que permita tomar conciencia y salvaguardar nuestra identidad cultural; es con esta visión que se propone desarrollar la identidad musical nacional de nuestros estudiantes con una estrategia metodológica acorde a las necesidades, requerimientos y realidad de país, sumergiéndonos en el origen de nuestros antecesores, rescatando sus tradiciones y manifestaciones que vienen a conformar las raíces más profundas y de las que debemos fortalecernos como artistas.

\section{Formulación del problema.}

¿Cómo desarrollar la identidad musical nacional en los estudiantes de la especialidad de Cuerdas de un conservatorio?

\section{Preguntas científicas.}

¿Cuál es el estado actual del desarrollo de la identidad musical nacional en los estudiantes de la especialidad de Cuerdas de un conservatorio?

¿Cuál es la perspectiva teórica de la estrategia metodológica para desarrollar la identidad musical nacional en los estudiantes de la especialidad de Cuerdas de un conservatorio? 
¿Qué criterios teóricos y metodológicos se debe tener en cuenta en la modelación de la estrategia metodológica para desarrollar la identidad musical nacional en los estudiantes de la especialidad de Cuerdas de un conservatorio?

¿Cómo validar la estrategia metodológica para desarrollar la identidad musical nacional en los estudiantes de la especialidad de Cuerdas de un conservatorio?

\section{Objetivos de la investigación}

\section{Objetivo general.}

Proponer la estrategia metodológica para desarrollar la identidad musical nacional en los estudiantes de la especialidad de Cuerdas de un conservatorio

\section{Objetivos específicos o tareas científicas.}

Diagnosticar el estado actual del desarrollo de la identidad musical nacional en los estudiantes de la especialidad de cuerdas de un conservatorio.

Fundamentar teórica y metodológicamente la estrategia metodológica para desarrollar la identidad musical nacional en los estudiantes de la especialidad de cuerdas de un conservatorio.

Determinar los criterios teóricos y metodológicos a tener en cuenta en la modelación de la estrategia metodológica para desarrollar la identidad musical nacional en los estudiantes de la especialidad de cuerdas de un conservatorio.

Validar por juicio de expertos la estrategia metodológica para desarrollar la identidad musical nacional en los estudiantes de la especialidad de cuerdas de un conservatorio.

\section{Enfoque, tipo y diseño de investigación}

La presente investigación se enmarca dentro del paradigma sociocrítico e interpretativo, es interpretativo que según Pérez (2004) esta metodología "intenta comprender la realidad; describe el hecho en que se desarrolla el acontecimiento; profundiza en los diferentes motivos en los hechos; el individuo es un sujeto interactivo, comunicativo que comparten significados" (pp. 27-40) 
El paradigma interpretativo; se basa en el proceso de conocimientos, en el cual se da una interacción entre el sujeto y objeto, pero no realiza generalizaciones a partir de los resultados obtenidos. Tiene como fin principal ahondar nuestro conocimiento en comprender la interacción y conducta de las personas estudiadas, lo que se consigue interpretando los significados, acciones y pensamientos.

El paradigma sociocrítico; para Mosteiro y Porto (2017) el paradigma sociocrítico pretende superar el reduccionismo del positivismo y el conservadurismo del paradigma interpretativo, introduce la ideología de forma explícita y la reflexión crítica en los procesos del conocimiento; tiene como finalidad transformar y analizar la estructura de las relaciones sociales y dar respuesta a determinados problemas generados por estas; cuestiona la neutralidad de la ciencia y de la investigación. (pp.19)

Según Rodríguez (2005) además de ser un paradigma en respuesta al reduccionismo y conservadurismo, propone una ciencia social que no sea totalmente empírica ni únicamente interpretativa.

\section{Enfoque de investigación}

De igual manera la investigación tiene un enfoque cualitativo de carácter interpretativo que según Hernández, Fernández y Baptista (2014) “puede verse como un conjunto de prácticas interpretativas que se basan en una lógica y proceso inductivo explorar y describir; utiliza la observación, recolección y análisis de los datos; evalúa el desarrollo natural de los sucesos”. (pp. 8 y 9)

\section{Tipo de investigación}

La investigación aplicada constituye un enlace importante entre la ciencia y la sociedad, según Padrón (2006) es el punto en el que los conocimientos son revertidos a las áreas de necesidad ubicadas en el entorno, y tiene como objetivo resolver problemas específicos frente a una determinada situación. 
La investigación educativa es una búsqueda constante de respuestas que permitan comprender los problemas e interrogantes que se manifiestan en una situación problemática. González, Zerpa, Gutiérrez y Pirela (2007) "la investigación educativa genera una transformación en el quehacer docente, debido a que busca el trabajo en equipo, cooperativo, comunitario con una secuencia sistemática y con cambios permanentes en el proceso, con el objetivo de llegar al contexto de la realidad social de los actores" (pp.293)

\section{Diseño de investigación}

El diseño de la investigación es no experimental que según Hernández (2014) “son estudios que se realizan sin la manipulación deliberada de variables y en los que solo se observan los fenómenos en su ambiente natural para analizarlos” (pp.154).

Es descriptivo de acuerdo a los autores Martínez y Rodríguez (2005), estas clases de investigación "se limitan a describir determinadas características del grupo de elementos estudiados, sin realizar comparaciones con otros grupos. Se circunscriben a examinar una población definida, describiéndola a través de la medición de diversas características” (pp. 14)

\section{Población y muestra}

La población está conformada por un aproximado de 500 estudiantes y 150 docentes de las distintas especialidades de un conservatorio.

\section{Muestreo no probabilístico}

El muestreo fue no probabilístico, es decir a criterio del investigador por lo tanto la muestra fue de 31 estudiantes de la especialidad de cuerdas y dos docentes de un conservatorio.

\section{Unidad de análisis}

La unidad de análisis estuvo conformada por los docentes y estudiantes de la especialidad de cuerdas (Viola, violín, Violoncelo y Contrabajo). 


\section{Métodos teóricos, empíricos y estadísticos o matemáticos}

\section{Método de nivel teórico.}

Los métodos de nivel teórico que fueron utilizados en el proceso de investigación fueron: histórico - lógico, hermenéutico - dialectico, análisis - síntesis, inductivo - deductivo y modelación.

Según Rodríguez y Pérez (2017) el método histórico - lógico “se emplea cuándo se busca los antecedentes del problema científico y durante la elaboración de los fundamentos teóricos y metodológicos; su finalidad es la búsqueda de la información” (pp.186). Se usó este método para recopilar sistemáticamente los antecedentes históricos que demarcan el origen, la evolución y el estado actual de la identidad musical nacional en los estudiantes de cuerdas de un Conservatorio de Lima.

De acuerdo a los autores Arráez, Calle y Moreno (2006) "la hermenéutica es una actividad interpretativa que permite la captación plena del sentido de los textos en los diferentes contextos por los que ha atravesado la humanidad" (pp.174). El cual surca todo el trabajo de investigación en el estudio y apreciación de las fuentes, para la definición, enriquecimiento, explicación y complementación de los datos recabados en los trabajos realizados, tomando como punto de partida el enfoque del proceso de formación de la identidad musical. Este método se empleó para la revisión y análisis de la documentación y establecer una interpretación concisa de los textos investigados y poder determinar el real significado de las palabras por las cuales se expresa la intención de los autores y de esta manera potenciar los fundamentos teóricos y aportar al diseño de una estrategia metodológica para desarrollar la identidad musical nacional en los estudiantes de cuerdas de un Conservatorio de Lima.

Para Rodríguez y Pérez (2017) el análisis y síntesis "se refiere a dos procesos intelectuales inversos que operan en unidad; el análisis y la síntesis funcionan como unidad dialéctica; puede predominar uno u otro procedimiento en una determinada etapa". (pp. 182). 
permite la búsqueda, indagación y el procesamiento de la información, partiendo desde la descomposición del objetivo de estudio, conocer su realidad y la forma en que se relacionan sus componentes para finalmente describirla de forma holística e integral. Este método lo empleamos durante el análisis de los documentos y los resultados obtenidos de la aplicación de los instrumentos, lo que nos dio un enfoque para complementar los fundamentos teóricos y contribuir al diseño de una estrategia metodológica para desarrollar la identidad musical nacional en los estudiantes de cuerdas de un Conservatorio de Lima.

De acuerdo a Cerezal y Fiallo (2003) el método inductivo - deductivo indica que "las relaciones entre la inducción y la deducción tienen como base, la lógica objetiva de los hechos, procesos y fenómenos de la realidad” (pp. 12). Lo que facilita fijar la conexión entre lo individual con lo general en su propia realidad, lo inductivo utiliza premisas particulares para ir a una conclusión general y lo deductivo usa conceptos generales para llegar a una conclusión especifica. Este método se aplicó para determinar las inferencias lógicas, al establecer un sistema de planteamientos teóricos de índole conclusivo, orientadas a perfeccionar y sustentar la base metodológica y epistemológica de la investigación y coadyuvar con la teorización de las categorías apriorísticas y emergentes, así como con sus subcategorías.

Reyes y Bringas (2006) plantean la modelación como "un proceso complejo que demanda una forma superior de construcción teórica” coincide con Rodríguez y Pérez (2017) "la finalidad de este método es la construcción de conocimientos como parte del ajuste o conformación del sistema teórico, conceptual o metodológico del proceso de investigación" (pp.188). este método se aplicó al modelar la propuesta metodológica sustentada en los fundamentos teóricos y metodológicos para aportar al desarrollo de la identidad musical nacional en los estudiantes de cuerdas de un Conservatorio de Lima. 


\section{Método de nivel empírico.}

Según Cerezal, Fiallo y Huaranga (2016) los métodos empíricos permiten la recopilación de datos relacionados al fenómeno de investigación; se admiten los conceptos y significados realizados sobre los métodos por los autores referenciados. Los métodos empíricos empleados para la investigación fueron: la observación de clases, la entrevista, la encuesta y juicio por criterio de expertos.

La observación, citando a Hernández, Fernández y Baptista (2014) “implica adentrarnos profundamente en situaciones sociales y mantener un papel activo, así como una reflexión permanente” (pp. 399). Se usó este método con el propósito de verificar la preparación teórica y didáctica de los docentes al llevar a cabo el proceso pedagógico del curso de Especialidad Instrumental y contribuir con el desarrollo de la identidad musical nacional de los estudiantes; como instrumento se utilizó la guía de observación de clases.

La entrevista, para los autores Cerezal y Fiallo (2003) “el objetivo es para obtener información confiable sobre hechos y opiniones, además de enriquecer, completar o constatar la información obtenida por el empleo de otros métodos de investigación” (pp. 59). Su aplicación tuvo como finalidad constatar la preparación teórica, didáctica y metodológica de los docentes de las especialidades instrumentales en relación al desarrollo de la identidad musical nacional en los estudiantes; se utilizó como instrumento la Guía de Entrevista semi estructurada.

La encuesta, según Cerezal y Fiallo (2003) complementa el proceso de investigación, dado que al aplicarse a mediana o gran escala permite conocer las opiniones, criterios y valoraciones en relación a determinados temas que poseen los encuestados que han sido seleccionados en la muestra. Se utilizó este método con el fin de verificar el grado de satisfacción de los estudiantes con la forma en la que los docentes dirigen el proceso enseñanza 
- aprendizaje y si desarrolla la identidad musical nacional; se aplicó un cuestionario y una prueba pedagógica.

Juicio por criterio de expertos, con la finalidad de validar la eficacia de la estrategia metodológica se aplicó este método recurriendo a especialistas de destacada trayectoria y amplia experiencia en un tema específico que expresaron su juicio acerca de la validez y pertinencia de la propuesta como resultado de la investigación. Se utilizó dos fichas que evaluaban las dimensiones internas y externas de la propuesta.

Métodos estadísticos o matemáticos, dada la complejidad de la información obtenida y la necesidad de esclarecer y procesar esta gran cantidad de datos, se empleó este método que según Obregón (2010) “consiste en una secuencia de procedimientos para el manejo de los datos cualitativos y cuantitativos de una investigación" (pp.17). el cual permitió llevar a término el procesamiento de la información obtenida del diagnóstico por medio de la estadística descriptiva utilizando el paquete estadístico SPSS-V25 culminando los correspondientes análisis.

\section{Técnicas e instrumentos de recogida de datos}

El proceso de recopilación de información, se llevó a cabo a través de la aplicación de diversas técnicas e instrumentos:

La técnica de la observación de clases se dio a través del instrumento guía de observación realizada a los docentes de especialidad Instrumental con la finalidad de tener registro de la aplicación de estrategias y conocimientos teórico-didácticos en relación al desarrollo de la identidad musical nacional en los estudiantes durante el proceso enseñanza-aprendizaje.

La técnica de la entrevista a docentes se realizó con el instrumento guía de entrevista semiestructurada compuesta por nueve preguntas realizadas a los docentes las cuales fueron alineadas a los parámetros establecidos con la finalidad de conocer la preparación teórico didáctica en relación al desarrollo de la identidad musical nacional en los estudiantes. 
La técnica de la encuesta se llevó a cabo con los instrumentos como el cuestionario compuesto por quince preguntas dirigidas a los estudiantes con el objetivo de conocer el grado de satisfacción que experimentan con la forma en la que los docentes de especialidad dirigen el proceso enseñanza - aprendizaje para desarrollar la identidad musical nacional.

En tal sentido, también se aplicó el instrumento de la prueba pedagógica compuesta por siete preguntas dirigidas a los estudiantes con la finalidad de verificar el nivel de conocimientos teóricos en relación a la identidad musical nacional; para ambos instrumentos las preguntas estuvieron en referencia a indicadores establecidos.

\section{Validación de los instrumentos}

Los instrumentos de recolección de datos fueron entregados a tres expertos, dos metodólogos y un temático, los cuales emitieron a su juicio la validez y posterior aplicación de los mismos. Se entregó a cada experto una carpeta con la ficha de validación, los instrumentos y la matriz de categorización. De manera independiente cada experto valido la pertinencia, la relevancia y la construcción gramatical de cada uno de los ítems de cada instrumento.

\section{Categorías y subcategorías apriorísticas}

Tabla 1

Categorías y subcategorías apriorísticas.

\begin{tabular}{lll}
\hline Categorías Apriorísticas & Subcategorías apriorísticas \\
\hline Identidad Musical & Identificación musical \\
Es el sentido de pertenencia & Es el sistema de contenidos de la música tradicional presentes \\
consustancial a las & en las comunidades, las cuales son reconocidos, recuperados y \\
tradiciones musicales de la puestos en valor, para transmitir, revitalizar y difundir los & precisan los & aportes culturales del contenido de las obras musicales. \\
localidad, que pres \\
sentimientos \\
identificación & de & (Álvarez, 2017). \\
\hline
\end{tabular}


concientización de los Concientización musical

elementos identitarios de la Es la valoración de los elementos identitarios que conforman las música local, que permiten raíces culturales de la comunidad, conlleva la reafirmación de asumir actitudes que develan métodos y procedimientos de búsqueda de información acerca la asunción del patrimonio de los contenidos de las obras musicales de la comunidad con su musical. (Álvarez, 2017). ～entorno sociocultural. (Álvarez, 2017).

\section{Estrategia}

metodológica

La estrategia metodológica es la unión de forma integrada y coherente de técnicas didácticas, estrategias, actividades y recursos de enseñanza aprendizaje. Viabilizan el proceso de los aprendizajes esperados tomando en cuenta el enfoque de los principios pedagógicos orientado en competencias. Fomentan en los estudiantes la

$$
\text { capacidad }
$$

de interpretación, análisis y procesamiento de la información para su uso posterior en la producción de nuevos conocimientos logrando así aprendizajes significativos. (Moya, 2017).

\section{Técnicas didácticas}

Son procedimientos de menor alcance que las estrategias didácticas, dado que se utilizan en períodos cortos (parte de una asignatura, unidad de aprendizaje, etc.); cuyo foco es orientar específicamente una parte del aprendizaje, desde una lógica con base psicológica, aportando así al desarrollo de competencias. (Moya, 2017).

\section{Actividades didácticas}

Son acciones necesarias para lograr la articulación entre lo que pretende lograr la estrategia y técnica didáctica, las necesidades y características del grupo de estudiantes. Su diseño e implementación son flexibles y su duración es breve desde una clase a unos minutos. (Moya, 2017).

\section{Recursos de enseñanza aprendizaje}

Los recursos o materiales educativos, son todos los instrumentos de apoyo pedagógico, asistencia tecnológica y herramientas didácticas, que construimos o seleccionamos con el objetivo de brindar a los estudiantes, un mayor acercamiento al conocimiento y la elaboración de los conceptos para facilitar así un mejor aprendizaje. (Moya, 2017). 


\section{Justificación de la investigación}

Teórica.

Esta investigación busca aportar de manera teórica con un enfoque socio constructivista a la construcción de las teorías epistemológicas abordadas sobre la identidad musical que permitan subsanar los problemas del ejercicio docente en relación al desarrollo de la identidad musical nacional en los estudiantes de la especialidad de cuerdas de un Conservatorio de Lima. Para ello las teorías apriorísticas se sustentaron bajo los aportes de Vygotsky (1988), Ortiz (1995), Hall (2003), Bejar \& Rosales (2005), Guadarrama (2006), Molano (2007), Calderón (2011), Costa (2015), Álvarez (2015), Álvarez (2017), Rodríguez (2019), quienes coinciden en que el desarrollo de la identidad cultural - musical es esencial en la formación de la persona, ya que comprende el conocimientos histórico y social de su cultura modificando el modo de actuación en referencia a lo propio. Esto sumado a las estrategias metodológicas, servirán al investigador como base a futuras investigaciones.

\section{Metodológica.}

Como resultado de la investigación se presenta a la práctica pedagógica superior, la estrategia metodológica modelada para contribuir al desarrollo de la identidad musical nacional en los estudiantes de Cuerdas de un conservatorio de Lima, desde el proceso de enseñanza-aprendizaje a nivel universitario. La misma que se encuentra bajo un nuevo e innovador enfoque pedagógico que, en aplicación de los docentes, permitirá a los estudiantes tomar conciencia de la riqueza y diversidad cultural que poseemos; así mismo las diferentes técnicas o instrumentos aplicados servirán para trabajos de investigación posteriores.

\section{Práctica.}

La estrategia metodológica es el producto científico resultante de la investigación, el cual permitirá que los docentes y personal involucrado en el área, encaminen de manera adecuada los procesos de enseñanza-aprendizaje y contribuir al desarrollo de la identidad musical 
nacional en los estudiantes. Asímismo, esta estrategia metodológica será una herramienta útil que podrá ser usada en la formación técnico instrumental de las especialidades que ayudara a consolidar el objetivo principal para la que fue diseñada.

\section{Estructura de la tesis}

La investigación inicia con el diseño teórico metodológico que abarca la introducción, mención del problema, como también los aspectos relacionados al tipo y diseño de la investigación la cual se estructuró en tres capítulos.

Capítulo I: Compuesto por la sistematización teórica de las categorías y subcategorías apriorísticas que parten de fundamentos holísticos que dan sustento al investigador y lo empodera en las bases científicas, teóricas y prácticas en relación al objeto de estudio.

Capitulo II: Referente al diagnóstico o trabajo de campo en donde se diseñó, validó y aplico las técnicas e instrumentos de recojo de información los cuales dio a conocer el estado real del problema y por medio del proceso de triangulación, se reconocieron las categorías emergentes e influyentes en el problema de investigación.

Capitulo III: Comprende la modelación de la estrategia metodológica con base en los fundamentos científicos: socioeducativo, psicológico, pedagógico y curricular, así como el diseño, implementación y evaluación de la puesta en práctica y la validación por criterio de expertos de la producción científica aportada.

Finalmente, se presentan las conclusiones resultantes del proceso de investigación, recomendaciones, referencias y anexos. 


\section{Capítulo I}

\section{Marco teórico}

\section{Antecedentes de investigación}

\section{Antecedentes nacionales.}

Ramírez (2019) propone una estrategia metodológica para contribuir al desempeño docente del Programa Iniciativa Pedagógica Orquestando del Ministerio de Educación del Perú (Minedu), posee un enfoque cualitativo y desarrolla el paradigma interpretativo, argumentativo, narrativo, de diagnóstico, descriptivo, naturalista y socio critico; la población fue de aproximadamente cuatro mil estudiantes y setenta docentes, la muestra fue no probabilística y selecciono cuatro docentes y sesentaicinco estudiantes, para el recojo de información aplico la entrevista a docentes, la observación de clases y un cuestionario cerrado a estudiantes. Se evidenció las carencias y limitaciones del desempeño docente en relación al desarrollo integral de los estudiantes y sus características individuales; propone la realización de capacitaciones al docente orientadas en estrategias, procedimientos y acciones diversas vinculadas al proceso enseñanza-aprendizaje.

Escalante (2018) realizo una investigación con el objetivo de analizar el papel que desempeña el wayno ayacuchano en la formación de la identidad de los pobladores de Huamanga.

Su investigación se realizó con un enfoque cualitativo y descriptivo, lo que permitió evidenciar la fuerte influencia de este género musical en la vida social de la comunidad, ya que plasma en el sus costumbres y vivencias cumpliendo además un papel formativo en la identidad de la comunidad. uso una muestra de 231 participantes siendo una población homogénea con rango de edad entre los 18 y 60 años, utilizo técnicas e instrumentos para el recojo de información como entrevistas, encuestas, focus group, cuestionarios, fichas estructuradas, así como la observación con su participación activa en algunas actividades. Concluye que, el huayno 
ayacuchano como manifestación cultural fortalece y cimienta la categoría de identidad nacional en los pobladores de Huamanga en Ayacucho.

Flores (2017) desarrolló un estudio con la finalidad de determinar la relación que existe entre la identidad cultural y el aprendizaje significativo en los estudiantes de la especialidad de Música del departamento de Educación Artística en la Facultad de Ciencias Sociales y Humanidades de la Universidad Nacional Enrique Guzmán y Valle. La investigación fue de tipo sustantiva, con diseño descriptivo correlacional, los instrumentos usados para el recojo de información fueron el cuestionario orientado para la identidad cultural como para el aprendizaje significativo. Los resultados concluyen en la necesidad de una formación continua de saberes previos por parte de los docentes del área para desarrollar el sentido de pertenencia en los estudiantes, así como la puesta en valor de los elementos identitarios culturales que poseen muchos de ellos que provienen del interior del país.

Montero (2017) realizó un estudio con la finalidad de conocer los componentes que unifican las interacciones sociales, interculturales e interétnicas a través de la música fusión como herramienta de expresión y discusión social, facilitadora de nuevos gustos y estéticas y como posible tecnología de solución de conflictos, fue un estudio cualitativo, donde se aplicaron técnicas de la entrevista a una muestra de 37 sujetos entre las edades de 18 a 35 años, en su investigación explora los discursos que emplean los músicos de fusión al describir sus proyectos y el alcance que tiene con el público, destaca como esta fusión musical que engloba distintos géneros musicales como el wayno, la chicha, la cumbia unida con el reggae, el rock, el jazz entre otros, produce sentimientos profundos de identidad, empatía, patriotismo y unidad en los distintos niveles sociales en especial en la clase alta tradicional limeña. También pone en evidencia el potencial de esta música como herramienta para viabilizar las interacciones entre los diversos estratos étnico, racial, socioeconómico a través de las cuales los jóvenes pueden 
redefinir su "yo" y estar inmersos en una visión de país más homogénea, igualitaria y menos clasista.

Moya (2017) realizó una investigación con la finalidad de identificar la incidencia de las estrategias metodológicas empleadas por los docentes en la formación de la actitud crítica en los estudiantes de los institutos superiores públicos del distrito de Puente Piedra. la investigación fue de diseño descriptivo, explicativo de corte transversal no experimental sin manipulación ni sometimiento a pruebas las variables de estudio, la población estuvo constituida por 500 estudiantes de tres instituciones superiores públicas, con edades entre los 17 y 20 años de ambos sexos. La muestra fue de tipo no probabilístico conformada por 340 estudiantes. Para la recolección de datos se usaron técnicas e instrumentos como la encuesta, entrevista y la observación. Las conclusiones indican que casi el 60\% de los estudiantes perciben que el nivel a las estrategias metodológicas es adecuado pero que no estarían en un nivel elevado en actitud crítica, además de afectar a otras dimensiones como: actitud científica, reflexión crítica y pensamiento dinámico.

\section{Antecedentes internacionales.}

Espinoza (2020) desarrolló una investigación con la finalidad de aplicar una estrategia metodológica para el tratamiento axiológico de la dimensión intercultural en la formación docente de la carrera de Educación básica de la Universidad de Machala, Ecuador. La investigación responde al paradigma cuantitativo, se usaron métodos analíticos sintéticos, de diseño estadístico y experimental. En la investigación se evidencia la desigualdad y discriminación que existe para con los estudiantes indígenas y afroecuatorianos quienes deben asumir los elementos y componentes culturales de una sociedad imperante, realidad que no es lejana a los procesos de formación docente. Los resultados indican que la aplicación de la estrategia propició un positivo cambio en las acciones y actitudes de los estudiantes al reconocer 
y valorar los derechos de todos los ciudadanos ecuatorianos sin diferencia de origen étnico, cultura o género.

Arellano (2019) realiza una revisión crítica del concepto de identidad en la música latinoamericana de tradición escrita, partiendo de diversos sucesos de carácter histórico, político y social que motivan la búsqueda constante de una identidad. En su investigación expone los fenómenos sociales que, desde la colonización europea, los conflictos y guerras por la independencia, el desplazamiento y marginación de la música tradicional y la eliminación de la cultura indígena ocasionaron un perjuicio en el desarrollo musical y cultural de la región; de igual manera el racismo, el maltrato y descuido de la población indígena, así como una búsqueda constante y obsesiva de referentes culturales extranjeros distorsionan el concepto de identidad. El autor pone en evidencia que el proceso de institucionalización, al crear conservatorios de música, escuelas de arte, orquestas sinfónicas, sociedades musicales entre otros, se estructuraron partiendo de la lógica cultural europea, por lo que la música tradicional de cada pueblo fue marginada del criterio oficial y académico. Finalmente recomienda dar importancia al potencial de trasformación del arte en Latinoamérica, pues a través de él, se evidencia los mecanismos de opresión estética, económica, marginación social entre otros, para fomentar y promover el resurgimiento de una cultura auténticamente latinoamericana.

García (2019) realizó un estudio con el objetivo de interpretar y tener una comprensión holística del sentido de las practicas musicales en la formación integral universitaria, los cuales generalmente son considerados como simples dinámicas culturales o espacios de entretenimiento de carácter extracurricular. Aborda el concepto de formación integral como componente relevante en la práctica educativa y lo articula con la comprensión de la misma, que poseen los estudiantes desde sus experiencias formativas relacionadas a prácticas artísticas. La investigación tiene un enfoque cualitativo que se desarrolló en el contexto de la educación superior universitaria, se usó la interpretación hermenéutica con el análisis documental y la 
interrelación del binomio formación integral - practica musical consolidándose en una estrategia metodológica; el resultado final indica que los estudiantes valoran estas prácticas musicales como ejercicios sociales que ayudan al reconocimiento de su personalidad e identidad en la amplia diversidad que existe en el contexto universitario, de esta manera se viabiliza la asimilación de lenguajes simbólicos que promueven el dialogo intercultural partiendo de expresiones artísticas que generen reflexión social y estética.

Álvarez (2015) el estudio tuvo por finalidad proponer una estrategia basada en un modelo pedagógico para solucionar las insuficiencias que existen en la formación de los instructores de arte de música en cuba que limita el desarrollo de su identidad musical. Este modelo pedagógico enlaza las relaciones entre identidad y conciencia musical y el protagonismo comunitario como elemento implicado en el desarrollo de la formación de la identidad musical; la muestra estuvo compuesta por 40 instructores de Arte de Música, conformando un grupo heterogéneo en cuanto a sexo, edad, lugar de residencia y centro de trabajo. El autor, utilizó métodos y técnicas de carácter cualitativo en su investigación, observación, talleres de opinión crítica y reflexión colectiva, entrevistas, así como la misma experiencia pedagógica que propiciaron el vínculo entre los instructores de arte de música con los compositores, grupos e intérpretes que desde sus propias localidades comprobaron la efectividad del modelo pedagógico propuesto.

Garza (2015) propone un modelo pedagógico para el desarrollo de la identidad cultural de los estudiantes de la preparatoria N. 1, de la Universidad Autónoma de Nuevo León, Monterrey, México. La investigación toma como premisa de que es en Latinoamérica en donde el estudio y análisis de esta problemática cobra mayor relevancia y complejidad debido al contexto histórico, y es en los estudiantes universitarios, considerando su lugar de procedencia y diversidad, en donde la identificación y concientización con su cultura se ve confrontada. La investigación tuvo un enfoque cuantitativo, se hizo un diagnóstico para medir el desarrollo de 
la identidad cultural, desde el proceso formativo del estudiante. la muestra estuvo conformada por 40 profesores de distinta especialidad a los que se les realizo entrevistas, 200 estudiantes que desarrollaron un cuestionario para apreciar el nivel actual y perspectiva respecto a su identidad cultural, tras la evaluación de indicadores y resultados del diagnóstico se propone un modelo pedagógico que está conformado por tres subsistemas con sus respectivos componentes: proceso de gestión extensionista, proceso de formación axiológica y proceso contextual de identidad de la cultura universitaria.

\section{Fundamentos teóricos de la identidad musical}

Considerando que la investigación estará orientada a desarrollar la identidad musical nacional en los estudiantes de cuerda de un conservatorio, mediante la aplicación de una estrategia metodológica con fundamento en la teoría sociocultural de Vygotsky (1988) quien sostiene que el aprendizaje es el resultado de la interacción de la persona con su medio social; por lo que el individuo toma conciencia de quien es en relación al medio en donde se encuentra. Empezaremos por estructurar los lineamientos que usaremos como ejes teóricos en el desarrollo de la investigación, posteriormente identificaremos las dos categorías principales: identidad musical, y estrategia metodológica.

Para una mejor comprensión de las categorías propuestas iremos desglosando cada una de ellas desde su concepción inicial hasta el grado actual en que se encuentran y a la vez buscar los puntos en que se entrelazan ambas categorías.

\section{Estudio histórico de la identidad}

La identidad es la esencia de lo que somos como individuo, grupo social o nación, también es la conciencia que cualquier persona posee en relación a sí misma y que por consecuencia la hace distinta a las demás, implica características definidas, procesos y rasgos. Aunque una gran cantidad de estas peculiaridades que conforman la identidad son heredadas o innatas, el medio o entorno influye fuertemente en la individualidad de cada sujeto. Es por ello que el concepto 
de identidad se vincula con algo propio o con el sentido de pertenencia que a su vez puede quedar oculta, desfasada o hasta subordinada por influencias o presiones externas.

Todo ello nos hace considerar el concepto identidad como un componente principal en la estructura interna de una entidad ya que permite a cada persona contemplarse como ente individual o colectivo y adquirir una comprensión de sí mismo en relación a otras personas o grupos. Hall (2003) menciona que las identidades permanecen autónomas, individuales no llegan a unificarse, se fragmentan constantemente entre sí, se constituyen de diferentes maneras a través de prácticas, diálogos y posiciones diversas.

Arteaga, (2012) refiere el termino identidad al espacio socio psicológico de pertenencia, integrado por el conjunto dialectico de rasgos, significaciones y representaciones compartidas por los miembros de una institución, tales caracteres facilitan que las personas tomen conciencia de sí mismos relacionándose entre ellos, buscando y encontrando similitudes o diferencias con otros elementos.

En esa misma línea, Hall (2003) sostiene que la identidad nace del proceso de la identificación que se define como la articulación y la diferenciación en la cual está inmerso el sujeto. La identidad es el producto de ese fenómeno, de esa interrelación del hombre a su entorno y la construcción individual de su propia estructura.

En todos los lugares donde se asienta una comunidad, pueblo o sociedad; sus integrantes, están en constante interacción y confrontación con tradiciones, costumbres e ideologías totalmente distantes a las propias, como sostienen Bejar \& Rosales (2005) que de manera constante nos enfrentamos al otro, al que es diferente y lejano. Entendemos que este acontecimiento sucede a nivel mundial no solo en los países del Nuevo Mundo por ello el impacto que tiene en nuestra sociedad la modernidad del mercado o la globalización remueve nuestra conciencia, nuestro ser, nuestra identidad. 
Una institución posee identidad cuando sus miembros están interrelacionados entre sí con una visión conjunta, entrelazando sus aspiraciones, sueños, estilos de vida, anhelos y rasgos sin perder su singularidad en el grupo sino cohesionando sus características individuales que refuerzan los lazos internos de pertenencia e identificación creando un sentido de pertenencia para con la institución, en congruencia manifiesta Ortiz (1995) (como se citó en Salazar y Mugno, 2015) "la identidad no debe encerrar a sus miembros, sino que debe permitir que se enriquezcan con otros lugares" (pp. 27). La identidad que las personas comparten se recibe, es enriquecida constantemente, se nutre, se transforma y puede perderse o diluirse por influencia de otras culturas sobre sus miembros.

En los países que han sido colonizados la línea de su identidad y cultura ha sido resquebrajada por lo tanto la búsqueda de su identidad conlleva un sentido defensivo y rechazo hacia esta cultura opresora dando pase a un sincretismo en conjunción con la nueva cultura dominante. Estos pueblos deben redefinir su identidad entrelazando sus conceptos primarios de lo que han sido con la visión de lo que vislumbran ser.

De este planteamiento, es que surge la identidad cultural que de acuerdo a Molano (2007) es un conjunto de tradiciones, valores, orgullos, símbolos, creencias y modos de actuación, que se articulan e interactúan como elementos que componen un grupo social promoviendo que los sujetos puedan fundamentar su sentimiento de pertenencia. Similar postura posee Rodríguez (2019) quien menciona que la identidad cultural es una línea de tradiciones, costumbres y valores que construyen la idiosincrasia de una comunidad o de un determinado grupo humano. Por medio de la identidad cultural se adquiere un sentido de autenticidad y pertenencia, la cual es infaltable para preservar y transmitir las características de cada pueblo o nación.

La identidad es un elemento principal en el proceso de formación y consolidación de la cultura ya que esta engloba hechos, actitudes, conocimientos y tradiciones que son la base sobre 
la que se construye una sociedad; para Guadarrama (2006) la cultura es la unión de formas de comportamiento que hemos adquirido, que demuestran juicios y opiniones acerca de las condiciones de vida y que se transmiten por medio de procedimientos simbólicos de generación, los que incluyen el lenguaje, las creencias, mitos y el saber. En el mismo sentido Guadarrama (2009) también menciona que la cultura corresponde al nivel de dominio que tiene el hombre sobre las condiciones de vida de su ser, de su existencia a través de la historia, hecho que implica igualmente control sobre su conciencia y proceder espiritual facilitando una mayor libertad y beneficio para su comunidad.

Álvarez (2017) concibe la identidad musical como el sentido de pertenencia consustancial de las tradiciones musicales de una comunidad, que determinan los sentimientos de autenticidad y toma de conciencia de los elementos que conforman e identifican la música local y que permiten asumir posturas de valoración de su patrimonio musical.

En esa línea, Costa (2015) refiere que la formación de la identidad musical se produce en la unión, del proceso de enculturación, en que se adquieren usos y tradiciones de la sociedad y la formación personal en el que las experiencias musicales no son solo instructivas sino también experiencias educativas valorativas. De igual manera Calderón (2011) refiere la identidad musical como "el marcado sentimiento de pertenencia hacia las tradiciones musicales de una nación o localidad, a partir del conocimiento de los diferentes elementos que conforman y complementan a la música como manifestación del arte que le permite al individuo interactuar y auto identificarse con el patrimonio musical que lo rodea". (pp. 25).

En estos referentes se puede percibir un juicio estético, de apreciación y valoración de estos elementos por lo que la identidad musical está relacionada con la práctica educativa de la persona la cual facilitaría realizar esta apreciación. La cultura es propia del ser humano, ya que rige la autoconciencia de los pueblos y comunidades a través de su historia. 


\section{Identificación musical.}

Todas las personas que integran una comunidad llegan a identificarse con los elementos que son propios de la música que componen, interpretan y disfrutan partiendo de los intereses y necesidades de cada generación que es nutrida y transmitida por los antecesores como parte de su propia realidad y de la importancia social que este legado representa.

Álvarez, (2017) concibe la identificación musical como el sistema de contenidos propios de la música tradicional de una comunidad, los cuales son identificados, valorados, transmitidos y difundidos a los integrantes niños, jóvenes y adultos de la comunidad, está conformado por los componentes acercamiento musical, contextualización musical y sensibilización musical.

El acercamiento musical, es el resultado de la relación entre el sujeto, familia y música que se produce en la comunidad; en una primera fase el acercamiento se enfoca en el conocimiento de lo que acontece de forma general a nivel de sociedad y a su vez de la comunidad de forma particular, partiendo desde el aprecio y valoración de los contenidos artísticos, muestra la lógica de apropiación de los contenidos de las obras musicales locales, perfila los conocimientos esenciales que deberán interiorizar los profesores y estudiantes a la vez que desde un enfoque pedagógico se transmitirán los conocimientos principales acerca de los elementos identitarios de la música de la comunidad, este proceso no es pasivo sino activo ya que parte de la necesidad cognitiva en relación con el hecho de poder ubicarse en su propio contexto y de esta manera formar los aspectos de identificación identitaria.

Al darse este acercamiento se promueve la discusión académica para abordar los problemas que surgen en la formación de los estudiantes, en este proceso se identifican y ubican los contenidos que prepararan a los estudiantes para la aprehensión de los elementos identitarios de la música basados en la teoría y análisis académico desde un enfoque ontológico. Esto conlleva a que durante el proceso de enseñanza de la música tradicional se deben integrar la teoría y la práctica partiendo del análisis y reconocimiento en un contexto socio cultural 
(Vygotsky 1982) con marcado predominio en las virtudes y potencialidades pedagógicas de los contenidos del repertorio musical de la comunidad.

La contextualización musical, facilita los medios para lograr la representación del hecho, la localización geográfica del elemento cultural incluyendo el tiempo y condiciones en que la obra fue compuesta, los conocimientos teórico prácticos acerca de la formación de los valores musicales de la comunidad; es ahí en donde profesores y alumnos interactúan con oyentes que tienen preferencias disimiles de aceptación o rechazo a las obras musicales, al margen de que sean locales o no; todo esto permite que la orientación educativa para formar la identidad musical tome curso hacia la conformación de las actitudes identitarias en el ámbito de la pedagogía, que involucra la conjunción de el acercamiento musical, la contextualización musical y un tercer componente la sensibilización musical que se reflejan en la vivencias y los sentimientos ligados a estos elementos identitarios de la música.

Finalmente, la contextualización musical es un medio para fomentar respeto admiración y aprecio hacia los elementos identitarios de la música tradicional, logrando conocer de esta manera las raíces, tradiciones, y costumbres que forman parte de la historia de los pueblos.

Sensibilización musical, es la relación que se da entre el conocimiento de las obras musicales y la formación de sentimientos en los estudiantes y profesores para contribuir a la formación de la identidad musical. Para que se produzca esa sensibilización con la música tradicional se requiere que los profesores den un tratamiento especial a la temática y contenidos relacionados con la historia de la música de la comunidad relacionados con: los orígenes socio históricos de la identidad musical, los aportes musicales y elementos identitarios, las costumbres y tradiciones musicales de la familia y comunidad, la vida y obra de compositores e intérpretes de la comunidad.

Finalmente, la interacción que se produce entre los componentes acercamiento musical, contextualización musical y sensibilización musical, concede a la subcategoría identificación 
musical una función cognitiva, tomando en cuenta que se enfoca en la asimilación de conocimientos, el desarrollo de destrezas y hábitos y sienta la base para la formación de valores relacionados con el mundo y su comunidad.

La función de esta subcategoría permite la formación de la identidad musical a medida que se consolidan los contenidos de las obras musicales de la comunidad, la historia de los referentes musicales ya sean compositores e intérpretes, es por ello que se establecen las relaciones de coordinación con la subcategoría concientización musical y entre sus componentes se entrelazan e instauran conexiones de coordinación.

\section{Concientización musical.}

La sub categoría concientización musical nos da el cimiento para la formación de la identidad musical que buscamos desarrollar en los estudiantes del conservatorio, interrelaciona los elementos cognitivos con los valorativos, esta valoración funcional es la que busca consolidar los conocimientos del suceso histórico social en el cual origino la cultura que los identifica.

Para Álvarez, (2017) la concientización musical es una vía para fomentar sentimientos de admiración respeto y amor hacia los elementos identitarios de la música tradicional, de esta manera se logra el conocimiento acerca de las raíces, costumbres, tradiciones de índole social o familiar. Interrelaciona los elementos cognitivos con los valorativos, integra los componentes significatividad musical y la valoración funcional musical, y estos se manifiestan en el componente expresión conativa identitaria.

La significatividad musical, es el componente que conlleva el sentido de pertenencia que alcanzan las obras musicales de la comunidad para los estudiantes y profesores, en el que implica relaciones entre las capacidades técnico-musicales y el nuevo conocimiento de los elementos de la obra musical. En tal sentido, engloba los conocimientos, actitudes, intereses, motivaciones y la experiencia previa de los profesores y estudiantes lo que facilita que el 
análisis de las obras musicales adquiera un nuevo sentido, impulsa el establecimiento de conexiones entre los nuevos contenidos y el mundo afectivo de los estudiantes y profesores, facilita las relaciones entre los conceptos ya asimilados y los nuevos que se van consolidando.

La valoración funcional musical, consolida los conocimientos del proceso histórico en el que se formó su cultura, la identificación y aprecio a la música de su comunidad y su participación en el desarrollo de los elementos identitarios que la caracterizan; se demuestra en la aceptación de los elementos de diversas obras musicales, así como su activismo en la protección y conservación del propio repertorio musical.

Este componente tiene su base en las vivencias y emociones positivas de los estudiantes y profesores al aportar con su reflexión y critica coherente en cada función de la música considerando todo su ámbito, contexto familiar y comunitario, en la valoración de las cualidades, categorías o criterios estéticos que aporta la obra musical. Todos ellos reflejan la orientación positiva enfocada hacia esta identidad y tienen la cualidad de ser vivenciales, afectivas, duraderas y reguladoras del proceder de los estudiantes y profesores para tomar acciones y solucionar los diversos problemas que pueden presentarse.

La expresión conativa identitaria, es el componente referido a la actuación gestual y verbal de los estudiantes y profesores en relación a la aceptación o no de la identidad musical en todos sus contextos. Posee sus fundamentos en las actitudes asumidas, al expresar sentimientos naturales, libres y espontáneos en los que se demuestren las emociones y complacencia.

Los elementos identitarios de la música deben generar actitudes de aceptación y desfrute en los entes participantes, en ellos se debe cristalizar sus sentimientos a través de la creación de obras musicales o de interpretación instrumental de las composiciones propias de la comunidad. Este componente facilita que las actitudes y posturas que asumen frente a los estímulos musicales dados desde la familia, escuela o la comunidad, se manifiesten en el modo de 
proceder, la consolidación y reafirmación de la identidad musical.

Ambas subcategorías, identificación musical (función cognitiva) y concientización musical (función valorativa) con sus respectivos componentes, integrados en la comunidad; facilitan para los profesores, la estructuración y definición de los elementos identitarios de la música con el fin de poder abordar y aplicar los contenidos que deben interiorizar los estudiantes durante su formación profesional.

La idea de formación de la identidad musical se podría considerarla como un proceso de identificación y concientización en los estudiantes del conservatorio, de unir los contenidos de las obras musicales concebidas por compositores o ejecutadas por interpretes ya sean académicos o no que reflejan hechos, costumbres y tradiciones de carácter histórico y social de la localidad o región, que demuestran un sentido de autenticidad en su desenvolvimiento profesional.

Para García, (2008) este enfoque resulta fundamental; buscar la interrelación entre interculturalidad e identidad musical debido a que en la interculturalidad se concretan los elementos propios de las costumbres, ritos, manifestaciones socioculturales que son portados por diversas familias de la comunidad, y se cohesionan como características propias de la identidad musical lo cual favorece el desarrollo de las tareas y funciones pedagógicas que realizan los profesores de música. La interculturalidad implica comunicación, trato, interacción de culturas de forma horizontal sin sobreponer una sobre otra fomentando la igualdad, convivencia, armonía y respeto entre ellas. Está basada en el respeto a la diversidad de las culturas, sin embargo, en ese proceso es probable que surjan conflictos dada la diversidad, crecimiento y desarrollo de las culturas es por ello que estos desacuerdos deben solucionarse con un dialogo constructivo y diplomático.

Referirse a la interculturalidad, necesariamente salen a relucir otros términos relacionados entre sí como la multiculturalidad o pluriculturalidad ambos con definición similar 
a pesar de la concepción etimológica en sociología que considera multicultural al paralelismo de varias culturas y pluricultural cuando se integran entre ellas.

Al respecto, García (2008) menciona que "el multiculturalismo es el reconocimiento de una realidad (Perú es un país con una estructura cultural y lingüística diversa); e interculturalidad es la práctica de un multiculturalismo", (pp. 18). En concordancia con tal afirmación podemos indicar que la educación a través de un enfoque intercultural es el mecanismo adecuado para promover la unidad intercultural partiendo de la diferencia multicultural.

Por otro lado, la identidad musical, se consolida en la unión de los elementos musicales de las variadas culturas que son portadas por los grupos y familias que conviven y subsisten en la comunidad. Esto se da a través de los diálogos e interacción cultural que se producen en la interacción de los miembros de un pueblo o comunidad.

Cuando hablamos de música, referimos a una fuerza que une e identifica en si misma a una comunidad, este fenómeno se observa en todas las culturas a través de la historia de los pueblos, estos aspectos deben constituir núcleos esenciales del contenido de las asignaturas que se imparten en las entidades de educación básica y superior que a su vez permitirían la interrelación entre la identificación musical con la concientización musical como parte de su formación integral, los que se consolidarían en la formación de valores en los estudiantes.

Álvarez, (2015) sostiene que las características y rasgos de la identidad musical que se manifiestan en las comunidades o regiones del país deben ser aprendidas e interiorizadas, estas se sintetizan en: (a) El arraigo musical; (b), la trascendencia musical; (c). la vigencia musical; (d), la interculturalidad; (e) y la sonoridad musical.

Resulta plausible que el conocimiento de la identidad musical, así como sus componentes intrínsecos que rigen su existencia como característica esencial de las identidades 
de las comunidades, no puede disociarse en la construcción teórica y práctica de una estrategia metodológica como la que estamos planteando con un trasfondo profesional pedagógico.

Es en la comunidad en donde surge y se desarrolla la música tradicional, (Miranda / Tello, s/f) "una tradición, entonces, no es algo que exista a priori y de lo que pueda nutrirse cualquier compositor; por el contrario, la noción misma de la tradición es sólo una forma entre varias de observar el fenómeno artístico" (pp.40) entonces surgen los juicios musicales, criticas, las vivencias y las apreciaciones del fenómeno sonoro, así como la valoración de los rasgos identitarios del hecho musical desde la perspectiva personal o grupal de los sujetos; por lo que la función de la comunidad en esta investigación que busca desarrollar la identidad musical es esencial.

Exactamente, cuando los estudiantes del conservatorio van desarrollando sus capacidades, conocimientos y habilidades que le permitirán discernir acerca del fenómeno musical, llegar a una asimilación de la música internacional, nacional y sobre todo regional; se consolida la formación de la identidad musical ya que se establece un nexo intimo con la producción musical de su comunidad, se desarrolla su sensibilidad y apreciación musical y reconoce los diferentes contenidos así como los variados tipos de música.

La orientación pedagógica en los estudiantes es necesaria desde su formación inicial ya que les permitirá aprender, interiorizar y sensibilizarse con el hecho artístico de la cultura musical de las comunidades.

El proceso de la formación de la identidad musical se da en cada región o localidad del país las cuales tienen un protagonismo esencial en este proceso, pero son los estudiantes, futuros músicos profesionales y docentes, quienes serán los encargados transmitir, difundir la historia, tradiciones, costumbres de su comunidad en si sostener el ciclo vital de una parte importante de la cultura. 
La comunidad, por ser el ambiente sociocultural en donde los estudiantes se desarrollan pasa a ser un espacio de suma importancia para el proceso formativo. Es vivaz heterogéneo y su identidad, como ente comunitario, se sostiene en el desarrollo diferenciado, así como en su diversidad. Los músicos de cada comunidad se sienten identificados con los elementos que constituyen y caracteriza la música que interpretan, componen y difunden, basándose en los intereses y necesidades de cada grupo generacional a los que le es inculcada por sus antecesores.

Los maestros del conservatorio, dentro de su labor formativa, deben buscar que los contenidos de las asignaturas, presenten el enfoque y temáticas que se relacionen con la historia de la música tradicional, considerando los orígenes históricos, aportes musicales a la identidad musical regional así como nacional partiendo desde un enfoque valorativo relacionando lo extranjero con lo propio e innato; también se debe considerar las costumbres y tradiciones musicales, la vida y obra de compositores e intérpretes representativos de cada región del país.

Es necesario que los contenidos del repertorio musical tradicional lleguen a los estudiantes de forma didáctica y amena, que les facilite poder identificarse con ellos; el enfoque educativo debe favorecer que todas estas manifestaciones culturales musicales que han interiorizado desde la escuela, la familia y sus comunidades aunado a una formación técnico musical académica, les permita la formación de la identidad musical nacional.

Para este fin resulta imperativo que los maestros del Conservatorio conozcan los contenidos del repertorio tradicional y valoren su importancia, sientan interés, motivación y satisfacción por su enseñanza. Los maestros del Conservatorio en su doble función de artistas y pedagogos tienen la responsabilidad de educar y formar a las futuras generaciones de artistas y educadores proponiendo estrategias para desarrollar, preservar y difundir la música tradicional en los diferentes aspectos y contextos. 


\section{Métodos históricos o activos en la educación musical.}

En la mayoría de las veces en que los métodos activos han sido estudiados, se les ha valorado más por brindar soluciones al docente de educación musical en el aula, como si fuera considerado un recetario para la enseñanza, y muy poco abordados desde una perspectiva pedagógica. Es entonces que, al referirnos al método musical, este posee, en el rango histórico de la enseñanza musical, connotaciones exactas relacionadas con el aprendizaje de un instrumento y del solfeo, es decir una secuencia ordenada de ejercicios y conceptos para facilitar los aprendizajes.

En ese sentido, podría describirse como un manual o texto estructurado que, de acuerdo a las épocas y exigencias ha ido nutriéndose por cada autor, su evolución fue refinándose técnicamente a requerimientos específicos y necesidades que permitan exaltar las personalidades musicales de compositores e intérpretes ya sea instrumental o vocal.

Sumado a ello, cada docente aborda teorías del aprendizaje que también determinan su proceder e interacción con sus estudiantes, usan diferentes modelos didácticos que según la definición de Pont (1996) "son herramientas que utilizan los profesores e investigadores para avanzar en su labor de construcción de un cuerpo de conocimiento en relación con los procesos de enseñanza - aprendizaje”.

Pont clasifica los modelos didácticos en modelos clásicos, entre ellos el modelo socrático que se basa en el dialogo y preguntas del profesor, la ventaja de este modelo es la constante interacción con los estudiantes; el modelo tradicional se caracteriza por la explicación o discurso por parte del docente, la actividad didáctica se enfoca en él y en los contenidos que transmite.

El modelo activo, tiene sus bases en pensadores Rousseau, Pestalozzi, Froebel entre otros, este modelo caracterizo a la Escuela Nueva que se desarrolló durante el siglo XIX y posteriormente tomó el nombre de Escuela Activa, este modelo le dio importancia y 
protagonismo al alumno como ente activo de su propio aprendizaje, es el modelo Decroly quien coincide con este concepto ya que promueve los aprendizajes a partir de conocer, que es lo que le interesa al alumno, que son los temas que llaman su atención a los cuales denomina como "centros de interés".

El modelo racional-tecnológico, está basado en el cartesianismo, de concepción positivista y neopositivista. Que se caracterizan por buscar una respuesta observable, verificable y el análisis detallado de la materia que se enseñara, como es expuesto en las taxonomías de objetivos Bloom (1971) en las que ordenada y sistemáticamente se procede de lo simple a lo complejo.

El modelo de mediaciones, se enfoca en los procesos que interviene entre los estímulos y respuesta, concibe el aprendizaje como una reestructuración del conocimiento que produce niveles de competencia en la construcción de los estímulos. Se toma en cuenta los procesos internos de los entes inmersos en el proceso enseñanza-aprendizaje considerando que este proceso es sumamente complejo en el cual intervienen las subjetividades de los participantes por tal motivo asumen gran relevancia todos los elementos que forman parte del proceso de comunicación. Este modelo tiene un grado de importancia secundario ya que surgió posteriormente al momento histórico en que se produjeron los modelos activos en música.

A los modelos contextuales, se le asigna importancia al contexto en el que se desarrolla la acción didáctica, en la cual están inmersas diversas variables de índole personal, social y ambiental tomando en cuenta a los participantes y la situación en que se da el proceso educativo.

Para esta investigación nos enfocaremos en los métodos activos que están en vigencia actualmente pasando por alto los primeros métodos activos que alcanzaron gran acogida en Europa, estos estuvieron enfocados en solucionar el aprendizaje de la lectoescritura musical por tal motivo son considerados netamente técnicos y no comparten el concepto educativo en que la música tiene un papel preponderante. 
Considerando la importancia formativa de la educación y la pedagogía actual podemos decir que estos métodos fueron sistemas de aprendizaje para la música y no por la música, por lo tanto sus autores Jackes Rousseau, quien invento un sistema que consistía de una serie de números que reemplazaban el nombre de la notas, John Curwen quien tomo como referente el trabajo de la profesora noruega Sarah Glover 1835, el sistema Curwen que se enfocó en el uso del Do móvil, Guillaume Louis Bocquillon Wilhelm 1836 y Pierre Galin quienes basaron su trabajo en el Do fijo. Estos reformistas estarían dentro de la categoría de neopositivistas ya que su concepto de la música es entendido como objeto lo que en términos de modelo pedagógico corresponde al modelo tradicional.

\section{Métodos activos - Escuela Nueva.}

Dalcroze Emile Jaques, (Austria) basó su método al observar cómo sus estudiantes del conservatorio no disponían de una figura mental del sonido, la cual es necesaria para que el trabajo del curso de armonía no sea exclusivamente teórico, partiendo de esa observación empírica es que construyo gradualmente un sistema articulado entre música y movimiento con la convicción de que la dinámica corporal interactiva permitiría construir aquella imagen mental del sonido que con los métodos técnicos no se llegaba a concretizar.

Dalcroze en relación al ritmo observo como los niños tenían serias complicaciones para comprender la notación musical tradicional, en ese entonces basada en la interrelación de los números con los valores de las notas musicales; estas figuras rítmicas que en principio parecen complicadas de descodificar en realidad son sucesos rítmicos que los niños ya han experimentado cotidianamente cuando caminan, saltan, corren, respiran incluso al hablar existe un ritmo en la dicción de las palabras, es por ello que el ritmo antes de asociarse con la notación musical, es una experiencia fisiología y biológica que permanece latente en toda la vida del ser humano siendo para Dalcroze el componente musical que acompaña al hombre desde que nace y por consecuencia hace que la música sea más fácil de apreciar cultivar y amar. 
El método de Dalcroze presenta las siguientes características: es paidocéntrico, tiene relación con el despertar natural y curiosidad del niño manteniendo un rol central de la actividad, el docente es guía y mediador proponiendo materiales musicales que se desarrollan mediante el juego, a diferencia del método tradicional, que se seleccionaba solo a los más dotados para la música, este planteamiento involucra a todos los niños, jóvenes y adultos e incluso discapacitados logrando una verdadera inclusión social, la autonomía y la autoafirmación está contemplada en la metodología por lo tanto los niños tienen la libertad de escoger que herramientas o recursos les permiten construir aprendizajes.

Orff Carl, (Alemania) la base del método Orff son la unión del lenguaje verbal, la música y danza, considera que no existen niños ni personas que no tengan talento musical o sean completamente no musicales, de modo que con una metodología adecuada se puede desarrollar la percepción rítmica, las formas musicales, niveles y alturas sonoras además de participar en dinámicas grupales que faciliten estos aprendizajes. En su enseñanza utiliza elementos propios de su forma de composición, como intervalos diatónicos, notas pedal, ostinatos, así como armonía en movimiento paralelo interpretados por instrumentos y voces relacionados al movimiento corporal.

Estas características de su método permitieron introducir en las aulas escolares de los países occidentales instrumentos de una mejor calidad de la que se solían usar hasta ese entonces además de su idea principal la "célula rítmica", que a través de las palabras y la división en silabas, permite observar el aprendizaje infantil en relación con el ritmo, dándole sentido a los sonidos y no percibirlos como pulsos aislados.

En ese sentido, Orff (1963) menciona que “no es nunca música sola, ella está asociada al movimiento, danza y palabra, es una música que cada uno realiza por sí mismo, en la que estamos involucrados no como auditores sino como co -interpretes. Ella es pre-intelectual, no conoce grandes formas ni arquitecturas, produce ostinati, pequeñas formas repetitivas y de 
rondo. Música elemental, es terrenal, innata, corporal, es música para que quienquiera que sea puede aprender y enseñar, es adecuada para el niño".

Al igual que el método Dalcroze, el método Orff es considerado plenamente como una propuesta didáctica dentro del rango de los modelos activos señalando las siguientes características: el estudiante es protagonista activo, los procedimientos son desde lo más simple hacia lo complejo esto como influencia del neopositivismo, el concepto de "célula rítmica" que es el mejor ejemplo de la observación y experimentación que realizo Orff, el planteamiento es inclusivo ya que no hace distinción entre los estudiantes, el enfoque creativo permite a los estudiantes libertad y autonomía en la gestión de sus interés y motivaciones además responder a sus inquietudes y necesidades.

Kodály, (Hungría) basa su método en el desarrollo psicomotor del niño, es decir que las capacidades maduran y progresan en un medio social que estimule y favorezca estas capacidades, Lucato (2001) para Kodály la educación musical debe formar parte de su formación integral del niño y estar presente en el desarrollo como persona incluyendo con una educación conjunta del oído (sonidos), vista (la lectoescritura), las manos (la práctica instrumental) y el corazón (que potencia la expresividad y la sensibilidad).

Este método usa la voz, como eje principal, ya que es el instrumento más accesible para todos, utiliza melodías tradicionales del país natal del niño, así como canciones infantiles ya que estas al tener ritmos y notas similares, hace que estos elementos se integren progresivamente y de manera amena a su aprendizaje facilitando más adelante la incorporación de los conceptos teóricos.

El objetivo técnico-musical de Kodály consistía en el aprendizaje de la lectoescritura musical para ello se apoyó en la quironimia que tiene fundamentos en Guido de Arezzo y la solmización, con alturas sonoras relativas y las iniciales de los nombres de las notas. Este método podríamos alinearlo con los autores del siglo XIX; considerando las circunstancias 
históricas en que Kodály desarrollo su método se le asigna un valor importante al repertorio local tradicional, llegando a ser considerado repertorio oficial reemplazando paulatinamente los repertorios locales e integrado en todas las escuelas del país.

Willems, (Bélgica) su método tuvo una característica diferente en relación a los autores antes mencionados, formuló una teoría psicológica basada en su concepción filosófica y pedagógica de la música enmarcada por su atención y preocupación por la vida interior del ser humano. Willems establece un paralelo entre las estructuras formales de la música y la estructura psicológica del hombre, de esta manera correlaciona los elementos ritmo, melodía y armonía con lo que él concibe como los tres componentes esenciales de la personalidad humana, la sensorialidad, la afectividad y la racionalidad.

Su teoría posee un gran valor histórico ya que es el primer educador musical que relaciona la música con la psicología a pesar de no hacer referencias concisas y factuales con las investigaciones psicológicas de ese entonces como son el caso de las teorías de Gestalt, el psicoanálisis de Freud, el condicionamiento de Pávlov y las teorías conductistas; podemos reconocer la teoría de Willems como un componente filosófico para la música además que de forma similar a los métodos precedentes posee una acercamiento activo hacia la música empezando por vivenciarla fomentando las habilidades de percepción, reproducción, improvisación y memoria antes de proceder a su estudio gramatical y la lectoescritura musical, el niño tiene un rol activo en el proceso de enseñanza, conlleva un planteamiento democrático que coincide con los métodos anteriores, procede de los más simple a lo complejo lo cual es un nivel de facilitación didáctica, contiene actividades creativas brindándole autonomía y libertad para elegir recursos de su interés y motivación.

Martenot, (Francia) inventor de las ondas Martenot y del instrumento del mismo nombre, en su método, se interesó por mejorar la enseñanza del solfeo que de forma tradicional se había ido desarrollando durante el siglo XIX. 
Este músico y pedagogo, plantea un proceso gradual y secuencial que conlleve al aprendizaje de la lectoescritura, dentro de un ambiente pedagógico agradable y motivador haciendo que la experiencia musical sea vivencial y afectiva. Para este fin desarrollo una serie de postulados que modifican el aprendizaje de la teoría musical en actividades y dinámicas lúdicas haciendo mucho más atractivo el proceso de enseñanza.

Martenot, al igual que los otros autores, parte del sonido hacia la escritura logrando que este paso sea gradual, transitando por diferentes y variadas etapas planteadas en los Cuadernos del Método; su propuesta pedagógica estuvo orientada a la alfabetización de la música ya que se enfocó exclusivamente en el aprendizaje de la lectoescritura musical como eje central del concepto.

Suzuki, (Japón) el método Suzuki está basado en la forma en que el niño aprende el lenguaje materno, la repetición constante acompañado de estímulos y aliento a medida que aprende y supera cada paso es esencial para esta metodología. Suzuki observo que los niños responden muy bien a cualquier estimulo incluso los más elaborados y complejos, desarrollan su voluntad mientras adquieren habilidades que fortalecerán durante su crecimiento.

El método propuesto es exigente en sus detalles, cada ejercicio que el estudiante aborda es controlado minuciosamente y debe cumplir las exigencias técnicas antes de proceder con el siguiente dentro de una secuencia ordenada por niveles de mayor dificultad que se desarrolla escalonadamente; de esta manera el grupo conserva un nivel equilibrado ya que las diferencias técnicas que podrían existir en cada estudiante serian mínimas o son superadas con celeridad.

Las características más notables del método son: está dirigido a niños a partir de los tres años de edad, se da prioridad a la práctica instrumental diaria creando en ellos disciplina y responsabilidad, la participación de los padres o tutor es constante, las clases son individuales y grupales dándole importancia a estas últimas por el rol motivador que conlleva, el repertorio debe ser ejecutado de memoria, los materiales usados son un libro con ejercicios impresos (que 
no se espera que sean leídos) acompañados de un disco o casete, esta suprimida la lectoescritura musical, el maestro es guía y modelo a seguir.

El método Suzuki está enfocado en el aprendizaje de un instrumento. Por lo tanto, las competencias que se generan están en el ámbito de la técnica instrumental, por ello conviene hacer investigaciones respecto a las características que determinan la capacidad de concentración y la voluntad para la práctica constante, componentes que son indispensables en el aprendizaje musical, particularmente en el estudio de un instrumento.

\section{Teoría sociocultural de Vygotsky}

Vygotsky, nace en la ex Unión Soviética, en un momento importante para su nación, después de haberse consolidado la revolución rusa emerge una nueva sociedad que exige la conformación de un nuevo hombre, Vygotsky por su formación humanista y gran cultura reúne las expectativas para un nuevo concepto de la educación; sus intereses por la psicología tienen su origen en los albores de la cultura, considerando de que la misma es el producto del quehacer del hombre.

Vygotsky se empeñó en proponer una teoría que contemplara una concepción del desarrollo cultural del ser humano por medio del uso de instrumentos como el lenguaje que es considerado instrumento del pensamiento.

Su teoría es contraria a la que mantiene la psicología la cual estaba dividida en dos concepciones, la cognitiva y la naturalista. Ante esta situación, plantea una nueva noción de psicología con base en la metodología y en la génesis del materialismo dialectico; su concepto de la manera en que funciona el proceso cognitivo del ser humano introduce el reconocimiento de los procesos cerebrales subyacentes al desarrollo de las capacidades psicológicas y su formación, como la descripción del contexto social en el que dio tal suceso. 


\section{Su teoría tiene los siguientes objetivos:}

El hombre, concebido como un ser histórico social, o histórico cultural, es decir es definido por la cultura que él crea. Está determinado por las interacciones sociales.

El proceso de razonamiento mental es propio del ser humano y es producto del aprendizaje que se da de la interacción social; de la asimilación de la cultura y de las dinámicas sociales.

El desarrollo mental es un proceso socio genético, la actividad cerebral interioriza los significados sociales que se originan de los sucesos culturales.

El lenguaje es el elemento importante en el crecimiento, desarrollo y formación de las capacidades psicológicas superiores; el lenguaje comprende diversas formas de expresión concreta, oral, escrita, gestual, o abstracta artística, musical y matemática.

La cultura se asimila y se interioriza bajo la forma de procesos neuro físicos que forman parte de las funciones fisiológicas del cerebro, estas viabilizan el desarrollo y formación de los sistemas mentales superiores.

La teoría sociocultural de Vygotsky toma como base inicial, las funciones psicológicas de las personas las cuales catalogó como elementales y superiores. Se podría considerar que las funciones psicológicas elementales son de origen biológico; se manifiestan en los niños y en los animales; se reconocen por las acciones involuntarias o reflejas; por las reacciones automáticas e inmediatas y son controladas por el ambiente externo.

Por otra parte, las funciones psicológicas superiores parten o presentan un origen social, se manifiestan exclusivamente en el hombre; poseen intención en sus acciones que se dan a través de la mediación. Olivera (1993) “proceso de intervención de un elemento intermediario en una relación" (pp. 26).

Estas son el resultado de la interacción de elementos biológicos (funciones psicológicas elementales) y culturales que fueron cambiando a través de la historia humana. Así pues, 
Vygotsky sostiene que las funciones psíquicas poseen un origen sociocultural, ya que son el resultado de la interacción del hombre con su contexto social y cultural.

Para Vygotsky, el lenguaje es el componente principal en el desarrollo cognitivo; determina prácticamente las funciones superiores, la percepción del ambiente se transforma, formándose nuevas memorias y surgiendo nuevos procesos de pensamiento.

El lenguaje es el principal mediador en la formación y en el desarrollo de las funciones psicológicas superiores, facilitando por ejemplo identificar los objetos del ambiente, mencionar sus cualidades y la relación que puede darse entre los propios objetos.

Lucci (2006) menciona que:

(...) el lenguaje materializa y constituye las significaciones construidas en el proceso social e histórico. Cuando los individuos las interioriza, pasa a tener acceso a estas significaciones que, por su parte, servirán de base para que puedan significar sus experiencias, y serán, estas significaciones resultantes, las que constituirán su conciencia, mediando, de ese modo, en sus formas de sentir, pensar y actuar. (pp.9).

Como resumen podríamos decir la teoría elaborada por Vygotsky quiebra con las corrientes hasta ese entonces establecidas y nace de un nuevo concepto de hombre y realidad.

\section{Fundamentos teóricos de estrategia metodológica}

Al hablar de estrategia nos remontamos al léxico militar usado para planificar y dirigir una ofensiva a gran escala, considerando esto la estrategia vendría a ser el plan general o global.

Si trasladamos ese concepto al plano educativo, se refiere a las estrategias metodológicas que según Moya (2017) indica, la estrategia metodológica es la unión de forma integrada y coherente de técnicas didácticas, estrategias, actividades y recursos de enseñanza aprendizaje. Viabilizan el proceso de los aprendizajes esperados tomando en cuenta el enfoque de los principios pedagógicos orientado en competencias. Fomentan en los estudiantes la capacidad 
de interpretación, análisis y procesamiento de la información para su uso posterior en la producción de nuevos conocimientos para logar de esta manera los aprendizajes significativos.

En consonancia el Ministerio de Educación (2015) las define como "son formas de selección, organización (combinación y ordenamiento) y uso de métodos, técnicas y recursos (materiales) orientados hacia el logro de objetivos holísticos, tomando en cuenta y en estrecha relación y coherencia con los contenidos, sujetos (participantes) y contextos”. (pp. 9) de esta manera una estrategia metodológica puede incluir a determinados métodos, técnicas y recursos que se pueden seleccionar, diseñar y aplicar para procesos formativos comunitarios, interculturales, productivos entre otros.

Como menciona Alcaraz, (2004) "las estrategias son procesos para la elección, coordinación y aplicación de Habilidades; En el campo cognitivo la secuencia de las acciones se orienta a la adquisición y asimilación de la nueva información, estas también surgen en función de los valores y de las actitudes que se pretenden fomentar”. (pp. 47)

En ese sentido, el Minedu (2015) indica que "las estrategias metodológicas son acciones flexibles, que pueden adecuarse a diversas realidades y circunstancias del proceso educativo". (pp. 9)

Las estrategias necesitan de un dominio y aplicación en donde se interrelacionen los componentes y procedimientos educativos para poder delimitar las acciones y actividades que se organizan con el fin de alcanzar las metas propuestas.

Para Quintero (2011) “las estrategias metodológicas son las que permiten identificar principios y criterios a través de métodos, técnicas y procedimientos que constituyen una secuencia ordenada y planificada permitiendo la construcción de conocimientos durante el proceso enseñanza aprendizaje (pp. 19).

Por lo tanto, se puede afirmar también que las estrategias son el conjunto de procedimientos y técnicas usados en la enseñanza para fomentar y producir aprendizajes, 
Ausubel en Alcaraz (2004) afirma que "el aprendizaje significativo es el que se transmite en cualquier situación, debe estar estructurado no solo en sí mismo sino con respecto al conocimiento que ya posee el alumno" (pp. 47). Es decir que el aprendizaje significativo lo conforman todos conocimientos previos que el alumno posee y se relacionan con aquellos conocimientos que se requieren adquirir de forma que sean la base de estos nuevos conocimientos.

Es imperativo que estos nuevos conocimientos queden instaurados en la estructura cognitiva del alumno y formen parte de la memoria comprensiva a largo plazo. Los docentes hacen uso de estas estrategias planificando las acciones y generando aprendizajes significativos, exploran los conocimientos previos de los estudiantes, se cumplen los objetivos propuestos además de facilitar las evaluaciones. Ahora bien, a todas estas estrategias podemos considerarlas como estrategias de enseñanza; sin embargo, las estrategias de aprendizaje precisan Torres y Giron (2009) "son conjunto de pasos que el estudiante emplea de forma intencional como instrumento flexible para aprender significativamente" (pp. 20).

Se debe considerar, entonces, que las estrategias de enseñanza son aquellas que marcan al docente una manera de proceder en aula, estas estrategias organizan y encaminan las interrogantes, procedimientos, las explicaciones y despiertan en el alumno el deseo de aprender.

En ese mismo enfoque, Romero (2009) propone que "las estrategias de aprendizaje son el conjunto de actividades mentales empleadas por el estudiante, en una situación particular de aprendizaje, para facilitar la adquisición de conocimientos; también puede considerarse como el proceso o pasos que permiten el almacenamiento y/o utilización de la información”. (pp. 2).

En tal sentido, las metodologías son procedimientos plausibles que parten de una postura teórica; es la acción concreta del docente y el alumno mientras se da el proceso de enseñanza aprendizaje. 
Una óptima metodología es una mezcla equilibrada de otras metodologías; Fortea (S.F) menciona que, para su elección, previamente se deben tener en cuenta sus ventajas e inconvenientes, de la misma manera tener claramente definido el objetivo a lograr. Por consiguiente, se deben considerar la conjugación de ambos factores (estrategias y metodología) en función de comprender la ceñida relación didáctica - pedagógica que existe entre ambas.

Finalmente, se puede afirmar que los investigadores deben tomar plena conciencia de que las estrategias metodológicas que aplicaran deben estar en concordancia con los contenidos que desarrollaran, a la edad y nivel cognitivo de los sujetos.

\section{Clasificación de las estrategias metodológicas}

\section{Estrategias de enseñanza-aprendizaje.}

En el proceso de enseñanza el docente debe efectuar un sinnúmero de estrategias metodológicas para lograr los objetivos trazados con el fin de que sus estudiantes logren aprendizajes significativos. Toda estrategia debe ser diseñada por él orientada a los requerimientos del estudiante.

El diseño de las estrategias de enseñanza debe ser de tal manera que fomenten en el estudiante la observación, el análisis, la formulación de hipótesis, búsqueda de soluciones y el descubrimiento de conocimientos. Al elegir la estrategia de enseñanza hay aspectos que se deben tener en consideración; las características generales de los apéndices, el grado de dominio de conocimiento y contenido curricular, la meta que se espera lograr así como las actividades cognitivas y pedagógicas que desarrollara el alumno para alcanzarla, de igual manera es necesaria la observación y control de las estrategias de enseñanza previas verificando el progreso y aprendizaje del alumno; es necesario también considerar el contexto y otros elementos que pueden influir positiva o negativamente durante el proceso. 
Vásquez (2010) afirma:

(...) las estrategias de enseñanza se pueden considerar como aquellos modos de actuar del maestro que hacen que se generen aprendizajes, y por eso, estas estrategias son el producto de una actividad constructiva, creativa y experiencial del maestro, pensadas con anterioridad al ejercicio práctico de la enseñanza, dinámicas y flexibles según las circunstancias y momentos de acción. (pp.22)

Si buscamos que las estrategias de aprendizaje tengan un camino optimo en el aula, es el docente quien debe tener claro las inquietudes que tienen sus alumnos. Un objetivo es lo que un individuo se esmera en conseguir y se determina por el actuar del mismo en concordancia con lo que desea lograr. El alumno debe experimentar lo satisfactorio que es adquirir los conocimientos que le permitan entender, explicar y desenvolverse en pos de sus metas trazadas; existen diversas estrategias para orientar el aprendizaje de los alumnos:

Actividad Intencional, se produce cuando el docente planifica el actuar educativo coordinando con el alumno en vista de los objetivos trazados del aprendizaje.

Actividad Normativa, es la acción dirigida estrictamente por el docente pues hace prevalecer su autoridad como portador y mediador del conocimiento.

Actividad Interactiva, se establece de forma dinámica, ya que en este proceder existe una reciprocidad durante el proceso siendo más homogénea y equitativa la participación de ambos sujetos.

Sin embargo, la actividad más importante es la que lleva al alumno al nivel de reflexión, critica y entendimiento partiendo de sus propios conocimientos previos construyendo su propio saber siendo el docente un mediador para lograr un aprendizaje significativo.

\section{Técnicas didácticas.}

Los constantes avances en el campo del conocimiento y el saber, exigen una manera eficaz de estudio, ya que diariamente los estudiantes deben aprender una gran cantidad de conocimientos 
y comprenderlos a mayor profundidad. La actividad didáctica es un componente indispensable para el aprendizaje, considerando el ambiente adecuado para que el estudiante se sienta como el protagonista de este proceso y pueda crecer, ampliar su visión del mundo y convertirse en un agente de cambio para el progreso.

En ese sentido, Moya (2017) considera a las Técnicas Didácticas como procedimientos de menor alcance que las estrategias didácticas, dado que se utilizan en períodos cortos (parte de una asignatura, unidad de aprendizaje, etc.); cuyo foco es orientar específicamente una parte del aprendizaje, desde una lógica con base psicológica, aportando así al desarrollo de competencias.

En esa misma línea, Correa (2013) sostiene que "la técnica didáctica es un procedimiento didáctico que se presta a ayudar a realizar una parte del aprendizaje que se persigue con la estrategia. Se enfoca a la orientación del aprendizaje en áreas delimitadas del curso” (pp.8)

De igual manera Rosler (2007) menciona:

(...) es un error común pensar que la docencia es un arte intuitivo. Existe una gran cantidad de técnicas didácticas que pueden mejorar el rendimiento educativo. Es importante que el docente conozca las características de sus estudiantes, prepare estrategias para captar la atención del auditorio y se adapte a sus alumnos. (p.17.)

El docente se debe mostrar en todo momento de forma activa y creativa con sus estudiantes, debe conocerlos, buscar maneras activas y dinámicas de llegar a ellos y poseer un repertorio de técnicas de enseñanza que dispondrá de manera adecuada cuando se requiera. La experiencia en la aplicación de estas técnicas se afianzará con las practica, permitiendo al estudiante sentirse cómodo y motivado en clase, se debe tomar en cuenta el conocimiento profundo y detallado de estas herramientas y saber aplicarlas en el momento adecuado, guiando y dirigiendo hacia el logro de los objetivos propuestos. 


\section{Actividades didácticas.}

Moya (2017) las concibe como acciones necesarias para lograr la articulación entre lo que pretende lograr la estrategia y técnica didáctica, las necesidades y características del grupo de estudiantes. Su diseño e implementación son flexibles y su duración es breve (desde una clase a unos minutos).

Para Barcia y Rodríguez (2011) define actividades didácticas a aquellas que son propuestas por el docente y producen en el estudiante un proceso cognitivo que lo lleva a aprender. En esa línea, Anijovich (2010) indica que estas actividades pueden definirse como herramientas que posee el docente para sistematizar y estructurar las vivencias de aprendizaje de sus estudiantes. Estas actividades son acciones específicas aplicadas por el docente y se estructuran en función de las estrategias didácticas con otros elementos las cuales se pueden presentar de manera correlativa dando pase a técnicas y procedimientos aislados cada vez que no respondan a la lógica de las actividades circunscritas a ellas.

De igual forma, Cázares (2011) y Escamilla (2011) las denominan como el recurso didáctico que utiliza el educador, que, a manera de instrumentos, sirven de guías conformadas por una sucesión de pasos específicos y puntuales que ordenan un conglomerado de actividades. Coinciden con De la Herrán (2008) "las técnicas didácticas estructuran actividades que responden a modos de proceder desde la práctica” (pp.138).

\section{Recursos de enseñanza-aprendizaje.}

Al realizar una revisión bibliográfica notamos una variedad de nomenclaturas que se aplican para denominar a los recursos, distintos autores los llaman "recursos didácticos", "medios de enseñanza", "materiales curriculares", entre otros. Dada la diversidad de nombres que se les han dado, manifiesta la gran importancia que estos han adquirido en al ámbito curricular.

Moya, (2017) los define como: recursos o materiales educativos, son todos los instrumentos de apoyo pedagógico, asistencia tecnológica y herramientas didácticas, que 
construimos o seleccionamos con el objetivo de brindar a los estudiantes, un mayor acercamiento al conocimiento y la elaboración de los conceptos para facilitar así un mejor aprendizaje.

De esta manera vendrían a ser medios del proceso enseñanza-aprendizaje, no un fin, y cuyo uso, coincidiendo con Bernardo (2011) facilita la conexión entre el dialogo del docente y la realidad en la cual intenta ser participe al estudiante, estos recursos son solo un medio mediante el cual el docente dinamiza el proceso educativo. En esa misma línea Bernardo (1997) la adecuada selección y aplicación pueden influir favorablemente en el proceso de enseñanza aprendizaje convirtiéndolo de manera fácil, sencilla y eficaz por ende motivador.

Se debe tener en claro los criterios de elaboración o selección que estos recursos deben cumplir para consolidar su pertinencia en el aula, por ello deben tener un soporte físico o material, presentar un contenido coherente, información o mensaje, poseer una forma simbólica de exponer la información; como códigos verbales, sonoros, icónicos, entre otros, deben tener un fin o propósito educativo. Esta finalidad se vislumbrará en los logros de aprendizaje que se espera alcanzar. Por ello, la importancia de los recursos como componente de las estrategias didácticas, pues su adecuada selección y uso por parte del docente fomentara la construcción y consolidación de los aprendizajes en sus estudiantes.

\section{Importancia de las estrategias metodológicas.}

Son importantes las estrategias metodológicas para la construcción de aprendizajes; mediante procedimientos, parámetros, pautas y habilidades que nuestros estudiantes adquieren y apliquen ante situaciones o problemas diversos que se les presenten. Está en nosotros fomentar en los estudiantes estos diversos y variados conocimientos mediante el uso y aplicación de estrategias metodológicas con el propósito de aprender con el ejemplo.

En la actualidad, la humanidad sufre una transformación constante en donde el sistema educativo como entidad es la encargada de facilitar y resolver los problemas que se producen 
en el ámbito educativo; principalmente el educador quien se convierte en el principal responsable de la calidad educativa; siendo así es de suma importancia su formación académica para que pueda ser un mediador de los nuevos métodos, estrategias y técnicas educativas que ayuden a consolidar e incrementar el grado de competencia de los educandos en el proceso de enseñanza aprendizaje.

Por ello, resulta de suma importancia tener en cuenta que los estudiantes deben de aprender a aprender; el cual es un procedimiento consciente de transformación y aplicación de procesos intelectuales que hemos adquirido, con el propósito de que podamos recurrir a ellos en el proceso de adquirir conocimientos nuevos, habilidades, destrezas y en la construcción de valores y actitudes.

Considerando esta posición, Torres y Girón (2009) mencionan: que "el docente debe ayudar a los estudiantes a que alcancen su potencial intelectual y creativo, a través del empleo de estrategias, de acuerdo con los intereses de los estudiantes y demandas de la actual sociedad, para promover un aprendizaje significativo" (pp. 25). 


\section{Capitulo II}

\section{Diagnostico o trabajo de campo}

En el capítulo se describe los hallazgos y resultados obtenidos al aplicar las diferentes técnicas e instrumentos de recolección de datos (anexo 3) para lo cual se utilizaron métodos empíricos como la encuesta, realizada a 31 estudiantes de las especialidades de cuerda de un Conservatorio con la finalidad de constatar su nivel de conocimientos acerca de la Identidad Musical Nacional.

De igual manera, se aplicó una guía de entrevista semiestructurada a dos docentes de las especialidades afines elegidos por criterio y conveniencia con el objetivo de verificar la preparación teórica y didáctica que poseen los docentes sobre los fundamentos de la Identidad musical nacional en los estudiantes. Además, se realizó una observación del desarrollo de clases a ambos docentes durante el proceso de enseñanza-aprendizaje, con la finalidad de constatar los conocimientos teóricos y didácticos que poseen los docentes acerca de la Identidad Musical Nacional.

\section{Análisis, interpretación y discusión de los hallazgos por técnicas e instrumentos}

\section{Encuesta realizada a los estudiantes.}

Los cuestionarios se aplicaron a 31 estudiantes de las distintas especialidades de cuerda de un Conservatorio de música, estaba conformado por 15 preguntas semiestructuradas para marcar con cuatro alternativas: siempre, casi siempre, a veces y nunca. El objetivo fue constatar el nivel de satisfacción que experimentan los estudiantes de la especialidad de cuerdas de un Conservatorio de Lima con la manera en que el docente de la asignatura Instrumento Principal dirige el proceso de enseñanza - aprendizaje para contribuir al desarrollo de su Identidad Musical Nacional.

Al ser esta una investigación aplicada educacional, se consideró necesario procesar los cuestionarios por medio de la aplicación del programa SPSS (versión 25) el cual es un conjunto 
de programas enfocados a la realización del procesamiento y análisis estadísticos aplicados a las ciencias sociales. Los resultados más resaltantes fueron: los hallazgos del trabajo de campo demuestran (anexo 6), en cuanto al reconocimiento de la música tradicional relacionada al contexto de su comunidad, el $61,3 \%$ mencionan que casi siempre la reconocen y un $29,0 \%$ porcentaje alto también, indican que solo a veces la reconocen.

Esto evidencia que la gran mayoría de estudiantes no reconoce con total seguridad la música tradicional propia de las comunidades o regiones del interior del país; es decir saben que corresponde a un determinado género musical ya sea música andina, criolla o afroperuana, pero desconocen la región o comunidad a la que pertenece o el contexto en que fue creada. En contraste, a pesar de que la gran cantidad de estudiantes que provienen de las provincias, solo un pequeño porcentaje, 9,7\% reconoce e identifica la música tradicional de su región.

También, el 41,9\% mencionan que a veces el docente incentiva a practicar la música tradicional de su comunidad; y el $38,7 \%$ indica que nunca lo hace; se observa que la gran mayoría de docentes no fomenta o motiva a los estudiantes en la práctica de la música tradicional, esto es comprensible ya que el Conservatorio está orientado al estudio de la música académica y la alta exigencia de sus profesores se centra en ese objetivo, sin embargo se podría considerar también que hay una carencia de repertorio de música tradicional, adaptado y sistematizado a las exigencias académicas de las distintas especialidades instrumentales del Conservatorio, lo que al ser revertido, diversificaría la aplicación de métodos de apoyo a la técnica instrumental así como un repertorio que desarrolle y consolide la identidad musical nacional de los estudiantes.

En ese sentido, Ordog (2000) sostiene que la suma de intereses nacionales, así como sus expectativas en logros pedagógicos y estéticos contribuyen a que la música tradicional sea la base de la educación musical. En muchos casos la especialidad instrumental y la objetividad 
del docente, determina la aplicación y desarrollo de piezas de música tradicional para complementar y variar el repertorio.

Ante la pregunta ¿En tu elección de repertorio personal, consideras obras musicales tradicionales de tu comunidad? El 51,6\% mencionan que a veces en su elección de repertorio personal, consideran obras musicales tradicionales de su comunidad, y el 19,4\% menciona que nunca; ante estos resultados se evidencia una gran preferencia hacia la música académica, por tener relación directa con los estudios que realizan.

Se entiende, que a medida que alcanzan un nivel más alto en su formación, el repertorio académico les permite demostrar y desarrollar sus capacidades musicales a diferencia del repertorio de música tradicional, que en su mayoría o casi en su totalidad no está adaptado o esquematizado técnicamente a las especialidades instrumentales de cuerdas.

A pesar de ello el 12,9\% mencionan que siempre en su elección de repertorio personal, consideran obras musicales tradicionales de su comunidad; en algunos estudiantes esta decisión se da por un compromiso o necesidad de tener un repertorio amplio y diverso a exigencia de oportunidades laborales del medio en donde se desenvuelven.

Por otro lado, el $45,2 \%$ mencionan que a veces el docente realiza actividades significativas para que el estudiante aprecie y valore los elementos identitarios de la música de su comunidad y el $32,3 \%$ manifiestan que nunca. Es evidente que la falta de recursos y materiales, así como una estrategia metodológica orientada al aprecio y valoración de la música tradicional ayudaría al trabajo docente; si bien el abordaje y desarrollo de este repertorio tradicional no es un requerimiento perenne dentro de la currícula académica, cuando es aplicado resulta insuficiente y poco productivo; no se aprecia una estructura de trabajo concisa y muchas veces es dejado al criterio del estudiante. 


\section{Prueba pedagógica realizada a estudiantes.}

Los resultados de esta prueba para comprobar el nivel de conocimientos teóricos sobre la identidad musical nacional (anexo 7), muestran que un 74,2\% se encuentran en un nivel medio de conocimientos sobre la identidad musical nacional y un 9,7\% está en un nivel bajo.

En una observación analítica de esta prueba, vemos que los estudiantes tienen dificultades para definir el concepto de música tradicional, que según Jiménez (2016) es definida como música que es transmitida de generación en generación de forma oral como una parte más de los valores y de la cultura de un pueblo. En ese sentido Zumthor (1989) y Bernal (2000) coinciden en que la tradición oral agrupa los testimonios que se relacionan con el pasado y que son legados de boca a oído a través de generaciones.

En otro punto de la prueba, los instrumentos musicales usados para la música tradicional son característicos y peculiares, por lo tanto, llama la atención que tengan dificultad en reconocerlos o relacionarlos con las regiones, comunidades o inclusive festividades típicas que son importantes y relevantes en la cultura musical de todo músico; tal es el caso del chacombo, tinya, waqrapuku y arpa andina.

Concluyendo este análisis notamos una baja comprensión acerca de la importancia del legado cultural de las comunidades presentes en el repertorio musical tradicional, pues estos legados forman parte de nuestra identidad y está en nosotros valorarlos y difundirlos, tal como refiere Álvarez (2015) ...promueven sentimientos de identificación y concientización de los elementos identitarios de la música nacional, que permiten asumir actitudes que develan la asunción del patrimonio musical.

\section{Entrevista a los docentes.}

En referencia a la información obtenida de los docentes entrevistados, con el objetivo de conocer la preparación teórica y didáctica que poseen, sobre los fundamentos de la Identidad musical nacional en los estudiantes (anexo 8), se aprecia que existe una necesidad de contar con 
una asistencia o apoyo pedagógico en lo referente al tratamiento de los contenidos de la música tradicional y la identidad musical nacional.

En relación a la pregunta ¿Qué acción pedagógica realiza Ud. para que el estudiante logre identificar los contenidos de la música tradicional? Los docentes mencionan que existe una marcada influencia académica europea, ya que los contenidos, recursos y material pedagógico, así como la metodología de enseñanza proviene de estas escuelas europeas; así también indican que se da poca valoración a la música tradicional y un bajo conocimiento académico de la música tradicional peruana además de la necesidad de elevar y revalorar el repertorio tradicional frente a la música académica.

Por otra parte, la formación como músico profesional de un conservatorio implica un alto nivel artístico, conocimientos teóricos de los fundamentos de la música académica, así como un dominio completo de su especialidad; variables que están fundadas en principios académicos de escuelas europeas muy antiguas, inclusive el material pedagógico no ha variado a través del tiempo y se continúa aplicando hoy en día. Ello sumado a la falta de material académico para el estudio de la música tradicional, limita su conocimiento, aprecio y valoración frente a la música clásica o música académica en la cual el estudiante está inmerso a lo largo de su etapa formativa.

Por otro lado, cuando se les preguntó si ¿Considera importante difundir la música tradicional en su práctica musical? opinaron que se necesita tomar conciencia de la importancia de la música tradicional, fomentar su difusión además de promover su enseñanza; pero encuentran dificultades debido a la falta de recursos y materiales académicos de la música tradicional, así mismo, requiere de capacitación en los tratamientos y la aplicación de sus contenidos; también mencionan que hay carencia de un repertorio académico tradicional transversal a la currícula, así como la diversificación del material pedagógico en las especialidades. 
La institución no cuenta con el material adecuado para el tratamiento y aplicación del estudio de la música tradicional en las distintas especialidades instrumentales, el repertorio académico tradicional se limita a obras compuestas para pocas especialidades y con un trasfondo exclusivamente artístico, no está diseñado en función progresiva y técnica al desarrollo del estudiante, es a criterio del docente que se ejecutan en un determinado proceso de la formación o tan solo se abordan en el último ciclo de estudios para completar el repertorio de graduación exigido.

De igual modo, ante la pregunta ¿Qué actividades realiza para fomentar el aprecio, valoración y difusión de la música tradicional entre sus estudiantes? los docentes manifestaron, que hay un predominio de la música clásica, pues las exigencias académicas son altas y los estudiantes deben responder ante esas exigencias. Entonces la música tradicional debe estar al nivel de estos requerimientos técnicos, por lo que estructurar y adaptar el repertorio tradicional al nivel académico del conservatorio sería una prioridad. En concordancia Costa (1997) sostiene que la música tradicional es un paso previo al estudio de la música académica, usando sus contenidos rítmicos, melódicos y sonoros como material de transición para vencer las dificultades del aprendizaje técnico.

También resaltaron que se podría diversificar la enseñanza usando la gran cantidad y variedad de elementos culturales que tenemos, y finalmente indicaron que no existe un repertorio académico para instrumentos de cuerda basado en la música tradicional.

En relación a las estrategias que emplean para que el estudiante logre articular sus conocimientos previos con la nueva información y aplique esta, en la solución de problemas habituales en el instrumento; los docentes detallaron, que en el desarrollo de las piezas y estudios que el alumno va construyendo, están estructuradas de manera que va de menos a más, en consecuencia, si el alumno ha podido tocar una pieza sé entiende que está listo para la siguiente. 
En ese sentido, recalcan que es importante no saltar etapas, ya que el estudiante puede llegar a frustrarse porque no estaría listo para empezar a tocar la siguiente obra. Uno de los docentes indico que "los objetivos académicos y mejora de la técnica, tiene que ver con el hecho de ver obras cada vez más difíciles" coinciden en que la secuencia escalonada de los métodos y repertorio, la dificultad creciente en las obras a interpretar, los objetivos técnicos de la especialidad y la motivación al estudiante en el proceso de enseñanza -aprendizaje, son cruciales para que los estudiantes logren un aprendizaje significativo que trascienda en su vida profesional.

\section{Observación de clase.}

Los hallazgos encontrados en las observaciones de clases durante el proceso de enseñanzaaprendizaje (anexo 8), ponen en evidencia que las exposiciones fueron de forma tradicional expositivas, en un caso el docente llega al aula con cierto retraso; saluda, se disculpa e inicia su sesión. Inicia relacionando correctamente el nuevo contenido con las clases pasadas, pero no uso una dinámica de motivación, por ello los alumnos no están muy activos a participar y no despierta su interés.

Es importante la motivación al iniciar la sesión de clase, ya que predispone a los estudiantes a vincular esa experiencia con los nuevos conocimientos que impartirá el docente, por ello la preparación y articulación de la dinámica, video o audición que se utilice debe estar organizada con el tiempo adecuado para su aplicación.

En otro momento el docente explica los objetivos de la sesión, pero no son muy claros, no todos lo entienden, el demuestra entusiasmo al explicar los contenidos iniciales, trata de involucrar a todos los estudiantes, pero no se ve un orden en el abordaje del tema. El vincular los conocimientos o el simple hecho de entablar una conexión con los estudiantes requiere un liderazgo asertivo y cercano, la preparación y el dominio del tema es primordial, pero si no logra crear un lazo de confianza con el estudiante y permanece de forma vertical en la jerarquía 
del aula, todo intento por conseguir un aprendizaje significativo en ellos será en vano o simplemente lo asimilaran de forma transitoria y no será relevante en situaciones reales de la actividad profesional. También se observa que algunos estudiantes conversan entre ellos y usan el celular. Lo cual indica desconexión con el tema de clase. Finalmente realiza una audición de repertorio al tema con lo que logra captar la atención de los estudiantes.

Durante el desarrollo de la sesión de aprendizaje no se observa una estructura definida ni un orden, se basa únicamente en la repetición y en la ejecución de habilidades netamente musicales; al ser una sesión de practica instrumental es de esperar la dinámica de trabajo centrada en el modelamiento los estudiantes toman como referencia la ejecución dada por el docente y es replicada de acuerdo a indicaciones y pautas técnicas las cuales formaran sus capacidades musicales para la interpretación.

En referencia a este aspecto, Lavignac (1950) sostiene que:

La enseñanza en los conservatorios [...] es, sobre todo, dogmática. [...] El profesor es considerado impecable e infalible, lo que diga debe ser aceptado como artículo de fe, y el ejemplo que da debe ser imitado servilmente. Si es cantante o instrumentista, enseña a sus alumnos a tocar o cantar como él, a respirar, a pronunciar, a sostener el arco como él; les comunica algo de su propio estilo, los forma a su imagen, tan bien que, cuando se los escucha, se puede decir sin vacilar: Éste es alumno de tal profesor. Es lo que se llama formar escuela. [...] Cuando el maestro es realmente un gran artista, sabe dejar a cada uno lo que le es necesario para constituir su individualidad, y se consagra especialmente a desarrollar las cualidades innatas. (pp.365-366)

Otro docente desarrolla la sesión usando lenguajes artísticos precisos y definiciones muy acertadas; sin embargo, no fomenta de manera significativa el aprecio, la creación y expresión de los estudiantes en su práctica musical. basa el proceso de enseñanza en la repetición que si 
bien es el más usado para la enseñanza de los distintos instrumentos musicales es considerado muy tradicional y conductista; por ello este método no motiva al estudiante para lograr capacidades nuevas. Además, el docente no propone metodologías innovadoras, ni proyectos, no ejemplifica con circunstancias reales para lograr un aprendizaje significativo.

El aprendizaje de un instrumento musical requiere una práctica constante, aun mas si la decisión es ser un músico profesional, la disciplina y compromiso con las horas de estudio son uno de los primeros preceptos que aprendemos en la carrera. La práctica musical constante produce en los estudiantes un sentido de responsabilidad, perseverancia y satisfacción; no obstante, es el docente quien debe encausar asertivamente este proceso para alcanzar las metas trazadas y evitar que los estudiantes se sientan frustrados.

Hacia el cierre de la sesión no se generan análisis y pensamiento crítico de forma participativa, donde se verifique que los conocimientos ya han sido asimilados por los estudiantes. Tampoco se ha recordado los objetivos de la sesión y no ha explicado adecuadamente las conclusiones. Ha promovido la búsqueda bibliográfica y la investigación; sin embargo, no ha utilizado alguna estrategia para comprobar si se han cumplido los objetivos de la sesión, tampoco ha explicado adecuadamente las tareas que hay que realizar para la siguiente sesión y no ha gestionado adecuadamente el tiempo para el cierre.

\section{Análisis e interpretación de las categorías emergentes y las apriorísticas}

En esta sección se presentan las categorías emergentes genéricas o explicativas que han surgido al realizar la comparación, relación y clasificación de los códigos (anexo 9), este proceso de codificación, categorización y triangulación metodológica y de datos permitió la generación de siete categorías emergentes, de las cuales cuatro categorías coinciden con las categorías apriorísticas y los tres restantes son categorías nuevas.

Luego del proceso de la triangulación metodológica y de datos, se realizó la redacción de las conclusiones aproximativas (memos) para cada categoría emergente, lo cual se hizo sobre 
la base del conjunto de códigos agrupados por su semejanza. (anexo 8). Finalmente, se realizó la interpretación y discusión de los resultados, en esta discusión se aplicó la triangulación teórica. Al respecto, Okuda \& Gómez (2005) manifiestan que “durante la conceptualización del trabajo de investigación cualitativa suele definirse de antemano la teoría con la cual se analizarán e interpretarán los hallazgos” (pp. 122-123).

Las siete categorías emergentes obtenidas fueron: Importancia de la evaluación formativa en los procesos de enseñanza-aprendizaje; gestión del tiempo durante las sesiones de clase; capacitación y actualización en los contenidos de la música tradicional; estructuración y contenidos de la música académica y tradicional; carencia en el desarrollo de la capacidad de análisis de repertorio de la música tradicional - interpretación musical; asistencia pedagógica al estudiante; necesidad del acompañamiento pedagógica durante el procesos de enseñanzaaprendizaje; elementos de la música tradicional en la ejecución instrumental.

Culminando este proceso se llevó a cabo la interpretación de los resultados obtenidos utilizando triangulación teórica. En este punto se tomó en consideración posturas y aspectos tratados en el marco teórico los cuales permitieron estructurar la información para posteriormente analizar y evaluar su coherencia. Se realizó un trabajo de interpretación, comprensión y síntesis del producto obtenido lo que permitió al investigador comprender y reflexionar acerca de los resultados al ser contrastados con los referentes teóricos. A continuación, presentamos el cuadro de resumen de las categorías emergentes y apriorísticas: 


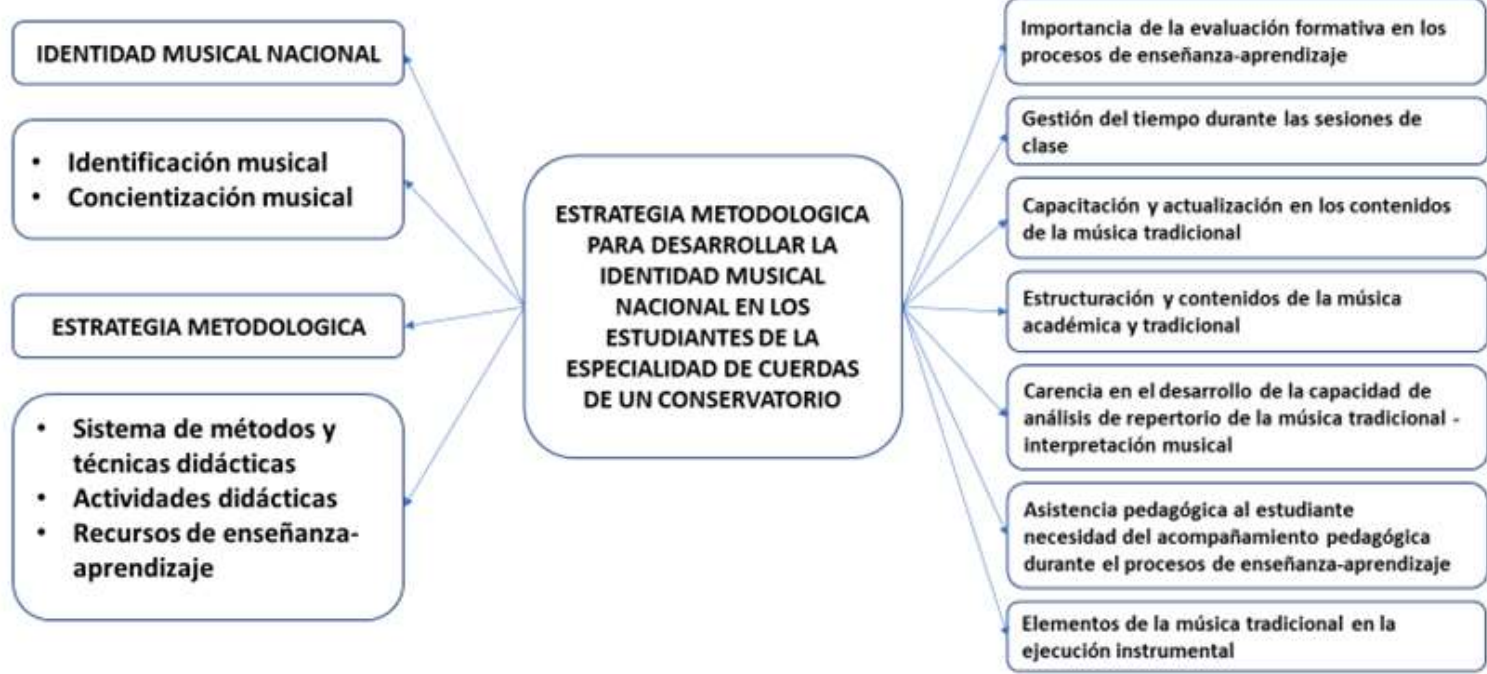

Figura 1. Presentación de las categorías apriorísticas y emergentes

A continuación, se detallan los hallazgos encontrados acerca de las categorías apriorísticas:

En relación a las categorías y subcategorías apriorísticas, específicamente sobre la subcategoría identificación musical, los hallazgos muestran que de acuerdo a los resultados de la encuesta un $61,3 \%$ mencionan que casi siempre reconocen la música tradicional relacionada al contexto de su comunidad, también un gran porcentaje el $41,9 \%$ considera que a veces y el $38,9 \%$ nunca el docente incentiva a practicar la música tradicional. A esto se suma que casi la mitad de los estudiantes, el 41,9\% mencionan que a veces cuándo ejecutan una obra musical tradicional, identifican los elementos característicos que la diferencian.

Llama la atención que el 51\% afirman que a veces en su elección de repertorio personal, consideran obras musicales tradicionales de su comunidad, y el 19,4\% mencionan que nunca las consideran dentro de su repertorio personal.

Como conclusión podemos decir que la gran mayoría de estudiantes un $74,2 \%$ se encuentran en un nivel medio de conocimiento sobre la identidad musical nacional; esto se debe 
a que existe un predominio de la música clásica "música académica" y un desconocimiento académico de la música tradicional peruana.

En ese sentido, Castilla (2002) refiere que el aprendizaje de la música, enlazado íntimamente con las manifestaciones tradicionales, como cantos, danzas y rituales de una comunidad, asimilaría más fácilmente un comportamiento musical que le seria dado de la mano de su propia cultura. Por ello resulta necesario incentivar la música tradicional en el proceso formativo además de su inserción en el currículo para revalorarla, darle equidad, importancia y difusión.

La música tradicional al ser estudiada y enseñada debe poseer un fin pedagógico y de esta manera elevar y revalorar el repertorio tradicional frente a la música académica. La falta de valoración a la música tradicional peruana, sumada a una escasa difusión con un objetivo o planteamiento académico vendría a recaer como responsabilidad cultural, académica y artística en cada músico interprete pues se debe ejecutar con profesionalismo el repertorio tradicional tanto como el académico.

En relación a la subcategoría Concientización musical los hallazgos revelan que del total de estudiantes encuestados el 38,7\% mencionan que casi siempre aprecian y valoran el legado cultural de su comunidad y un 9,7\% mencionan que a veces; también el 41,9\% mencionan que a veces el docente los ayuda en la valoración del legado cultural de las comunidades, y un $12,9 \%$ mencionan que nunca lo hace.

Es notable que solo el $16,1 \%$ lograron alcanzar un nivel alto de conocimiento sobre la identidad musical nacional y el $9,7 \%$ se encuentran en un nivel bajo, estos resultados demuestran un grado de conciencia e identidad musical nacional aminorado debido a una gran Influencia académica europea.

Es comprensible dada la necesidad de una formación técnica instrumental sólida y eficiente para ejecutar el repertorio musical académico; pero esto, sumado a la poca valoración 
de nuestra música tradicional y el escaso interés por difundirla, conservando su esencia y los elementos identitarios que la caracterizan, nos exigen tomar conciencia de la importancia que representa para nuestra propia identidad, como sugiere Castilla (2002) “...el folklore musical ha sido y continúa siendo una herramienta para la forja de la nación, un elemento identificador de la singularidad de un colectivo arracimado en torno a la nación” (pp.7) en ese sentido, se requiere un mayor apoyo académico tanto en la investigación, estudio y recopilación de estas manifestaciones musicales o a través del fomento y difusión de concursos recitales o actividades académicas que permitan dar un equilibrio entre la música académica y la música tradicional.

Para ello, es necesario estructurar el repertorio tradicional y adaptarlo a las exigencias y objetivos académicos del conservatorio; es importante señalar que para el docente el enfoque de la enseñanza de la música tradicional debe estar a la altura de los requerimientos técnicos exigidos.

Acerca de la subcategoría sistema de métodos y técnicas didácticas de acuerdo a los resultados el 45,2\% de los estudiantes encuestados mencionan que a veces el docente realiza actividades significativas para que el estudiante aprecie y valore los elementos identitarios de la música de su comunidad; un porcentaje considerable 32,3\% manifiestan que nunca el docente realiza estas actividades significativas y solo un 9,7\% mencionan que casi siempre el docente las realiza.

También, solo un 16,1\% manifiestan que a veces el docente suele aplicar ciertas estrategias y técnicas adecuadas en el proceso de enseñanza-aprendizaje. Al igual que un 3,2\% mencionan que nunca perciben que el docente reconoce y emplea diversas técnicas que ayudan a la comprensión del repertorio tradicional. Concluyendo se muestra que el 54,8\% de estudiantes encuestados mencionan que casi siempre logran entender con facilidad los procesos didácticos que realiza el docente en clase, y el 3,2\% mencionan que nunca logran entender. 
Se puede asegurar que existe una carencia de estrategias y técnicas para la creación, aprecio y valoración de la identidad musical nacional en la enseñanza y practica académica; durante el proceso de enseñanza - aprendizaje utilizamos una variedad de técnicas y métodos de enseñanza, pero a veces son aplicados de forma empírica e incompleta sin tomar en cuenta su real alcance y dimensión.

La experiencia del docente en el uso y aplicación de métodos y técnicas debe estar enfocada en función de los objetivos y en el logro de aprendizajes, para ello es indispensable la estructuración, orden y correlación de los contenidos. Estos métodos y técnicas de enseñanza deben estar alejados de la metodología de enseñanza tradicional, en la que la práctica instrumental era repetitiva y memorística la cual ofusca y suprime los procesos cognitivos superiores

El docente debe estar atento a las dificultades que pudieran presentar sus estudiantes, brindándoles métodos y técnicas de estudio acordes a sus potencialidades y que los ayuden a consolidar los aprendizajes; estos recursos deben estar organizados y compuestos por dinámicas de grupo, y estrategias lúdicas que involucren a los estudiantes y desarrollen sus habilidades musicales tanto como sus habilidades blandas. Es labor del docente ayudar y facilitar el ordenamiento mental del estudiante orientándolo a medida que se presentan los contenidos considerando cuales son los objetivos trazados a la realidad individual de cada uno.

Sobre la subcategoría actividades didácticas un gran porcentaje de estudiantes en un 19,4\% manifiestan que a veces logran articular sus conocimientos previos con la nueva información y aplicar en la solución de problemas cotidianos. un 16,1\% mencionan que a veces el docente planifica y aplica estrategias y técnicas que responden a los intereses y necesidades de los estudiantes y un 3,2\% mencionan que nunca el docente las realiza; también se evidencia que un $12,9 \%$ mencionan que a veces y solo el 3,2\% mencionan que nunca el docente aplica procedimientos que se adaptan a los niveles de aprendizaje de los estudiantes. 
En resumen, se detalla que más de la mitad de los estudiantes tienen ciertos inconvenientes para relacionar los conocimientos previos con la nueva información; a pesar de que el docente planifica y aplica estrategias para ayudar a sus estudiantes, estas no son las adecuadas o no se adaptan al nivel de aprendizaje de cada uno de ellos por lo que se evidencia un desconocimiento de actividades y estrategias para desarrollar el pensamiento crítico y metacognición.

Finalmente, en relación a la subcategoría recursos de enseñanza aprendizaje la mitad de los estudiantes $32,3 \%$ mencionan que a veces el docente diseña y aplica recursos didácticos atractivos en cada sesión de clase y solo el 3,2\% indican que nunca lo hace, también el 45,2\% mencionan que a veces el docente promueve el uso de diferentes recursos materiales y digitales en cada sesión de clase, un 12,9\% que nunca los promueve.

Se evidencia que existe una carencia de material pedagógico y recursos académicos (partituras, score, manuales técnicos, etc.) relacionados a la música tradicional esquematizados y adaptados a las necesidades académicas de las especialidades instrumentales. Esta escases demuestra el desconocimiento y poco interés por parte de la institución para la búsqueda, el diseño, preparación y aplicación de recursos didácticos adecuados que puedan facilitar el desarrollo de la identidad musical nacional en los estudiantes; también existe una falta de capacitación y actualización acerca de los recursos, materiales y procesos educativos que implicaría la creación y diseño de estos materiales de la música tradicional para su posterior estudio, análisis y aplicación del material pedagógico logrando una mayor vinculación entre las distintas especialidades.

Un elemento indispensable en el proceso pedagógico es el uso de las TIC su falta de implementación en las aulas y su uso en las sesiones de clase limitan el aprendizajes de los estudiantes (considerando que ellos están más familiarizados con la tecnología), pues si bien muchos docentes recurren al teléfono celular como herramienta de asistencia pedagógica para 
la búsqueda de información, clases maestras, conciertos y recitales en video de la pieza de estudio, resulta imperativo que la institución se equipare tecnológicamente y capacite a los docentes en el uso de estas herramientas de Tecnología de la Información y Comunicación.

A continuación, se describen los hallazgos encontrados sobre las categorías genéricas o explicativas emergentes:

\section{Importancia de la evaluación formativa en los procesos de enseñanza-aprendizaje.}

La evaluación formativa nos permite orientar la actividad por medio de informes sobre la manera en que se van alcanzando los objetivos. Martínez (2012) refiere que una evaluación formativa se consolida cuando los resultados que muestra acerca del desempeño de los estudiantes son analizada, adaptada y aplicada por los docentes, estudiantes o sus pares, con el fin de decidir las acciones siguientes en el proceso pedagógico.

Es necesario contar previamente con una evaluación y diagnostico técnico musical del estudiante, esto facilitará la estructuración de los contenidos que desarrollaran durante las sesiones de clase y serán dosificados a medida que el estudiante alcance los objetivos propuestos; durante este proceso el docente realizará un seguimiento constante a través de la aplicación de una rúbrica de avaluación, para ello debe explicar los procedimientos de aplicación de la misma, y esta puede ser reajustada de acuerdo al avance del estudiante.

Debemos señalar que la falta de aplicación de una rúbrica de avaluación en cada sesión de clase ocasionaría que la consolidación de saberes nuevos quedase inconclusa y por lo tanto tampoco se daría una retroalimentación; este proceso cognitivo es esencial para la triangulación de saberes previos en contraste con la nueva información, en ese sentido el docente debe brindar la asistencia y acompañamiento que requiere el estudiante.

La autoevaluación y coevaluación que se deben dar durante desarrollo de la sesión de clase permite a los estudiantes participar de manera activa en los procesos de evaluación, implica compartir y discutir con ellos los objetivos de aprendizaje y los resultados esperados, 
apoyándolos para que, de forma individual o grupal, reflexionen acerca de sus experiencias, valoren sus fortalezas y puedan programar sus avances en coordinación con el docente.

Es importante indicar que de la misma manera en que se evalúa formativamente a los estudiantes, los docentes también deben realizar una autoevaluación y reflexión de su accionar pedagógico, este proceso permitirá consolidar los enfoques y la manera de proceder en el ámbito de la evaluación.

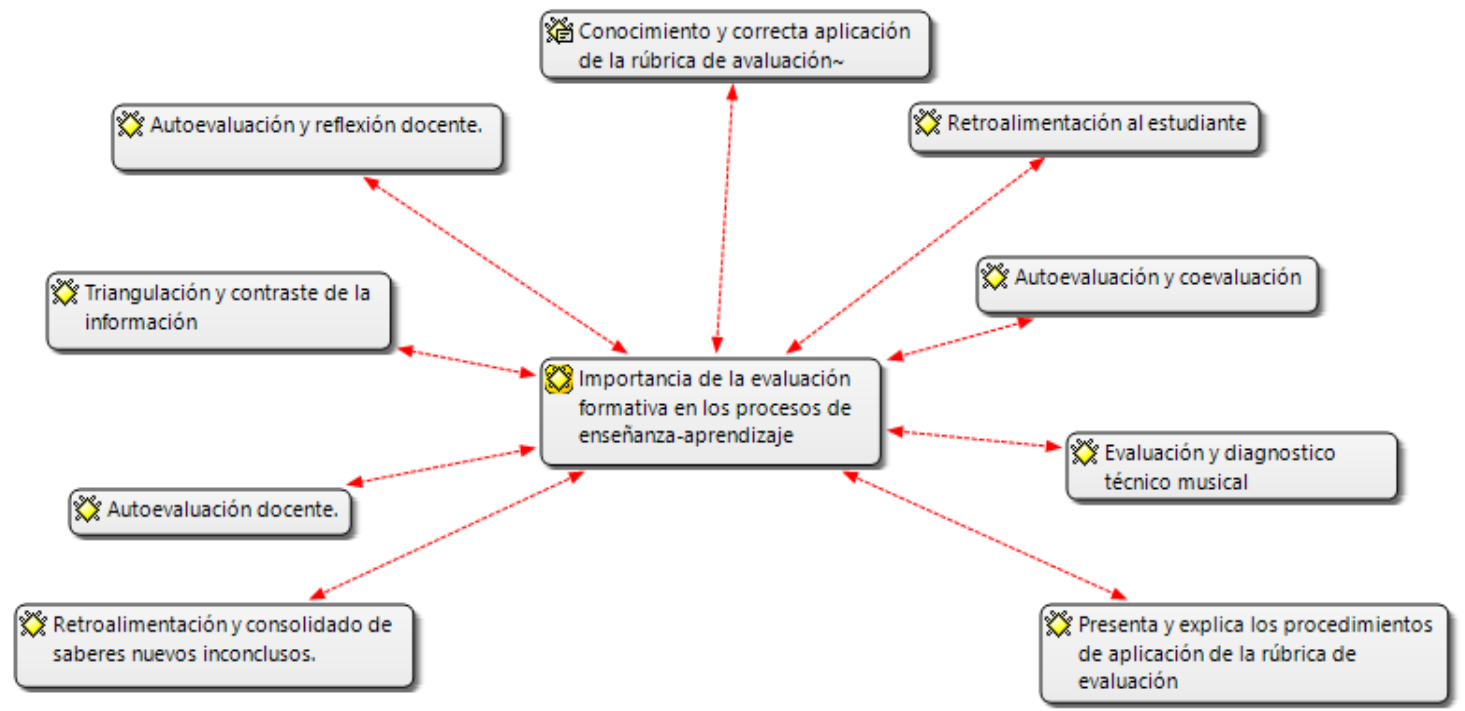

Figura 2. Categoría emergente

\section{Gestión del tiempo durante las sesiones de clase.}

Una enseñanza de calidad además del tiempo que se invierte en el estudiante, es una variable que el docente controla e influye directamente en el rendimiento, por ello la necesidad de tener organizada la sesión de clase y cumplir el esquema trazado. Una mala gestión del tiempo en la sesión ocasionaría que los objetivos planteados y los aprendizajes esperados quedaran inconclusos, los estudiantes no asimilarían los contenidos y limitaría sus conocimientos para la sesiones siguientes; Caroll (1963) “el grado de aprendizaje de una tarea está en función de la relación existente entre la cantidad de tiempo que ocupa realmente el estudiante en ella y el 
tiempo necesario para aprender" (pp. 237 - 269), este problema en la gestión de tiempo surge por la falta de conocimiento, orden e integración del docente al proceso y estructuración de las sesiones de clase.

Tomando en cuenta que toda sesión posee un inicio, en donde se dan a conocer los contenidos, plantean los objetivos y debe motivarse al estudiante por medio de estrategias, recursos o materiales que despierten su interés, suele pasar que en esta fase de la sesión se invierte demasiado tiempo lo cual limita el desarrollo de los contenidos, que es ahí en donde se afianza y consolida los temas y objetivos propuestos. Finalmente, el cierre de la sesión debe tener consistencia y coherencia con el planteamiento inicial, la retroalimentación es clave en este punto pues afianza los aprendizajes logrados para las demás sesiones.

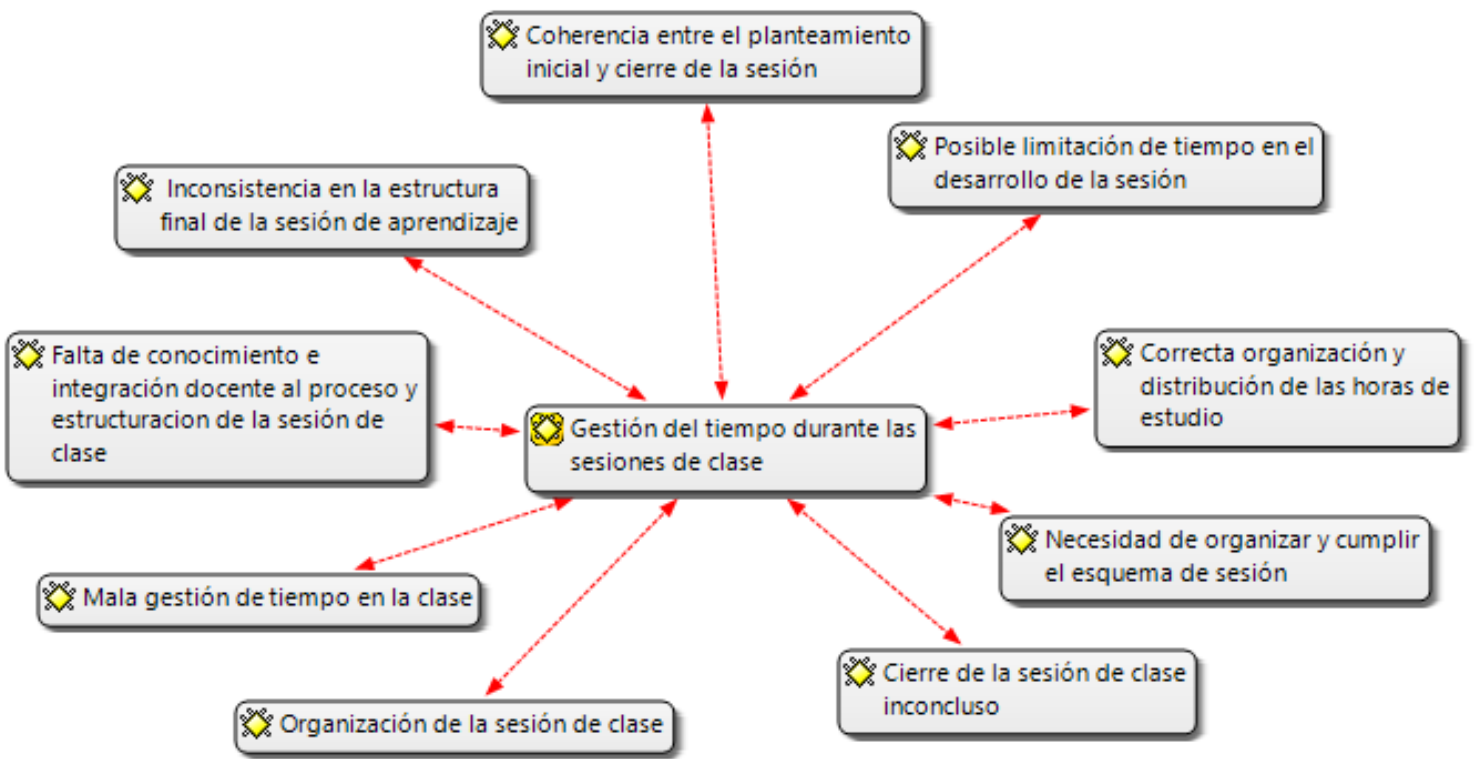

Figura 3. Categoría emergente

\section{Capacitación y actualización en los contenidos de la música tradicional.}

En relación a la capacitación y actualización en los contenidos de la música tradicional los entrevistados manifiestan que es un tema principal para la mejora continua del trabajo profesional, lo que llevara a un mejor aprovechamiento de los aprendizajes en los estudiantes. 
Y que esta mejora para el desempeño docente debe estar bajo la supervisión de un área específica en la cual, se motive al docente brindándole las herramientas para la investigación en los temas y contenidos de la música tradicional y tenga un seguimiento al trabajo realizado.

La capacitación y actualización docente está sustentada por Camargo, Calvo, Franco, Vergara \& Londoño (2004) “debe entenderse como un proceso de actualización que le posibilita realizar su práctica pedagógica y profesional de manera significativa, pertinente y adecuada a los contextos sociales en que se inscribe y a las poblaciones que atiende.” (pp.81)

La falta de un acompañamiento pedagógico, capacitación y actualización pone en evidencia un bajo conocimiento y preparación de los temas a abordar, dificultades para hacerse entender además de que un docente no motivado no fomenta la creatividad, aprecio ni expresividad en la practicas musicales; al no contar con recursos, materiales ni estrategias o metodologías innovadoras, esta desmotivación se transfiere a los estudiantes y ocasiona un ambiente de rechazo hacia los temas y contenidos a desarrollar.

Los elementos que componen los contenidos de la música tradicional para su estudio y aplicación deben ser asimilados y comprendidos por el docente antes de facilitarlos a los estudiantes; la postura y el compromiso en el tratamiento de estos contenidos deben reflejar las capacidades del docente para dosificar y desarrollar los temas, logrando el aprecio y valoración de los elementos identitarios que conforman la música tradicional.

Debe mostrar un dominio del lenguaje artístico en relación a los temas, unificando ideas, conceptos, y puntos de similitud entre los contenidos de la música académica y la música tradicional. Al abordar una obra tradicional, el rol del docente como mediador es motivar, a través de experiencias propias, comentarios o sugerencias, al estudiante a buscar mayor información respecto a la obra y contrastarla con los conocimientos que posee, para este fin el esquema y preparación de cada clase debe estar correlacionada con la siguiente; este desempeño 
y asistencia al estudiante demuestra su profesionalismo, disciplina y un desarrollo de las habilidades blandas la cual promueve la empatía laboral y un ambiente de trabajo óptimo.

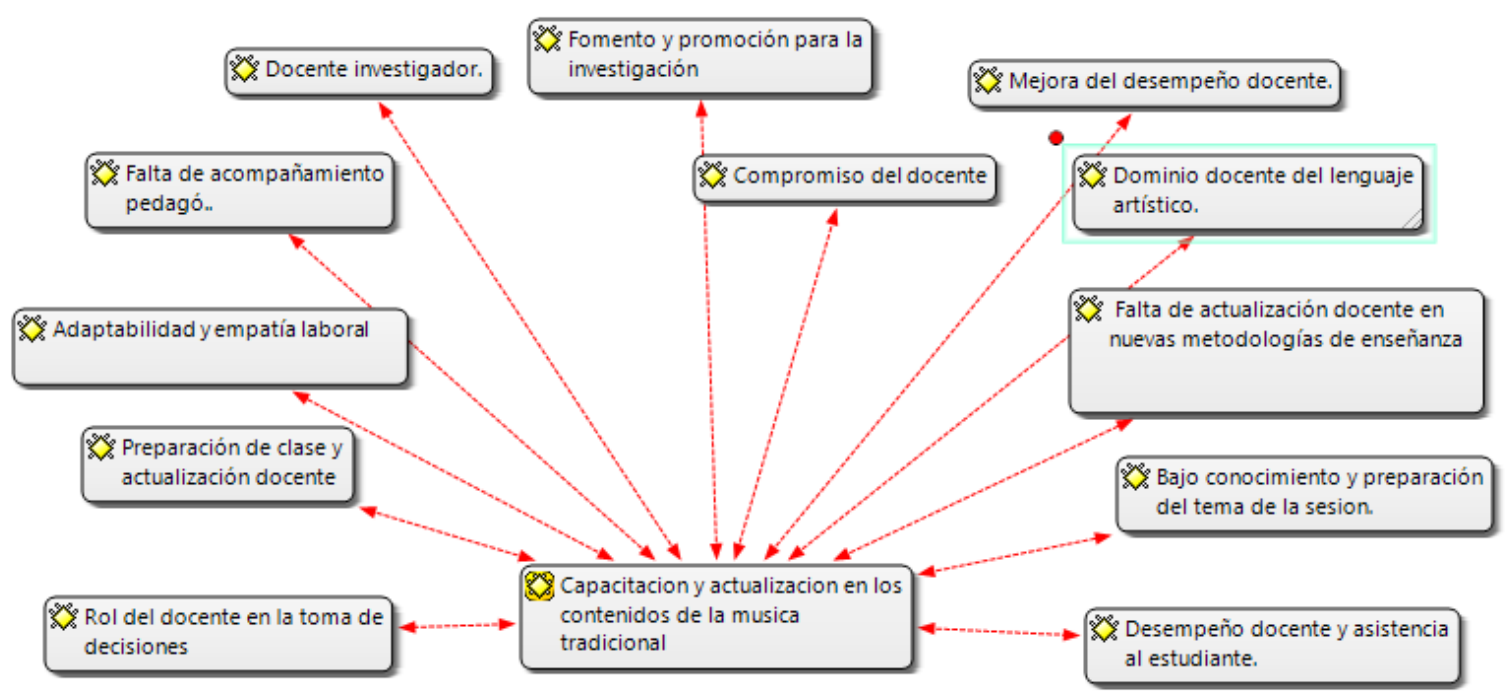

Figura 4. Categoría emergente

\section{Estructuración y contenidos de la música académica y tradicional.}

Respecto a la estructuración y contenidos de la música académica y tradicional los entrevistados mencionan que se debe tener un acercamiento correcto a la obra musical respaldado por un amplio conocimiento de las formas, estilos musicales, géneros y características de cada compositor. Rivera (2016) sostiene que las diversas obras de música tradicional, ya sean propias del país o extrajeras, han sido de inspiración a diversos compositores académicos; en ese sentido la música académica aporta recursos, herramientas y técnica al músico, las cuales también son requeridas para tener una mejor comprensión de los variados contenidos de la música tradicional.

La aplicación de estos elementos de la música en la práctica instrumental, grupos de cámara y orquesta deben estar sujetos al nivel interpretativo de los estudiantes los cuales se sustentan en ejercicios técnicos (escalas, arpegios, articulaciones etc.) repertorio de la 
especialidad, amplitud del criterio musical, así como la experiencia ganada a través de las practicas instrumentales.

También comentan que la carencia de un repertorio académico para instrumentos de cuerda basado en la música tradicional es un impedimento para poder desarrollar la identidad musical nacional en los estudiantes, recomiendan que se debe diversificar la enseñanza académica usando la gran cantidad de elementos culturales con coherencia en el repertorio asignado a la especialidad instrumental, además debe ser transversal en la currícula, diversificando este material pedagógico entre las distintas especialidades.

Consideran, que, si bien la institución exige un alto nivel académico, tanto a sus profesores como estudiantes, es necesaria una reorganización curricular tomando en cuenta el esquema de contenidos de la música tradicional, no solo como un concepto cultural que contribuya al desarrollo de la identidad en sus estudiantes, sino el aprovechar los recursos técnicos y académicos que ofrece.

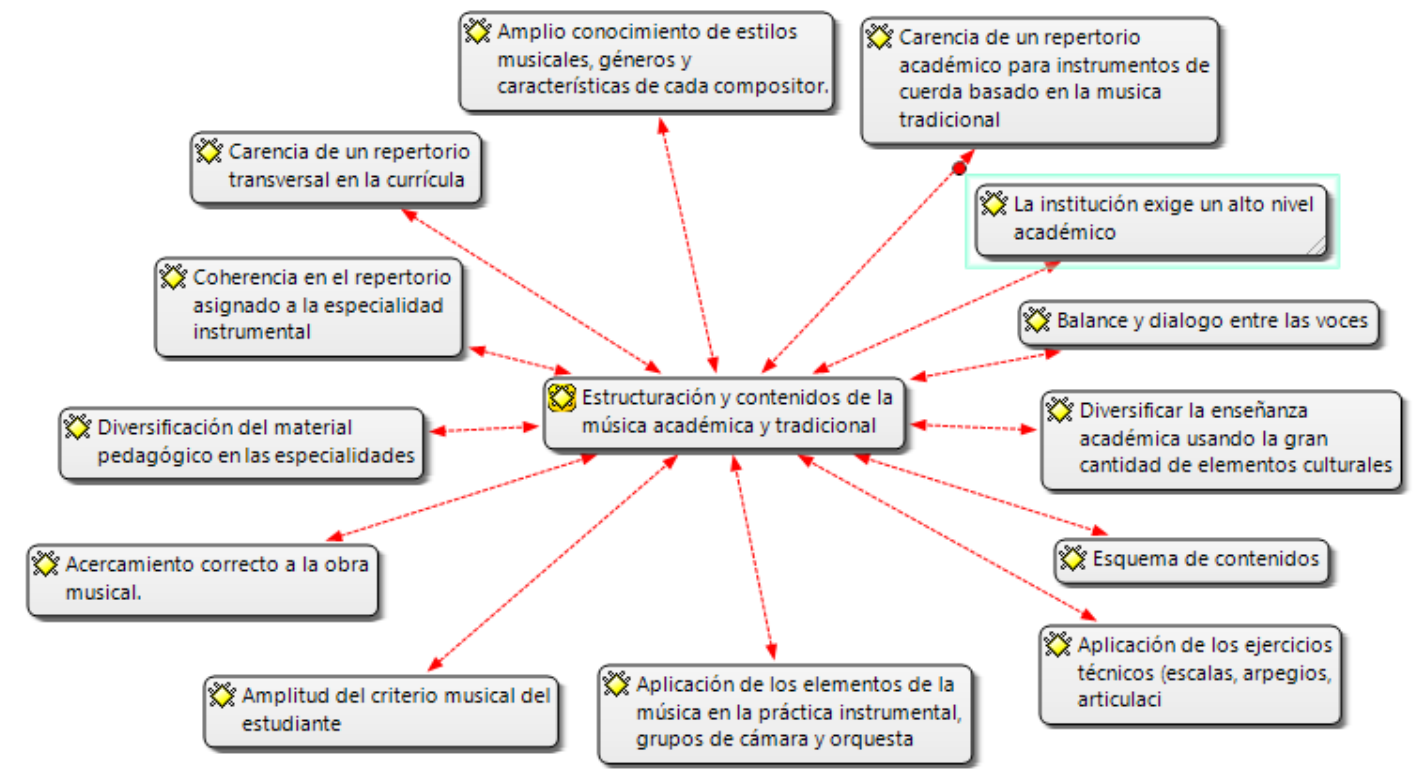

Figura 5. Categoría emergente 


\section{Carencia en el desarrollo de la capacidad de análisis de repertorio de la música}

\section{tradicional - interpretación musical.}

Respecto a esta categoría emergente los entrevistados opinaron que al existir un escaso material pedagógico (repertorio académico escrito) de la música tradicional, la búsqueda y análisis de las obras escogidas, entrevistas con el autor, comparación de repertorio, sugerencias al compositor son de suma importancia para conservar y difundir estas pocas obras tradicionales académicas.

Pedagógicamente, el repertorio implica el estudio, contraste y comprensión de la obra antes de su interpretación. El análisis musical, según Ferrara (1991) implica entender la interacción dinámica entre los distintos estados de significación musical y plantear procedimientos por medio del cual se pueda demostrar esos estados de forma individual y también en su interacción entre ellos.

Así pues, el estudiante debe dar evidencia del análisis crítico una vez que aplica sus conocimientos en la interpretación musical. Los entrevistados también remarcan que, sumado a las capacidades de análisis e interpretación, están las capacidades técnicas que debe desarrollar el estudiante (digitación, manejo del arco, sonoridad, registro de sus instrumentos) ya que sin ellas las posibilidades artísticas son limitadas.

También mencionan que cada estudiante músico debe ser consciente de su práctica instrumental, del desempeño y calidad interpretativa así como la correcta ejecución del repertorio académico tanto como del tradicional, por ello la fidelidad en la ejecución e interpretación de la partitura es uno de los preceptos que se les inculca desde la primera clase; así también la dificultad creciente en las obras a interpretar amplían sus posibilidades técnicas para ejecutar adecuadamente la obra en el instrumento que posee, usa recursos de interpretación: (escucharse, dialogar, frases musicales) los cuales tienen congruencia y correlación a medida que se desarrolla su musicalidad y criterio artístico. 


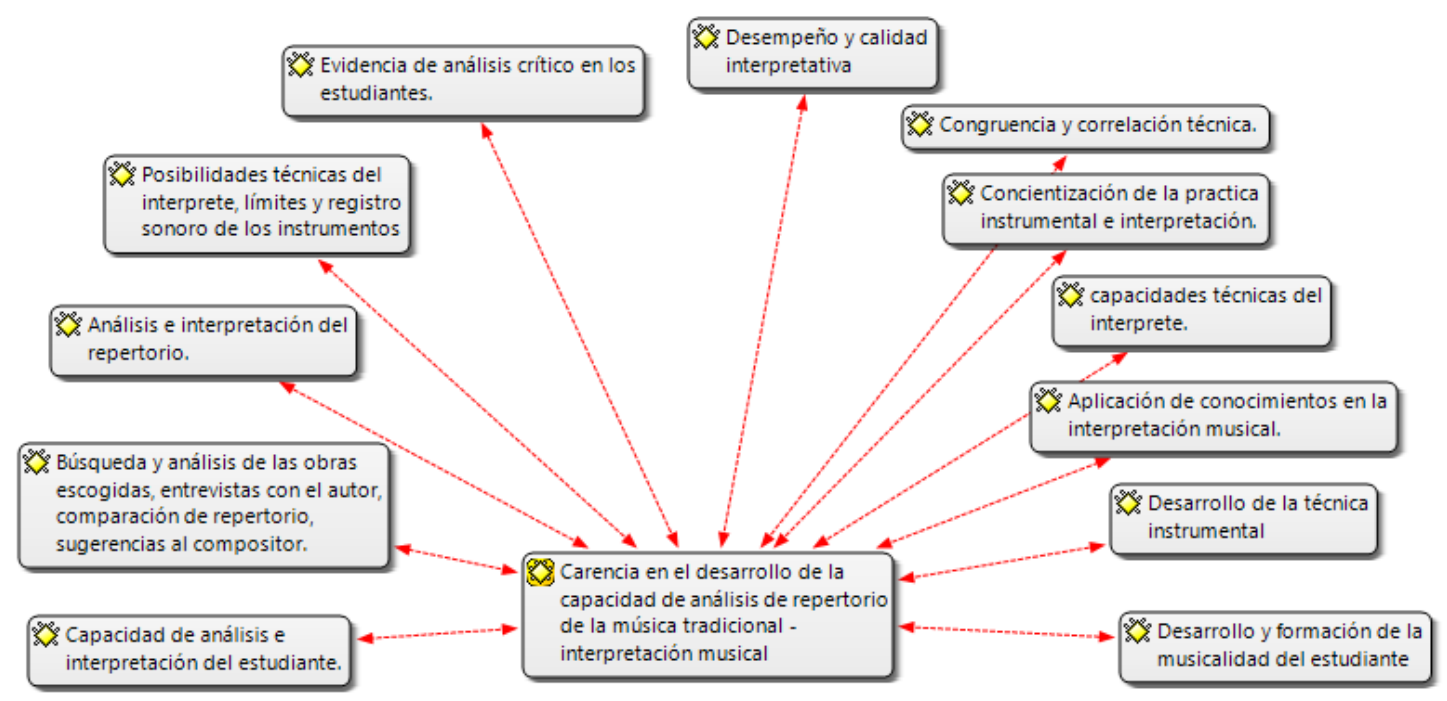

Figura 6. Categoría emergente

Necesidad del acompañamiento pedagógico durante los procesos de enseñanzaaprendizaje.

En relación a la asistencia pedagógica a los estudiantes, los encuestados y entrevistados indicaron que la desmotivación del estudiante es uno de los elementos que ocasiona un bajo desarrollo de las capacidades musicales, sumado a una falta de disciplina y orden en el estudio el desempeño del estudiante, así como su participación activa en las sesiones de clase se ven reducidas.

Manifiestan que si bien, es importante la motivación al estudiante en el proceso de enseñanza - aprendizaje; el acompañamiento pedagógico y asesoría al estudiante es fundamental durante toda la etapa formativa. La asistencia personalizada y orientación profesional le permitirán vincular y aplicar sus conocimientos adquiridos en diversas situaciones reales de desempeño. 


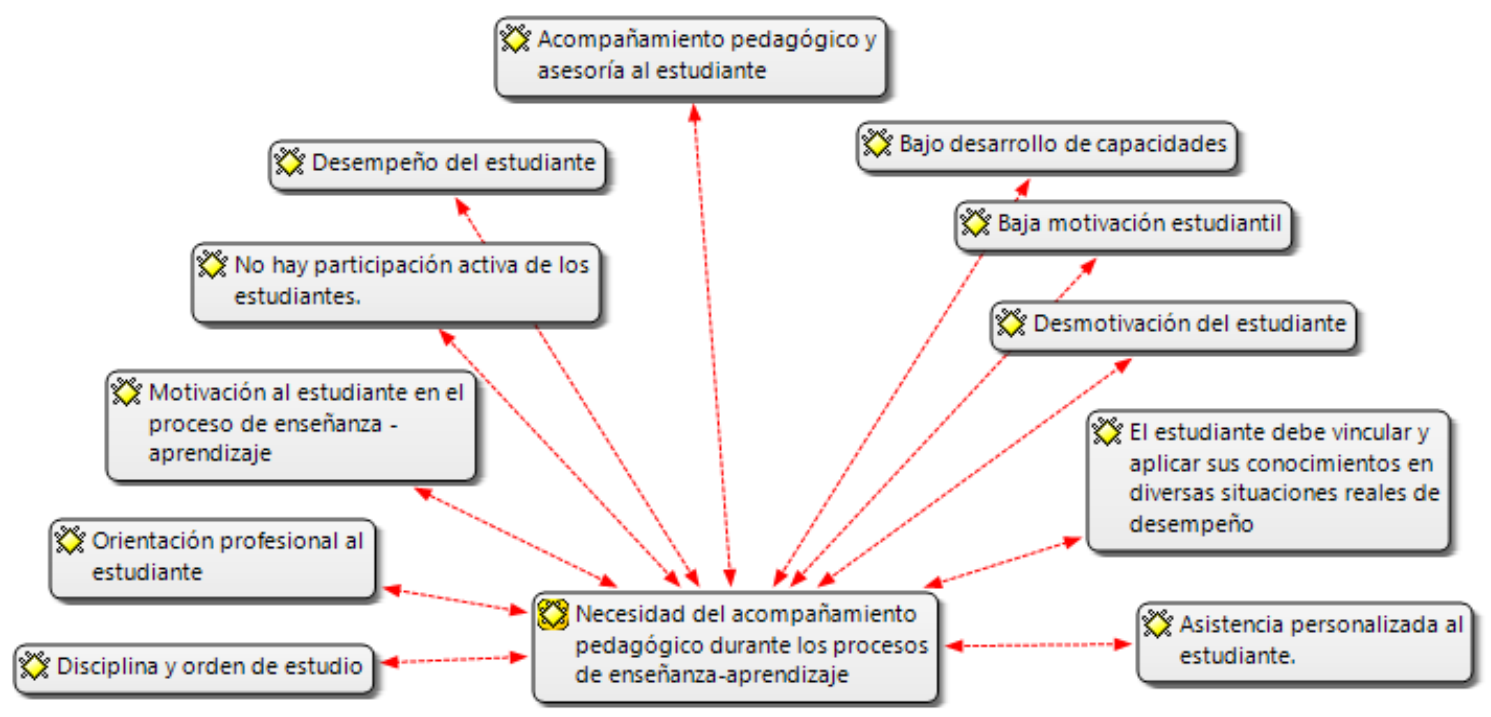

Figura 7. Categoría emergente

\section{Elementos de la música tradicional en la ejecución instrumental.}

De acuerdo a los resultados obtenidos, se evidencia una escasa difusión de la música tradicional con un objetivo o planteamiento académico, el repertorio de viola y la literatura académica de la especialidad están orientados en “adquirir y desarrollar las capacidades técnicas para ejecutar adecuadamente las obras de los grandes maestros".

Sin embargo, los elementos identitarios y contenidos de la música tradicional pueden formar parte también de los objetivos técnicos de la especialidad, la lectura y estudio del repertorio, la secuencia escalonada de los métodos y la práctica instrumental puede tener un equilibrio entre la música tradicional escrita y el repertorio técnico académico.

Rivera, (2016) menciona la emulación de sonidos, timbres, métricas y efectos pertenecientes a las numerosas músicas tradicionales, es un recurso (...) que puede llegar a significar un camino en su técnica (...) son los elementos y la forma en la que los utiliza los que definen la estética de su música (...) unido a los diversos lenguajes académicos (..) da como resultado la posibilidad de que su música sea diferenciable. 
Uno de los entrevistados manifestó su preocupación por el enfoque de la enseñanza de la música tradicional, pues existe la necesidad de vincularla a los objetivos académicos del Conservatorio y debe estar a la altura de los requerimientos técnicos exigidos, para ello el reconocimiento de sus elementos como el ritmo, melodía, armonía, timbre que marcan su particularidad intrínseca, se adaptan a las exigencias técnicas de las especialidades, como el uso de recursos sonoros, ejercicios de arco y digitación, aplicando técnicas de interpretación coherentes con el estilo de la obra y el compositor.

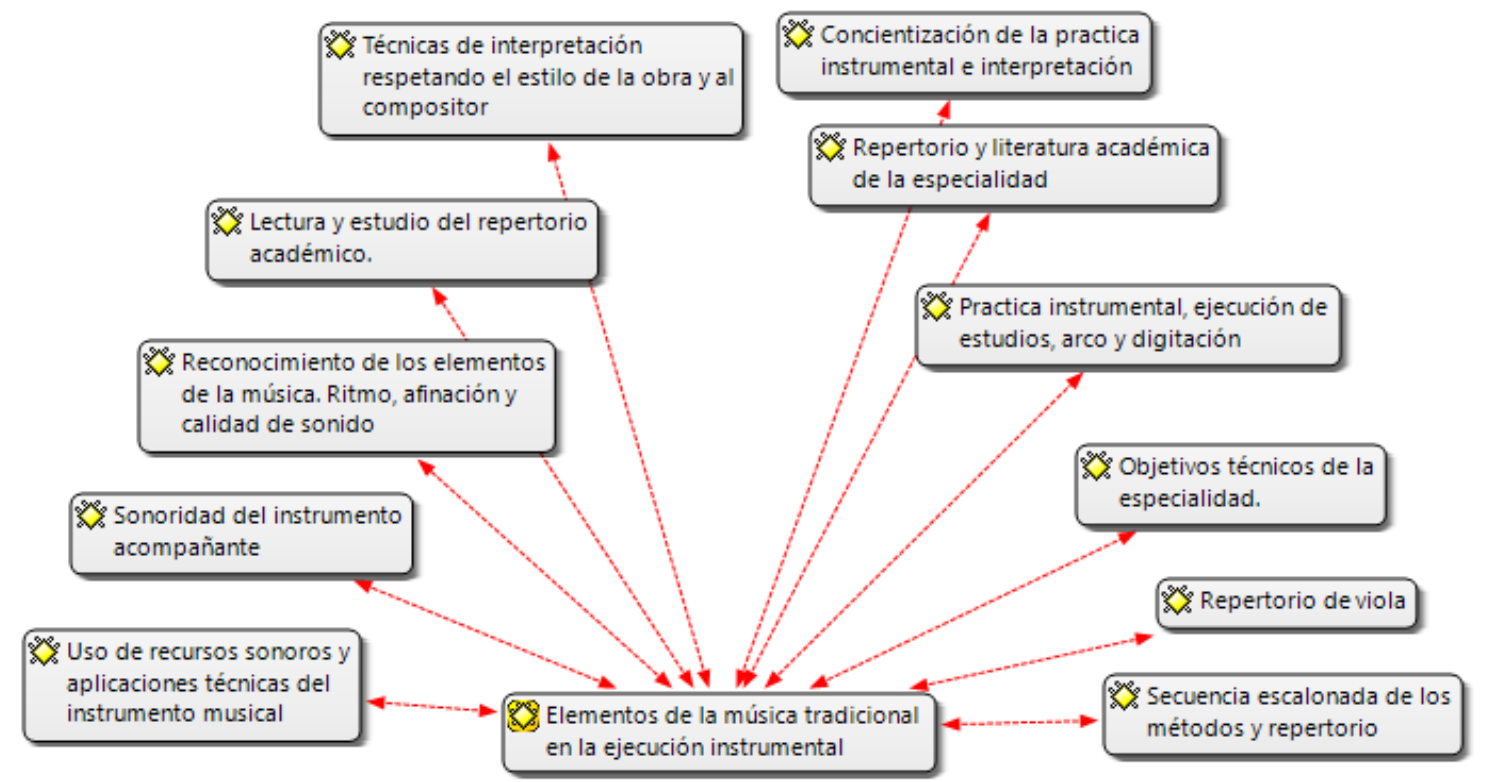

Figura 8. Categoría emergente

\section{Categorías influyentes en el problema}

Entre las categorías influyentes identificadas son las siguientes: Dificultades en la aplicación de la evaluación formativa por parte de los docentes; necesidad de capacitación y actualización de los docentes en los contenidos de la música tradicional; dificultades de los estudiantes en la identificación de los elementos de la música tradicional en la interpretación musical y las dificultades que presentan los docentes en la estructuración de los contenidos de la música tradicional. 


\section{Conclusiones aproximativas}

Una vez aplicados los instrumentos de recojo de información, los datos procesados muestran que en el cuestionario cerrado los estudiantes no reconocen la música tradicional, pueden identificar el género musical o características muy generales, pero no el trasfondo o contexto en que fueron creadas, lo cual demuestra una falta de identificación e interés por la cultura de su propia región, considerando que la gran mayoría de estudiantes provienen del interior del país. También se evidencia que en la elección del repertorio personal la mayoría de estudiantes pocas veces incluye música tradicional de su localidad, su preferencia esta hacia la música clásica académica, lo cual es comprensible ya que son estudiantes de un conservatorio; es por ello que solo consideran algunos temas tradicionales más populares del folklore nacional en su repertorio personal.

En cuanto a la prueba pedagógica, se evidencia un nivel intermedio en cuanto a conocimientos relacionados a la música tradicional, sin embargo, el no reconocer los elementos que la componen como los instrumentos tradicionales típicos o las asociaciones de las características que diferencian estas músicas, demuestran solo un conocimiento teórico y superficial, por lo que conseguir una interiorización de ese conocimiento y hacerlo significativo para el estudiante se hace imperativo.

La entrevista a los docentes y la observación de clase mostraron que existe un predominio académico hacia la música clásica, debido a la naturaleza de las especialidades instrumentales; pues el material pedagógico, así como la metodología de enseñanza, la técnica instrumental y la literatura académica provienen de escuelas europeas muy antiguas y que permanecen vigentes hoy en día.

Sin embargo, los docentes expresaron interés en promover y difundir la música tradicional a través de la enseñanza en sus especialidades, no solo como una obra más para el repertorio del alumno, sino que su tratamiento y aplicación forme parte de la estructura 
académica. Para ello es necesario contar con un enfoque, un diseño, una estrategia metodológica que permita abordar desde la primera etapa formativa del estudiante los conocimientos teóricos, técnicos y didácticos articulados para cada especialidad.

La falta de material pedagógico de la música tradicional como: métodos, manuales de estudio, escalas y ejercicios, guías didácticas entre otros; que tengan un enfoque académico, técnico adaptado a las diferentes especialidades instrumentales del conservatorio dificulta el aprecio, valoración y por ende su difusión. Es por ello, que abordar los temas de música tradicional resulta casi improvisado para el docente de la especialidad instrumental, además de carecer de estrategias y recursos didácticos o de una capacitación y acompañamiento pedagógico que facilite la asimilación de los contenidos en sus estudiantes, seria prioritario.

En referencia a las categorías emergentes, la evaluación formativa del estudiante implica por parte del docente realizar un diagnóstico previo. Esto para tener una visión amplia del trabajo pedagógico a realizar, así como para dosificar los contenidos a medida que los estudiantes logren las metas propuestas. Es necesario que el docente aplique en cada sesión de aprendizaje una rúbrica de evaluación, la cual debe ser reajustada de acuerdo al desarrollo del estudiante. Esta rúbrica permitirá consolidar los saberes nuevos logrando una retroalimentación completa.

La gestión de tiempo en la sesión de aprendizaje, implica para el docente tener un orden en la estructura de su sesión, además de un total conocimiento de los contenidos y temas que impartirá. Debe ser preciso en la apertura realizando una atractiva motivación con lo que captaría el interés de sus estudiantes facilitando el desarrollo de los temas, así también el cierre de la sesión debe afianzar los contenidos convirtiéndolos en saberes previos para las siguientes sesiones; en ese sentido es necesario remarcar que una mala gestión de tiempo ocasiona una asimilación de saberes inconcluso con lo cual se verían limitados sus aprendizajes en las posteriores clases. 
La capacitación y actualización en los contenidos de la música tradicional, significa para los docentes una mejora continua en el ejercicio de su labor profesional, brindándole las herramientas para la investigación en los temas y contenidos de la música tradicional, lo que se revertirá en una mejor mediación de conocimientos a los estudiantes. La falta de un acompañamiento pedagógico produce un bajo rendimiento del docente, poco dominio del tema, dificultades para hacerse entender y desmotivación frente a sus estudiantes, ante ello los contenidos de la música tradicional, para su aplicación, deben ser asimilados y comprendidos por el docente antes de facilitarlos a los estudiantes.

Estructuración y contenidos de la música académica y tradicional, al respecto los docentes mencionan que existe carencia de un repertorio académico para instrumentos de cuerda basado en la música tradicional, lo cual es un impedimento para poder desarrollar la identidad musical nacional en los estudiantes; recomiendan que se debe diversificar la enseñanza académica usando la gran cantidad de elementos culturales con coherencia en el repertorio asignado a la especialidad instrumental, además debe ser transversal en la currícula, diversificando este material pedagógico entre las distintas especialidades.

La carencia en el desarrollo de la capacidad de análisis de repertorio de la música tradicional - interpretación musical; al respecto los docentes señalan que el escaso repertorio tradicional académico escrito, implica el análisis y estudio de la obra, acercamiento con el compositor y sugerencias del mismo. Para conseguir una interpretación de alto nivel artístico el estudiante debe dar evidencia del análisis crítico una vez que aplica sus conocimientos en la interpretación y sumado a ello las capacidades técnicas que debe desarrollar el estudiante (digitación, manejo del arco, sonoridad, registro de sus instrumentos) ya que sin ellas las posibilidades artísticas son limitadas.

Necesidad del acompañamiento pedagógico durante los procesos de enseñanzaaprendizaje; tanto estudiantes como docentes manifestaron que la desmotivación del estudiante 
es uno de los elementos que ocasiona un bajo desarrollo de las capacidades musicales, sin embargo, la asistencia pedagógica y asesoría al estudiante resulta fundamental durante toda su etapa formativa.

Elementos de la música tradicional en la ejecución instrumental. Se muestra una escasa difusión de la música tradicional con un enfoque académico, el repertorio de viola y la literatura académica de la especialidad están orientados en "adquirir y desarrollar las capacidades técnicas para ejecutar adecuadamente las obras de los grandes maestros". Pero los elementos identitarios y contenidos de la música tradicional pueden formar parte también de los objetivos técnicos de la especialidad, las cuales deben estar a la altura de los requerimientos académicos exigidos. 


\section{Capitulo III}

\section{Modelación de la propuesta}

\section{Propósito}

La estrategia metodológica está orientada a desarrollar la identidad musical nacional en los estudiantes de la especialidad de Cuerdas de un conservatorio de Lima. La propuesta se sostiene por la triangulación de las categorías emergentes resultantes del trabajo de campo las cuales al ser contrastadas con los referentes teóricos facilita su diseño.

\section{Justificación}

Esta propuesta nace de los resultados obtenidos del trabajo de campo de donde se revela la falta de identificación de los estudiantes en relación a la música tradicional y a los elementos identitarios que la componen. En el diagnóstico del trabajo de campo se identificó también la carencia de estrategias y recursos didácticos que puedan aplicar los docentes para el desarrollo de la identidad musical nacional,

Esta realidad impulsa la construcción, sistematización y estructuración de una propuesta metodológica que contribuya al desarrollo de la identidad musical nacional en los estudiantes; lo cual conlleva la aplicación de una serie de actividades enfocadas para este fin. Es decir, la propuesta busca contribuir al desarrollo de la identidad musical nacional en los estudiantes de cuerdas de un Conservatorio de Lima.

\section{Fundamentación teórico científico}

\section{Fundamento socioeducativo.}

El conservatorio es una institución educativa fundamental para el estudio, interpretación, conservación y crecimiento del patrimonio musical. Se encuentra ubicada en el Centro Histórico de Lima rodeado de los más imponentes ejemplos de arquitectura monumental española, monumentos, iglesias y conventos, casonas y sus característicos balcones. La 
Organización de las Naciones Unidas para la Educación, la Ciencia y la Cultura (Unesco, 1991) lo declaró Patrimonio de la Humanidad.

A través de sus 112 años de existencia continúa formando a los músicos profesionales más importantes del Perú. La plana docente está conformada por los más destacados músicos peruanos y profesores de diversas nacionalidades los cuales aportan con sus propias tradiciones, vivencias y trayectoria a elevar la calidad educativa; la población estudiantil es de 524 alumnos distribuidos en las 25 especialidades que ofrece la institución. El conservatorio promueve la preservación, acrecentamiento y difusión del patrimonio musical nacional y universal, contribuyendo al fortalecimiento de nuestras identidades dentro de la diversidad cultural.

\section{Fundamento psicológico.}

Las edades de los estudiantes oscilan entre los 18 y los 25 años, se consideran muy afortunados de seguir la carrera y son felices con lo que estudian demostrando una gran vocación por la música; sin embargo, al ser estudiante de una carrera artística implica estar en un constante conflicto emocional, son sumamente sensibles a las críticas como a los halagos - en especial por parte de su maestro - tal como lo menciona Jorgensen (2009) la relación que se da entre el maestro y su estudiante conlleva una interacción entre el carácter del profesor y la personalidad del estudiante. Esta relación unas veces positiva y otras negativas los impulsa a esforzarse constantemente por lograr la perfección técnica e interpretativa en sus especialidades.

La función del docente no solo como educador, sino como modelo a seguir, implica una gran responsabilidad ya que las actitudes, experiencias, conflictos y vivencias que experimentan los estudiantes en el transcurso de la carrera ya han sido parte de la experiencia del maestro por lo tanto su guía, consejo y orientación es de vital importancia en la vida de sus estudiantes. En ese sentido, Tripiana (2009) menciona en su estudio que la decisión que toman los jóvenes por seguir la carrera profesional de música, conlleva una elevada y férrea autodeterminación, ya que en muchos casos la preferencia de la familia se orienta hacia otras carreras profesionales. 
Se evidencia la peculiar personalidad de los estudiantes de un conservatorio, desde el hecho de elegir una carrera artística la cual es muchas veces incomprendida por su familia y mantenerse firme en su decisión la cual siempre se verá confrontada por los desaires o inconvenientes que encontrará; pero también se dará cuenta que tomó la decisión correcta cuando a través de su carrera se convierta en un músico completo, íntegro y en su momento pueda transformar la vida de sus estudiantes siendo un mejor Maestro.

\section{Fundamento pedagógico.}

La estrategia metodológica considera la pedagogía como una ciencia de lineamiento social que tiene como principio la formación integral del ser humano para la vida. En concordancia Rojano (2008) sostiene que la pedagogía es un conjunto de acciones que se realizan en el ámbito educativo, sustentada en métodos y procedimientos que permiten sistematizar y ordenar el estudio de la problemática educativa presente en el entorno del proceso enseñanza- aprendizaje. Para esta propuesta tomaremos como base el enfoque sociocultural (Vygotsky, 1998) y el enfoque humanista propulsando las acciones educativas y métodos innovadores para el desarrollo de la identidad musical nacional en los estudiantes de cuerdas de un conservatorio de Lima.

\section{Enfoque sociocultural.}

El enfoque sociocultural parte del concepto de que los aprendizajes se logran por medio de la interacción de las personas en un medio social con actividades organizadas en las cuales los individuos con mayor preparación o más experiencia apoyan y guían a los demás.

Esta afirmación es consistente con Dana \& Goldstein (2015) quienes sostienen que existen funciones cerebrales específicas que son inherentes al ser humano y que no existen en los animales; como los procesos psicológicos humanos los cuales surgen de la interacción social. Tal afirmación refuerza la construcción de la propuesta la cual se asienta en el 
aprendizaje vivencial, cercano, social y heredado en la psique del hombre el cual perdura a través de generaciones.

Vygotsky (1998) sostiene que los aprendizajes se deben ir construyendo paulatinamente pues los conocimientos y herramientas culturales son transferidos de una persona a otra al interactuar en actividades sociales compartidas. En ese sentido Maynard \& Martini (2005) indican que el desarrollo cognitivo es el proceso mediante el cual las capacidades emergentes de una persona se relacionan con el medio y contexto cultural del desarrollo. Como resultado de este proceso dinámico se forma un individuo integro en el que de forma natural la experiencia, es una parte integral de que y como la persona piensa y actúa.

Considerando que los conocimientos se construyen socialmente y a través de la experiencia, es necesario introducir en los procesos educativos estas vivencias además de que los planes y programas de estudio incluyan en forma sistemática la interacción social no solo entre docente y estudiante, sino que abarque a la comunidad. Así también, interpretando a Vygotsky (1982) el docente debería promover los procesos de apropiación de saberes además de los instrumentos de mediación sociocultural que son aceptados, aprovechando su influencia y estimulando la participación de los estudiantes en un proceso de construcción colectiva.

\section{Enfoque humanista.}

Esta propuesta considera a los estudiantes como individuos íntegros, con deseos, aspiraciones, esperanzas, con valores; con capacidades no solo para aprender sino para interactuar con su entorno y hacerlo parte de si respetando las individualidades de los entes que lo componen.

Martínez (2004) menciona que la educación no solo debe capacitar al ser humano para desempeñar una función, sino que enriquece su vida y debe fomentar un desarrollo y crecimiento personal. Por ello es que el docente pasa a ser un facilitador humanista de todo el proceso evolutivo del individuo tanto personal como social. En ese sentido es que Ayala (2013) menciona que el Humanismo establece una educación centrada en los valores, la reflexión, las 
relaciones interpersonales y el intercambio de conocimientos en un grupo; cree en la educación individualizada y socializadora.

En base a lo expuesto podemos considerar a la educación como la piedra angular para el avance y desarrollo de un país, en el cual la profesión docente es prioritaria e insustituible para este fin. La educación enfocada en el desarrollo integral de la persona humana, posee una naturaleza predominantemente humanista y en el medio actual donde impera la violencia, la falta de valores, la inseguridad; resulta necesario afianzar la labor docente con un enfoque Humanista rescatando la esencia de la condición humana.

La pedagogía musical complementa la formación integral de la persona, Frühauf (2019) menciona que el sentido especifico de la pedagogía musical está referido a la formación académica y a la creación de teorías en sus diversos ámbitos; de esta manera toda acción pedagógica está sustentada en una base teórica la cual permite la reflexión acerca de lo estético, psicológico y sociológico sobre la influencia de la música y su significado.

La metodología musical se compone de diversos autores que han favorecido el acercamiento de la música a todos teniendo como premisa de que el proceso debe ser activo y participativo considerando al estudiante como el principal protagonista del aprendizaje. Cuevas (2015) considera que cada método fomenta el desarrollo independiente de algunos de los elementos formales de la música, pero que actualmente el conocimiento holístico del aprendizaje es el que predomina en la dinámica educativa. En ese sentido es potestad del docente adaptarse a una metodología de enseñanza considerando la realidad educativa en la que se encuentra, considerando siempre las necesidades y requerimientos educativos de sus estudiantes.

\section{Fundamento curricular.}

Esta propuesta metodológica está conformada bajo los lineamientos de la Ley Universitaria $\mathrm{N}^{\circ} 30220$, (2014) en su artículo $6^{\circ}$ menciona como fines de la universidad afirmar y transmitir 
las diversas identidades culturales del país. Además de preservar, acrecentar y transmitir de modo permanente la herencia científica, tecnológica, cultural y artística de la humanidad.

Así mismo la Ley General de Educación $\mathrm{N}^{\circ}$ 28044, (2014) en su artículo $31^{\circ}$ sostiene que la interculturalidad se expresa en todos los procesos pedagógicos y con prioridad en el aula y la institución educativa. En estos espacios, los estudiantes deben reconocer y valorar su propia cultura, la cultura del otro y la cultura del mundo a través de diversas experiencias socioculturales.

Congruente con estas disposiciones se considera adecuado la capacitación y actualización de los docentes con fundamentos teóricos, técnicas, dinámicas y estrategias de enseñanza - aprendizaje orientadas al desarrollo de la identidad musical nacional en los estudiantes. Para ello, se debe considerar el perfil profesional del docente en la especialidad ya que el mismo debe conocer, dominar, orientar y dirigir los procesos curriculares partiendo de la posición que asuma la institución. En ese sentido Díaz Barriga y Hernández (2010) mencionan que para un eficaz desarrollo de los aprendizajes se requiere el ordenamiento y agrupación de los contenidos curriculares en tres dimensiones fundamentales que son los conocimientos declarativos, contenidos procedimentales y contenidos actitudinales.

\section{Diseño de la propuesta}

La propuesta, estrategia metodológica para desarrollar la identidad musical nacional está diseñada y sustentada por fundamentos científicos que orientan y contribuyen al desempeño docente en el proceso de enseñanza - aprendizaje con el objetivo de conseguir un cambio en el pensamiento, el sentir y el hacer de los estudiantes. Esta propuesta esta presentada en dos fases, la primera se muestra con esquema teórico funcional del modelamiento de la propuesta y una segunda parte en donde se detalla el desarrollo de la misma. 


\section{ESTRATEGIA METODOLÓGICA PARA DESARROLLAR LA IDENTIDAD MUSICAL NACIONAL EN LOS ESTUDIANTES DE LA ESPECIALIDAD DE CUERDAS DE UN CONSERVATORIO DE LIMA}

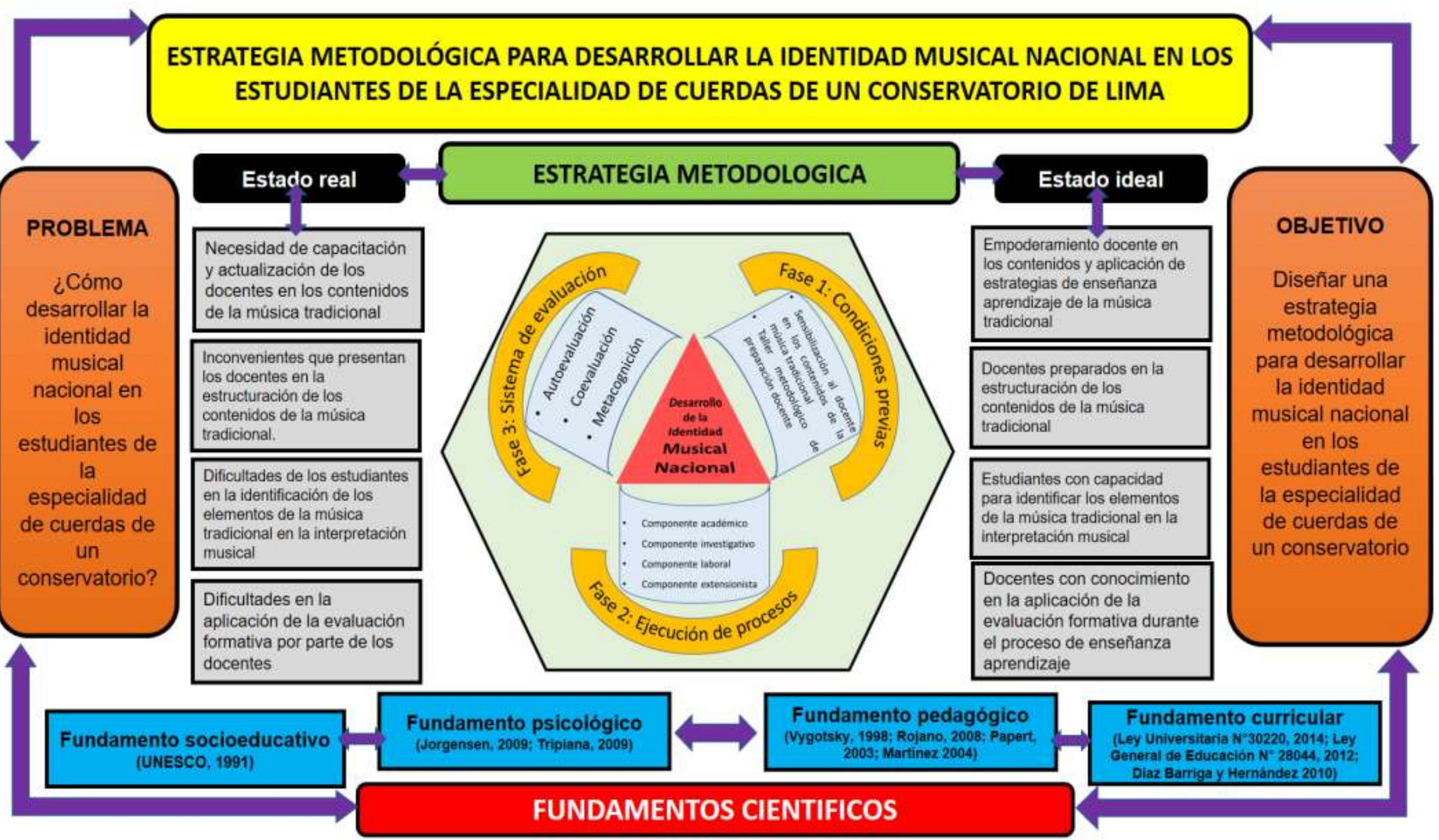




\section{Descripción del diseño.}

El esquema teórico funcional demuestra en su estructura la dinámica abierta y transversal del problema de estudio de la investigación, cuyo fin está encaminado a su transformación mediante la propuesta metodológica diseñada para contribuir al desarrollo de la identidad musical nacional de los estudiantes.

El esquema, responde al problema general de la investigación, poniendo en evidencia el estado real encontrado en el trabajo de campo, en la parte central se diseñó la dinámica de trabajo articulada por los componentes formativos presentes en el proceso pedagógico los cuales permitirán llegar a un estado ideal que corresponde al principal objetivo de la investigación.

Para su modelación se consideró la categoría apriorística identidad musical nacional sobre la cual se articularán las acciones y procesos que conformarán esta propuesta. Como parte de la presente investigación, el trabajo de campo puso en evidencia las fortalezas y deficiencias teóricas y metodológicas de los docentes y estudiantes para el tratamiento y desarrollo de la identidad musical nacional.

\section{Objetivo de la propuesta.}

El objetivo de la propuesta es contribuir al desarrollo la identidad musical nacional en los estudiantes de cuerda de un conservatorio de Lima a partir de la capacitación teórico-práctica de los docentes, aplicando una estrategia didáctica constituida en tres fases y estructurada con talleres metodológicos.

\section{Principios didácticos.}

Principio de carácter científico educativo; el diseño de la metodología está basado en los resultados obtenidos mediante el proceso y análisis de los instrumentos, lo cual deriva en un bajo nivel de desarrollo de la identidad musical nacional en los estudiantes. Para la asimilación de los contenidos de manera integral, holística y que contenga un significado perenne en los estudiantes, se debe emplear un desarrollo intelectual donde se observe una didáctica 
constructiva, análisis crítico, motivación, asimilación y una construcción de conocimientos para una formación completa e integral.

Principio de la activación de conocimientos y experiencias previas; este principio debe estar latente en los estudiantes ante un estado de asimilación y acercamiento de nuevos conocimientos de los contenidos de la música tradicional, anteponiéndose al desarrollo de habilidades y capacidades para lograr un aprendizaje significativo.

Principio de adaptación contextual; tomando en consideración al entorno, el tiempo, cantidad de estudiantes, sus aspiraciones y respuestas de los mismos a las actividades programadas.

Principio del carácter audiovisual; la obtención de nuevos conocimientos también es producida al emplear material gráfico y audiovisual, los que son de gran ayuda en la exposición de los temas y ejercicios planteados por el docente, como talleres y clases modelo con participación de artistas destacados de la música tradicional.

Principio de satisfacción docente; se produce cuando el docente manifiesta su satisfacción al ejecutar su trabajo, lo expresa a los estudiantes y obtiene respuestas positivas, consolidando autoridad y fomentando una mejor comunicación con sus estudiantes.

Principio de participación; los estudiantes integran el proceso donde la obtención y asimilación de nuevos conocimientos se produce a través de la motivación y la participación activa con la finalidad de desarrollar el aprendizaje. Sin embargo, es el docente quien cumple el rol de guía y el mediador que asistirá al estudiante a alcanzar sus metas.

Principio de la satisfacción de los alumnos; la cual consta en crear un clima agradable, cercano, positivo y de comunicación fluida entre los estudiantes y el docente.

Principio de la conciencia de aprendizaje; son los cambios óptimos generados por la adquisición de nuevos conocimientos, fomentando la autoevaluación en el estudiante a través de su dedicación, atención y tiempo. 
Estos principios didácticos contribuirán guiando la labor docente al momento de aplicar la estrategia metodológica para desarrollar la identidad musical nacional logrando de esta manera resultados óptimos en los estudiantes.

\section{Rol del docente}

La función del docente como facilitador, guía y mediador de los conocimientos nuevos, que se entrelazan con los saberes previos de los estudiantes, requiere no solo la enseñanza de estos, sino también una formación integral que fomente e impulse la autonomía de cada estudiante, así como el pensamiento crítico.

En esa línea, Ghenadenik (2017) sostiene que los docentes no deben ser únicamente capaces de brindar contenidos de calidad, sino que también cuenten con recursos pedagógicos y herramientas para el buen desempeño de su función. El docente promueve el desarrollo integral del estudiante fomentando la autorregulación del aprendizaje, logrando así una independencia cognoscitiva en su propia formación.

\section{Rol del estudiante}

El estudiante es activo de su propio aprendizaje, demuestra profundo interés por conocer cosas nuevas usando sus propios recursos con la mediación del docente, va formando en sí autodisciplina, análisis crítico y reflexivo, como también experimenta el trabajo en equipo y colaborativo. Estos componentes humanizan el proceso educativo formando una persona que piensa, actúa, crea y construye conocimientos personales y sociales, (Rugeles 2015).

Algunos parámetros de la función del estudiante están relacionados con su autoconocimiento, sus potencialidades y virtudes así como sus miedos e inseguridades que casi siempre pueden ser superadas con apoyo y guía del docente; de manera similar Wendorff (2019) menciona que el estudiante debe sentirse cómodo, seguro, escuchado y saber que está bien cometer errores porque de ellos se aprende, y las presiones de acabar la carrera en un determinado tiempo no significa que te harán un mejor profesional pues solo la experiencia y 
el conocerse a sí mismo, a través de la interacción con sus pares, que se da en la universidad consolida todas esas variables que componen una persona íntegra responsable y con un respeto y sensibilidad por el bien común.

\section{Desarrollo e implementación de la propuesta}

La estrategia metodológica está sustentada por fundamentos científicos que encaminan el proceso de enseñanza - aprendizaje contribuyendo a un mejor desarrollo de la identidad musical nacional, conciencia y valoración de los elementos identitarios que componen la música tradicional; todo esto a través de una eficiente y adecuada capacitación para un óptimo desempeño del docente por medio de la consolidación de las competencias articuladas en las fases de preparación de las condiciones previas, ejecución de procesos, y sistema de evaluación.

Quintero, (2011) menciona que el nuevo educador es el responsable de la calidad de la educación, por lo que su formación académica es de suma importancia para la aplicación de nuevos métodos, técnicas y estrategias que contribuyan a incrementar el nivel de competencia que poseen los estudiantes en el proceso de enseñanza - aprendizaje.

En esa misma línea, Díaz y Hernández (2010) sostienen que el uso y aplicación de técnicas y acciones que conforman la estrategia metodológica con el objetivo de concientizar, incorporar, desarrollar, ejecutar y generar mecanismos de autoevaluación se deben realizar para las sesiones de aprendizaje. Resulta primordial que el procedimiento de sistematización se ejecute de forma progresiva y sea integradora; de manera que se consiga el proceso de aprendizaje en los estudiantes logrando la metacognición.

La estrategia metodológica, tendrá un desarrollo por fases de forma secuencial para alcanzar el objetivo propuesto, el esquema teórico funcional demuestra gráficamente la dinámica del tratamiento y solución del problema de investigación. Tomando en cuenta los principios didácticos propuestos por los especialistas Herrán, Álvarez y Cardoso (2011), los 
cuales estarán presentes al momento de aplicarse la estrategia metodológica y se encuentran comprendidos y contextualizados al objeto de estudio y que desarrollamos a continuación.

\section{Fases de la implementación de la propuesta.}

La propuesta tiene como fundamento los resultados de los análisis teóricos efectuados, en los que se expone la necesidad de lograr una mayor integración entre los componentes de la identidad y a su vez, entre los componentes del proceso de formación de los estudiantes de Cuerdas, partiendo del análisis de la formación y desarrollo de la identidad musical nacional.

La estrategia pedagógica diseñada está dirigida a los docentes de especialidad instrumental, y tiene como objetivo el desarrollo de la identidad musical nacional en los estudiantes de la especialidad de Cuerdas de un conservatorio. Esta propuesta facilita la orientación de los docentes en su actividad pedagógica, desde una concepción identitaria, y favorece la formación y desarrollo de la identidad musical nacional en los estudiantes, con lo cual se contribuye a una formación integral.

La propuesta se divide en tres fases: Preparación de las condiciones previas, ejecución de procesos y sistema de evaluación formativa. 
Tabla 2.

Fases de implementación de la propuesta

FASES

Preparación de

las condiciones previas
Ejecución de procesos

\begin{abstract}
Sistema de evaluación formativa
\end{abstract}

\section{DESCRIPCION}

RECURSOS

Sensibilización al docente en los contenidos de la música tradicional con el objetivo de usar las potencialidades pedagógicas que posee la música tradicional para la formación integral del estudiante.

Capacitación de los docentes de la especialidad instrumental, se busca empoderar a los docentes en los contenidos y aplicación de estrategias de enseñanza aprendizaje de la música tradicional para que puedan estructurar y articular los elementos identitarios más relevantes de música tradicional con los componentes académicos de la asignatura especialidad instrumental. Para este fin se realizarán talleres que aborden cada componente del proceso formativo de la especialidad instrumental tales como: *Componente académico; se seleccionan obras musicales de distintas comunidades que cumplan ciertos parámetros académicos, así como intérpretes o compositores populares destacados que permitan el análisis y la adecuación de su interpretación y repertorio.

*Componente investigativo; se considerarán los diversos recursos pedagógicos presentes en la música tradicional propias de las comunidades las cuales deben ser valoradas y difundidas integrándolas en los contenidos académicos de la asignatura de especialidad instrumental.

*Componente laboral; para una mejor orientación se debe incluir estos elementos identitarios de la música tradicional con los contenidos académicos de la especialidad instrumental en los diferentes niveles de formación educativa con la participación de personalidades de la música tradicional.

* Componente extensionista; se debe considerar la inclusión de estos elementos en las actividades comunitarias donde se proceden los docentes y alumnos.

Sistema de evaluación formativa; la evaluación debe ser transversal en cada fase, se tiene en cuenta la calidad del diseño de los talleres considerando sus componentes, la evaluación debe darse de forma colectiva e individual tomando en cuenta la coevaluación y la autoevaluación de esta manera se pueden hacer los reajustes necesarios durante todo el proceso de la implementación de la propuesta.
Material audiovisual documentación de sustento histórico expositores, mesa de debate

Material audiovisual, partituras y documentación de sustento, Exhibición e interacción de instrumentos típicos

Clases maestras, conversatorios, foros, panel de debate, focus group, conferencias.

Ensayos abiertos, recitales de música tradicional, visitas a museos, ferias y festival de danza.

Rubrica de evaluación Cuestionarios Mapa conceptual Observación externa Anecdotario

Fuente: Elaboración propia (2020). 


\section{Ejecución de la estrategia}

Fase 1: Preparación de las condiciones previas.

\section{Sensibilización al docente en los contenidos de la música tradicional.}

Para que los docentes utilicen y apliquen los componentes y elementos identitarios de la música tradicional en la articulación de contenidos de la asignatura especialidad instrumental; ellos necesitan conocer y asimilar las potencialidades pedagógicas, técnicas y la variedad de recursos didácticos que se encuentran en la música tradicional. para ello se requiere sensibilizar a los docentes en los contenidos de la música tradicional, buscando un acercamiento académico en base al análisis y estructuración de los componentes de esta música, pero entrelazando la cosmovisión y el significado sociocultural que denota en cada elemento.

En ese sentido Curo (2017) menciona la necesidad de sensibilizar al docente para una práctica pedagógica reflexiva, poniendo en práctica distintos y adecuados recursos, así como un conjunto de estrategias que permitan asumir un cambio de actitud respecto a su función como elemento determinante en la mejora educativa.

La preparación de las condiciones previas se debe realizar a partir de los resultados del diagnóstico efectuado en el trabajo de campo. Se hará a través de un taller metodológico siguiendo la lógica en la inserción de los elementos identitarios de la música tradicional en la asignatura de la especialidad instrumental en los cuales se deben abordar los temas: (a) el sistema de conceptos y tendencias actuales en relación con la formación de identidades y los elementos identitarios de la música tradicional que contribuyen a su formación; (b) los contenidos de la asignatura de la especialidad instrumental que se relacionan con estas; (c) el tratamiento desde los componentes del desarrollo de la identidad musical y (d) la concepción identitaria de los elementos de la música tradicional, desde el proceso de formación de la identidad musical nacional. 
En el desarrollo y preparación de los docentes, para la tarea de la formación de la identidad musical nacional, se debe abordar los conceptos necesarios para esta labor, como son: identidad, identidad musical, identidad musical nacional y formación de la identidad musical nacional. Además, de considerar los fundamentos desde un enfoque filosófico, psicológico, sociológico, pedagógico y didáctico, de la formación de la identidad musical nacional y los elementos identitarios de la música tradicional en la asignatura de la especialidad instrumental. (Álvarez 2015).

Para brindar un adecuado soporte a la preparación de las condiciones previas; Se recomienda que el taller sea desarrollado por especialistas o docentes con amplia experiencia en el tema y se deben plantear integralmente los elementos identitarios de la música tradicional y su tratamiento en la asignatura de la especialidad instrumental.

Finalmente, los docentes recopilarán datos y contenidos relevantes los cuales le permitirán tomar conciencia y reflexionar sobre las temáticas desarrolladas considerando siempre las potencialidades presentes en los elementos identitarios de la música tradicional, en ese sentido, Batista, Trujillo y Barbán, (2018) mencionan que les corresponde a los profesores encontrar vías y formas para elevar el rigor del proceso educativo, actualizar los programas de investigación en función de las exigencias del desarrollo económico y social del país. Bajo este sustento toda acción docente debe favorecer la formación y desarrollo de la identidad musical nacional en los estudiantes de la especialidad de Cuerdas. 
Tabla 3.

Taller metodológico de preparación docente

\begin{tabular}{|c|c|c|c|c|}
\hline Nombre del taller & Objetivo & Método & Contenido & Recursos \\
\hline $\begin{array}{c}\text { El docente de } \\
\text { especialidad } \\
\text { instrumental y su } \\
\text { importancia en el } \\
\text { desarrollo de la } \\
\text { identidad musical } \\
\text { nacional }\end{array}$ & $\begin{array}{l}\text { Reflexionar acerca } \\
\text { del trabajo de los } \\
\text { docentes de } \\
\text { especialidad } \\
\text { instrumental y su } \\
\text { importancia en el } \\
\text { desarrollo de la } \\
\text { identidad musical } \\
\text { nacional en los } \\
\text { estudiantes. }\end{array}$ & $\begin{array}{l}\text { Reflexión y } \\
\text { debate }\end{array}$ & $\begin{array}{l}\text { Valoración } \\
\text { integral de la } \\
\text { labor docente en } \\
\text { el desarrollo de la } \\
\text { identidad musical } \\
\text { nacional }\end{array}$ & $\begin{array}{l}\text { - Video, proyección de } \\
\text { diapositivas, } \\
\text { documentos de } \\
\text { sustento. } \\
\text { - Audición en vivo, } \\
\text { clases maestras, } \\
\text { ensamble de } \\
\text { instrumentos } \\
\text { tradicionales. } \\
\text { - Mesa y panel de } \\
\text { debate }\end{array}$ \\
\hline
\end{tabular}

\section{Desarrollo}

Un moderador organiza la formación de equipos de trabajo tomando en cuenta un equilibrio en las relaciones afectivas e interpersonales de los integrantes, así como su congruencia en las respectivas especialidades instrumentales.

Se hace entrega del material bibliográfico y audiovisual necesario para el trabajo a cada coordinador de equipo.

Se dan las pautas generales de elaboración del trabajo: proyección de video, contraste con la información bibliográfica, ronda de preguntas.

\section{Asignación a cada equipo de trabajo}

\section{Equipo A}

¿Qué capacidades y conocimientos considera que debe tener el docente de especialidad instrumental para desarrollar la identidad musical nacional en los estudiantes?

¿Cuáles son las funciones y responsabilidades del docente en el contexto sociocultural para el desarrollo de la identidad en los estudiantes?

¿Qué elementos identitarios de las obras musicales, compositores o intérpretes de música tradicional reconoce?

¿Por qué considera importante en la labor docente la articulación con los contenidos académicos de Equipo B los elementos socioculturales de la música tradicional?

¿Qué contenidos específicos considera que debe poseer el docente de especialidad instrumental para desarrollar la identidad musical nacional en los estudiantes?

¿De qué manera planifica y organiza su sesión de clase?

¿Cómo evalúa su desempeño profesional?

¿Por qué es importante que los docentes de la especialidad instrumental diversifiquen e incluyan los

Tareas del grupo contenidos y elementos identitarios de la música tradicional en el contexto de formación académica?

Valorar críticamente la participación de cada integrante, del equipo y del grupo.

Fomentar durante el desarrollo del taller un ambiente propicio para el estudio, análisis, intercambio de ideas y reflexión.

Una vez que todos hayan realizado sus reflexiones, debates y valoraciones criticas de cada tema se procederá a realizar un resumen.

Cada equipo expondrá con argumentos sólidos sus apreciaciones, observaciones, valoraciones

\section{Cierre} reflexivas, así como sus recomendaciones de mejora.

A modo de conclusión, se procederá a evaluar individualmente a cada participante aplicando la autoevaluación, coevaluación y evaluación; partiendo de los conocimientos y objetivos logrados considerando aspectos específicos del taller.

Fuente: Elaboración propia (2020). 


\section{Fase 2: Ejecución de procesos}

En esta fase se realizará la capacitación de los docentes de especialidad instrumental para lo cual se elaborarán los talleres metodológicos teniendo en cuenta las temáticas propuestas e incluir otras que consideren necesarias, para su tratamiento en las asignaturas de especialidad instrumental. Para lograr tener un adecuado tratamiento interdisciplinar, los elementos identitarios de la música tradicional serán insertados de forma sistémica, desde los contenidos de la asignatura antes mencionada, los cuales deben estar orientados desde los diferentes componentes del proceso de formación universitaria.

Componente académico; los talleres metodológicos para los docentes deben considerar obras musicales, compositores e intérpretes que cumplan tres características esenciales tal como lo refiere Álvarez (2015) (a) el material escrito como partituras y textos deben ser expresados en un lenguaje comprensible y claro, técnicamente ser correspondiente con las exigencias para las que fueron seleccionadas; (b) el contenido debe ser coherente con principios éticos y estéticos los cuales son soporte del desempeño profesional y favorecen la formación de la identidad musical nacional; (c) el contenido textual, los ritmos y melodía que se mantienen a través de generaciones son evidencia de una lata calidad de interpretación y de solidos valores musicales.

Para lo cual se tomara en cuenta la presentación de obras con contenidos musicales que habiliten su inclusión en los diferentes subsistemas de formación, que estén orientadas a la formación integral de la persona, con base a los objetivos de desarrollo sostenible ODS, y a la preparación del hombre para la vida, que es el fin esencial de la educación actual, además deben incluir textos relacionados; por ejemplo, con la historia local, la ubicación geográfica, rituales como el pago a la tierra "Pachamama", marcación del ganado "herranza" entre otros aspectos que identifiquen a una determinada región o comunidad. En el caso de las obras instrumentales se apreciará el ritmo, la belleza de la melodía y la armonía. Entre las obras pueden encontrarse: 
Tabla 4.

Referentes musicales de la música tradicional

\begin{tabular}{ccc}
\hline Obra musical & Compositor o interprete & Región, localidad o comunidad \\
\hline "Carnaval" & Recopilador, Yaku taki (canto del & Cajamarca \\
"Ica" vals criollo & F. Pérez Anampa & Ica \\
"Yunya Pallay" Santiago & E. Paucar Camargo & Huancavelica \\
"Fina Estampa" & Chabuca Granda & Lima \\
"Sueños" yaraví & Hnos. Aspilcueta & Arequipa \\
"Buri Buriti"- danza guerrera & Tradicional & Ucayali \\
"Adiós pueblo de Ayacucho" & E. Medina "Tani" (recopilador) & Ayacucho \\
\hline
\end{tabular}

Fuente: Elaboración propia (2020).

En lo referente a los intérpretes, agrupaciones y compositores se debe considerar la expresividad musical, ejecución rítmica, que representen las raíces, la historia y las tradiciones de la cultura musical local, esta debe mostrar pertenencia a la identidad cultural nacional; también deben poseer una trayectoria musical reconocida, como ser un referente artístico de calidad interpretativa en su comunidad manteniendo la originalidad de los temas compuestos o interpretados.

Luego de seleccionar las obras musicales, teniendo en cuenta los requisitos anteriores, se debe hacer un trabajo minucioso que les permita dar tratamiento en cada una de las especialidades: el docente debe analizar la estructura de la obra musical, el proceso de interpretación, aprender la teoría y práctica de las obras tradicionales, en talleres de conjuntos instrumentales se les debe enseñar a ejecutar con diferentes instrumentos la obra (en caso de tener instrumentos tradicionales) y orientar acciones como buscar bibliografía referida al tema, seleccionar obras musicales de la localidad para su estudio y análisis en clase, utilizar variadas plataformas y materiales de información como películas, libros, revistas, periódicos y folletos relacionados con la vida y obra de músicos, compositores e intérpretes de música tradicional. 


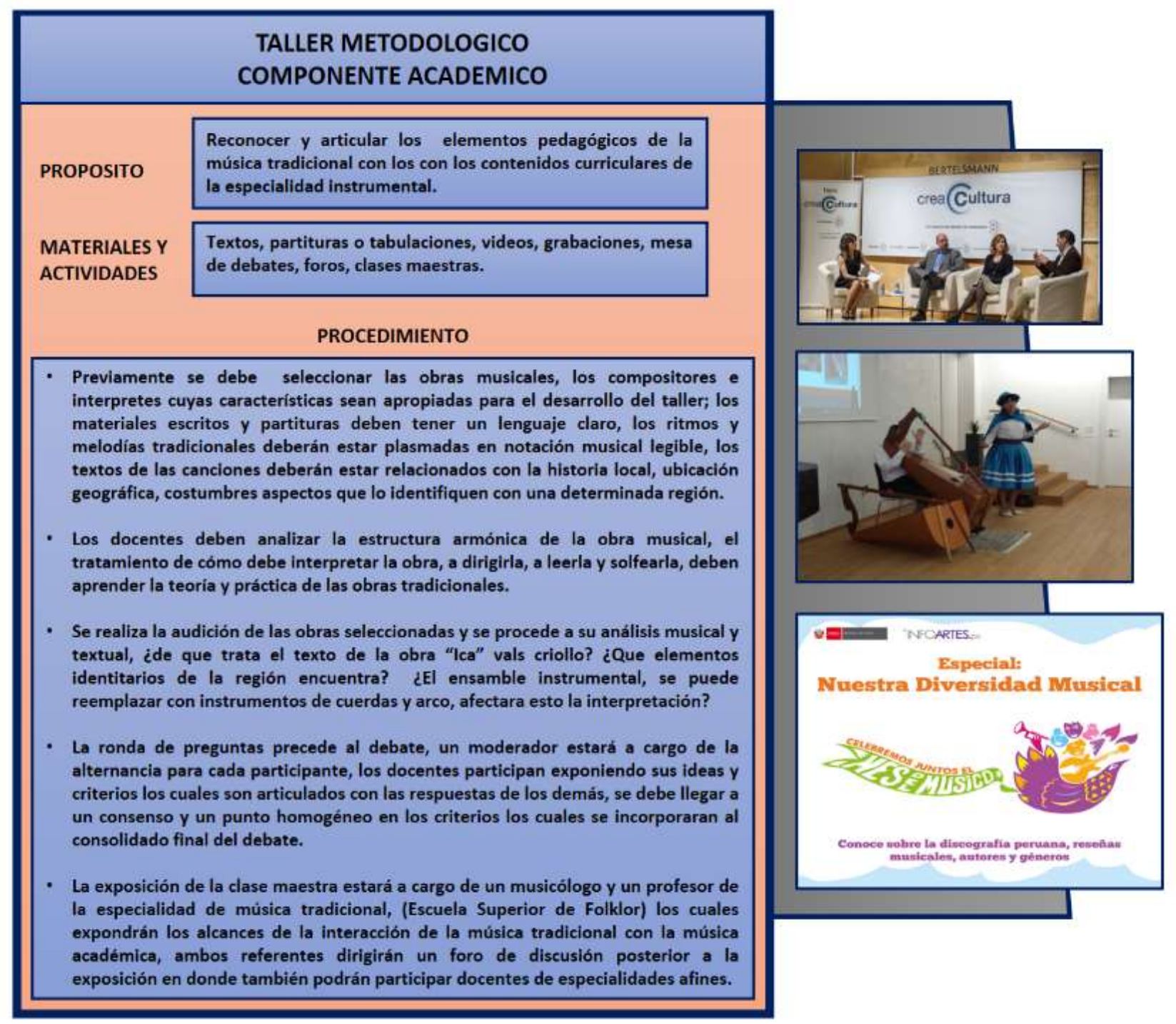

Figura 10. Taller Metodológico, Componente Académico.

Componente investigativo; se tomará en cuenta las potencialidades académicas que ofrecen los elementos identitarios de la música tradicional, y la relación de estos con los contenidos de la especialidad instrumental que se imparte en el conservatorio. Para lo cual se debe realizar el diagnóstico de una comunidad cercana para determinar los elementos identitarios de la música local presentes en ella; como parte de los trabajos de investigación, la entrevista con intérpretes, compositores y músicos instrumentistas deben realizarse de acuerdo al año académico del estudiante, investigar las familias con tradiciones musicales de la localidad, tomando en cuenta lo imperante de su obra, el arraigo, la trascendencia en la historia musical local y nacional que ha tenido su labor. 


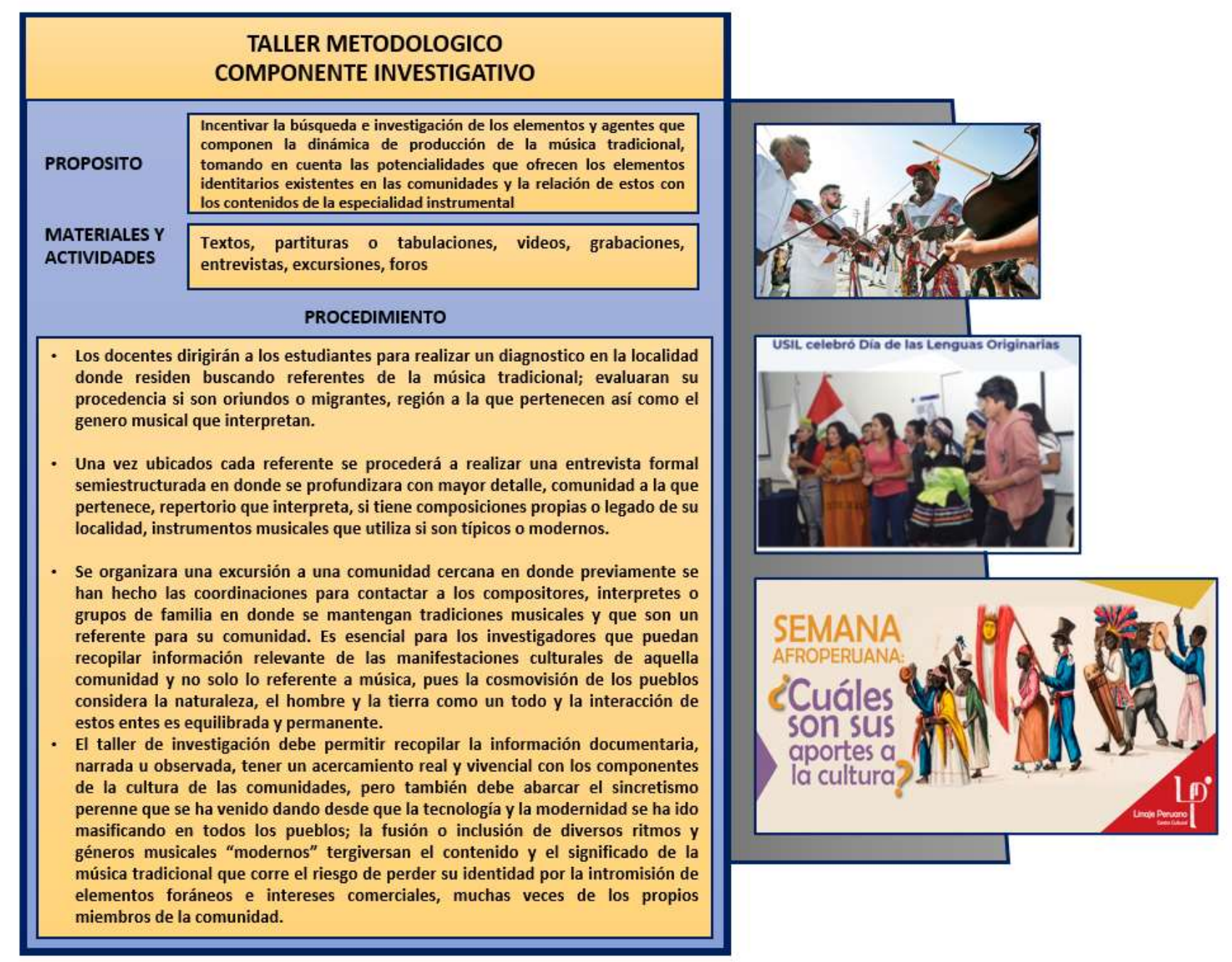

Figura 11. Taller metodológico, Componente Investigativo.

En el componente laboral; se deben considerar las potencialidades que ofrecen

los elementos identitarios de la música tradicional, presentes en las comunidades y su articulación con los contenidos de la especialidad instrumental. Para una mejor orientación de los estudiantes se debe incluir estos elementos en su formación profesional así como invitar a los talleres a personalidades de la música tradicional de la comunidad; incorporar obras musicales tradicionales en la elaboración de métodos de enseñanza o material de apoyo pedagógico (arreglos instrumentales, guías de estudio, compendio musical tradicional); así como incluir en los talleres dinámicas de emprendimiento y gestión de producción artística en los que participen activamente los estudiantes. 


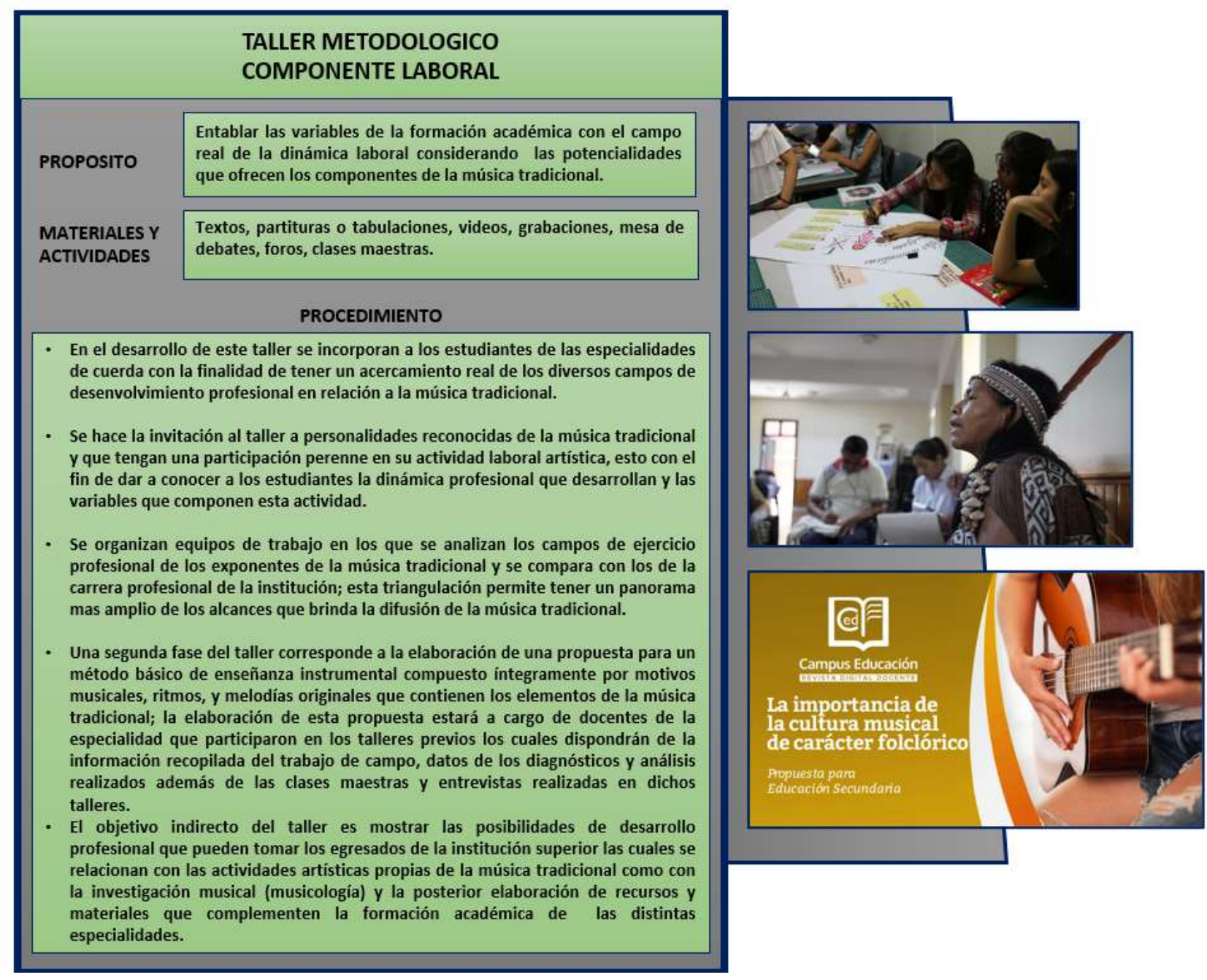

\section{Figura 12. Taller Metodológico, Componente Laboral.}

En el componente extensionista, se debe tener en cuenta las potencialidades que ofrecen los elementos identitarios de la música tradicional, existentes en las comunidades y la articulación con los contenidos de la especialidad instrumental, los cuales deben permitir tener un acercamiento e inclusión en la comunidad a través de actividades culturales donde estén presentes los rasgos y elementos identitarios de la localidad, organizar y dirigir coros, grupos danzarios, ensambles musicales y espectáculos con y sin acompañamiento instrumental; participar activamente en los diversos eventos históricos, artísticos y culturales de la comunidad incluyendo un repertorio donde se dé prioridad a la música tradicional. 


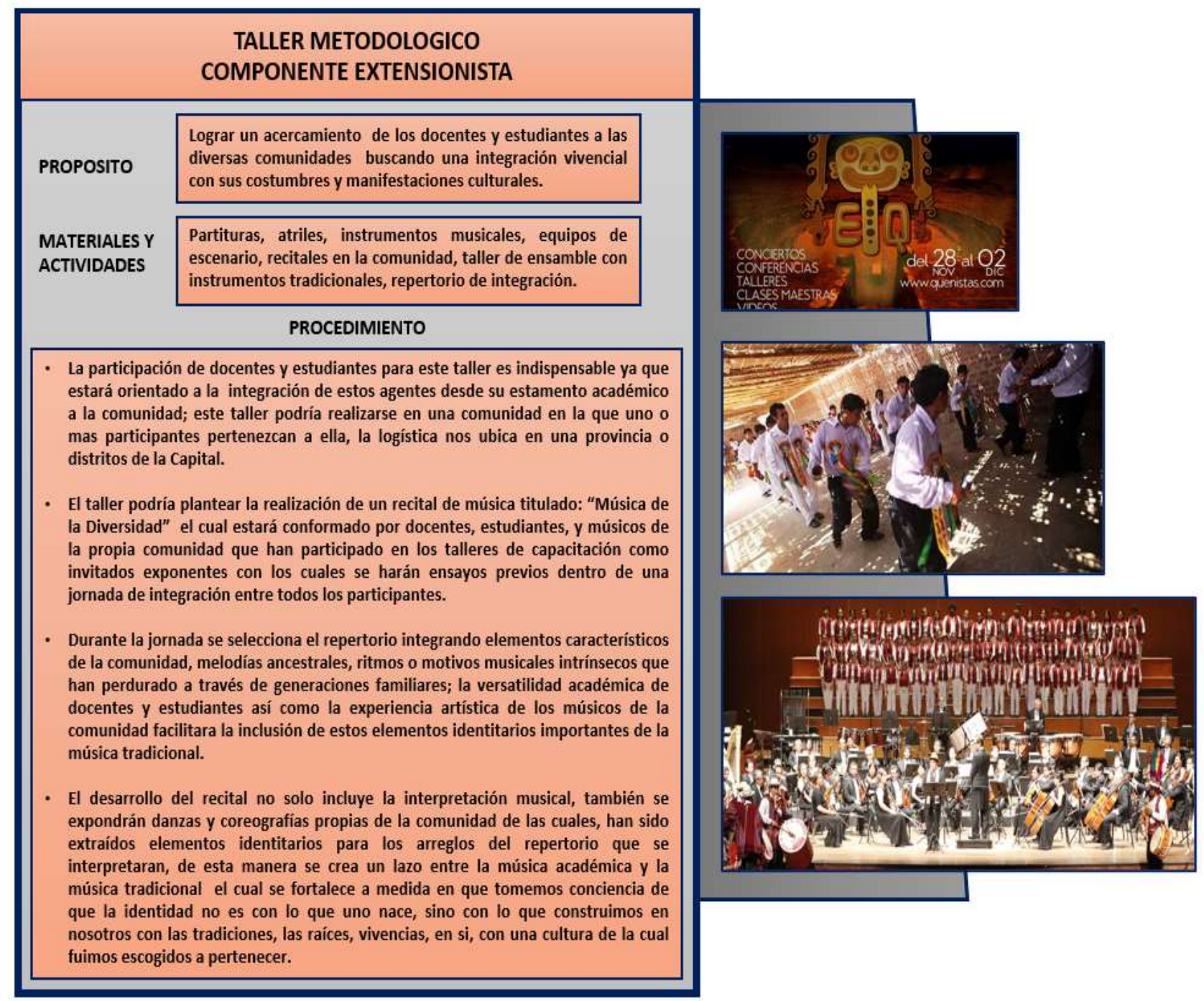

Figura 13. Taller Metodológico, Componente Extensionista.

Es esencial para el docente organizar de diversas maneras estos componentes de formación, y dar un adecuado tratamiento a los elementos identitarios de la música tradicional considerando las potencialidades socioculturales de las comunidades de donde proceden o desempeñan los estudiantes y su articulación con los elementos académicos de la especialidad instrumental.

Los talleres metodológicos deben realizarse vinculando los procesos cognitivo y afectivo, al referirse a cada elemento identitario de la música tradicional, los cuales deben contener información acerca de sucesos históricos, personajes de la historia y la música, la cultura de la localidad, sus costumbres, idiosincrasia, la ubicación geográfica. De esta manera 
se fomenta la significación y el valor funcional de la música tradicional, que le permite tomar conciencia con estos elementos y poder exteriorizarlos en su actitud y proceder afianzando su identidad.

Es importante que los docentes de especialidad instrumental tengan un protagonismo importante al plantear nuevas propuestas para el desarrollo de asignaturas, partiendo de un trabajo de investigación personal, donde buscaran compositores, intérpretes, grupos músicodanzarios, familias con tradiciones musicales existentes en las regiones. Esto brinda una oportunidad para contextualizar la información tomando en cuenta cada elemento identitario que ha perdurado por las diferentes épocas, las características y estilos de agrupaciones, intérpretes y composiciones que se mantienen en la preferencia y gustos de las comunidades y que sensibilizan al docente.

El desarrollo de los talleres con los docentes de especialidad y estudiantes debe propiciar un aprendizaje significativo para que alcancen una concientización musical, que se manifieste en la capacidad de generar valores, sentimientos, actitudes, a partir del contenido de los elementos identitarios de la música tradicional, en relación con los conocimientos que poseían sobre la música estudiada anteriormente.

El tratamiento ordenado, sistemático y planificado de los elementos identitarios de la música tradicional, permite a los estudiantes apreciar las obras musicales y valorar las funciones de la música desde su contenido, lo cual contribuye a obtener una educación integral permitiendo incorporar el repertorio musical de cada región y orientar investigaciones dirigidas a las potencialidades culturales de las comunidades, de tal modo que les facilite hacer juicios y valoraciones con lo cual demuestren en su actuación la formación de una identidad musical nacional. 


\section{Fase 3: Sistema de evaluación formativa.}

La educación superior experimenta un constante cambio en sus diversas áreas de funcionamiento, concretándose en la mejora de los procesos de enseñanza- aprendizaje los cuales deben presentar situaciones de aprendizaje pertinentes y en un contexto que fomenten el desarrollo de competencias y formen profesionales conscientes, reflexivos capaces de generar nuevos conocimientos y de comprender y cambiar la realidad.

En ese sentido la evaluación formativa demuestra una estrecha vinculación con las metodologías activas y los procesos de aprendizaje enfocados en el estudiante, considerando sus actitudes y valores que son esenciales para el desarrollo de la identidad musical nacional; esta afirmación es consistente con López (2009) quien sostiene que el propósito de la evaluación formativa es centrarse en el aprendizaje del estudiante y su capacidad para autorregular o dosificar su propio proceso de aprendizaje.

De esta manera, el control y la evaluación deben ser frecuentes a lo largo de todo el proceso formativo, es necesario actuar de forma constante y permanente, no esperar al final de cada etapa para tomar decisiones.

El diagnóstico es un recurso que podemos aplicar para medir el cambio en el proceso de formación y desarrollo de la identidad musical nacional, el cual debe ser continuo y progresivo. Los docentes deben evaluar por igual el desarrollo de los talleres metodológicos como sus resultados, de igual forma la inserción de sus temas en los contenidos de la especialidad instrumental, en la medida que estos fomentan y posibilitan la adquisición de saberes y capacidades, así como la consolidación de la identidad musical nacional.

Una característica importante que debe tener el proceso de evaluación es que se pueda realizar utilizando niveles de asistencia y soporte, que se controlan y evalúan de forma permanente, con el objetivo de lograr la formación y desarrollo de la identidad musical nacional 
en los estudiantes y que a su vez les permitan desarrollar en ellos modos de actuación adecuados.

Tanto la coevaluación como la autoevaluación son elementos que se deben considerar ya que son referentes en los modos de actuación de forma colectiva e individual que los estudiantes tomaran en cuenta al momento de ser ellos mismos quienes se evalúen con exigencia y seriedad.

Modelo de una sesión de aprendizaje

\section{Datos informativos}

\begin{tabular}{|l|l|l|l|}
\hline Curso & $\begin{array}{l}\text { Instrumento principal - } \\
\text { sesión individual }\end{array}$ & Ciclo & $7^{\circ}$ ciclo \\
\hline Especialidad & Cuerdas & Institución & Conservatorio \\
\hline Año & 2020 & Tiempo & 2 horas pedagógicas \\
\hline $\begin{array}{l}\text { Enfoque } \\
\text { curricular }\end{array}$ & $\begin{array}{l}\text { Constructivista: } \\
\text { Socio critico }\end{array}$ & Tema & $\begin{array}{l}\text { Identidad musical nacional, } \\
\text { aporte de la música tradicional } \\
\text { en la práctica instrumental } \\
\text { académica }\end{array}$ \\
\hline
\end{tabular}

\section{Aprendizaje esperado}

El estudiante reconoce los elementos pedagógicos de la música tradicional y los articula con los contenidos artísticos, teóricos y técnicos de la especialidad instrumental. Valora los elementos socioculturales de la música tradicional y su importancia en la formación de la identidad.

\section{Secuencia didáctica}

\begin{tabular}{|c|c|c|c|}
\hline $\begin{array}{c}\text { Procesos } \\
\text { pedagógicos }\end{array}$ & Estrategias y actividades & Tiempo & $\begin{array}{c}\text { Recursos y } \\
\text { técnicas }\end{array}$ \\
\hline Inicio & $\begin{array}{l}\text { El docente ingresa al aula y saluda cordialmente al } \\
\text { estudiante. } \\
\text { Activación de saberes previos } \\
\text { Se procede a la audición del concierto para Viola de } \\
\text { Bela Bartók y se profundiza en la biografía del } \\
\text { compositor, se resalta que usaba motivos y } \\
\text { elementos identitarios de la música tradicional de su } \\
\text { país Hungría. } \\
\text { Se le encarga al estudiante identificar el tema } \\
\text { principal de la obra para constatar el uso de motivos } \\
\text { o elementos tradicionales y hacer una comparativa } \\
\text { con compositores académicos peruanos que utilizan } \\
\text { elementos identitarios tradicionales en sus obras. } \\
\text { Conflicto cognitivo } \\
\text { El docente determina los elementos tradicionales } \\
\text { usados en la obra, así como el contexto en la que fue } \\
\text { compuesta, se demuestra al estudiante el potencial } \\
\text { artístico de estos elementos en la composición, como }\end{array}$ & $30^{\prime}$ & $\begin{array}{l}\text { Proyección de } \\
\text { video } \\
\text { Lluvia de } \\
\text { ideas } \\
\text { Material } \\
\text { bibliográfico } \\
\text { Partituras, } \\
\text { score. }\end{array}$ \\
\hline
\end{tabular}




\begin{tabular}{|c|c|c|c|}
\hline & $\begin{array}{l}\text { también la aplicación técnica de ritmos, sonoridades } \\
\text { y demás recursos que son propios de la música } \\
\text { tradicional de cada país así mismo se destaca la } \\
\text { importancia que posee en la formación de la } \\
\text { identidad cultural. }\end{array}$ & & $\begin{array}{l}\text { Instrumento } \\
\text { musical }\end{array}$ \\
\hline Desarrollo & $\begin{array}{l}\text { El docente presenta al estudiante un repertorio } \\
\text { preparado para la sesión, en donde se aprecia los } \\
\text { motivos musicales, ritmos, armonías y estructuras } \\
\text { armónicas que han sido adaptados de la música } \\
\text { tradicional y forman parte del repertorio académico } \\
\text { de diversas especialidades. } \\
\text { Se procede a la ejecución instrumental del } \\
\text { repertorio resaltando las características intrínsecas } \\
\text { de la interpretación de los elementos identitarios } \\
\text { expuestos cuidando la correcta correlación } \\
\text { académica de técnica e interpretación. } \\
\text { El estudiante debe interpretar el repertorio guiado } \\
\text { por el docente el cual le mostrara el potencial } \\
\text { musical que existe en los elementos de la música } \\
\text { tradicional aplicado al análisis e interpretación, } \\
\text { destacando las variables que componen el contexto } \\
\text { sociocultural de cada obra. } \\
\text { Se realiza un programa de repertorio tradicional que } \\
\text { alterna con el repertorio académico con el fin } \\
\text { contrastar, analizar, valorar y difundir los recursos } \\
\text { y componentes de la música tradicional en el marco } \\
\text { del trabajo académico de la especialidad. }\end{array}$ & $50^{\prime}$ & $\begin{array}{l}\text { Repertorio } \\
\text { diversificado } \\
\\
\text { Atriles, } \\
\text { partituras, } \\
\text { material } \\
\text { tecnológico de } \\
\text { asistencia }\end{array}$ \\
\hline Cierre & $\begin{array}{l}\text { El estudiante expone sus conclusiones, argumenta, } \\
\text { critica y manifiesta su parecer en relación a los } \\
\text { contenidos desarrollados. } \\
\text { Se realiza una autoevaluación del proceso } \\
\text { pedagógico evaluando los resultados obtenidos. } \\
\text { El docente utiliza una rúbrica de evaluación para } \\
\text { medir, analizar y reforzar los conocimientos que no } \\
\text { hayan quedado consolidados o errores que pudiesen } \\
\text { presentarse. }\end{array}$ & $20^{\prime}$ & $\begin{array}{l}\text { Ficha o } \\
\text { rubrica de } \\
\text { evaluación }\end{array}$ \\
\hline
\end{tabular}

\section{Rubrica de evaluación}

\begin{tabular}{|c|c|c|c|}
\hline Criterios de evaluación & Logro destacado & Logro previsto & En proceso \\
\hline $\begin{array}{l}\text { Conocimientos } \\
\text { relacionados a la } \\
\text { identidad musical } \\
\text { nacional. }\end{array}$ & $\begin{array}{l}\text { Conoce los } \\
\text { rasgos de la identidad } \\
\text { musical nacional. }\end{array}$ & $\begin{array}{l}\text { Conoce algunos rasgos } \\
\text { de la identidad musical } \\
\text { nacional. }\end{array}$ & $\begin{array}{l}\text { No tiene claridad acerca } \\
\text { de identidad musical } \\
\text { nacional. }\end{array}$ \\
\hline $\begin{array}{l}\text { Grado de conocimientos } \\
\text { en relación a la música } \\
\text { tradicional. }\end{array}$ & $\begin{array}{l}\text { Identifica las } \\
\text { obras musicales, } \\
\text { compositor, intérprete y } \\
\text { arreglista de la localidad } \\
\text { y que son parte de la } \\
\text { comunidad. }\end{array}$ & $\begin{array}{l}\text { Identifica algunas de las } \\
\text { obras musicales, } \\
\text { compositor, intérprete y } \\
\text { arreglista de lo localidad, } \\
\text { sin llegar a determinar la } \\
\text { comunidad en que vive. }\end{array}$ & $\begin{array}{l}\text { No tienen dominio de las } \\
\text { obras musicales de la } \\
\text { localidad, aunque } \\
\text { identifica algunos } \\
\text { intérpretes y miembros } \\
\text { de alguna comunidad. }\end{array}$ \\
\hline $\begin{array}{l}\text { Nivel de desarrollo de } \\
\text { las capacidades técnico- } \\
\text { musicales en el análisis e }\end{array}$ & $\begin{array}{l}\text { Domina la cultura } \\
\text { musical de su entorno, } \\
\text { reconoce la influencia }\end{array}$ & $\begin{array}{l}\text { Domina medianamente la } \\
\text { cultura musical de su } \\
\text { entorno, reconoce la }\end{array}$ & $\begin{array}{l}\text { No domina la cultura } \\
\text { musical de su entorno, no } \\
\text { reconoce la influencia de }\end{array}$ \\
\hline
\end{tabular}




\begin{tabular}{|c|c|c|c|}
\hline $\begin{array}{l}\text { interpretación de la } \\
\text { música tradicional. }\end{array}$ & $\begin{array}{l}\text { que esta tiene en la } \\
\text { comunidad, así como las } \\
\text { de otras culturas, posee } \\
\text { capacidades técnico- } \\
\text { musicales para el análisis } \\
\text { y la interpretación de la } \\
\text { música tradicional. }\end{array}$ & 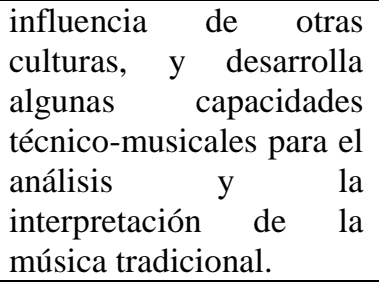 & $\begin{array}{l}\text { otras culturas, y } \\
\text { desarrolla pocas } \\
\text { habilidades técnico- } \\
\text { musicales para el análisis } \\
\text { y la interpretación de la } \\
\text { música tradicional. }\end{array}$ \\
\hline $\begin{array}{l}\text { Nivel de asimilación y } \\
\text { vinculación de los } \\
\text { contenidos de la música } \\
\text { tradicional con la } \\
\text { programación curricular } \\
\text { de la especialidad } \\
\text { instrumental. }\end{array}$ & $\begin{array}{l}\text { Incluye en su elección de } \\
\text { repertorio, obras de } \\
\text { música tradicional } \\
\text { basándose en su historia, } \\
\text { contexto, estructura } \\
\text { musical, compositor o } \\
\text { fuente primaria; es } \\
\text { consciente de la } \\
\text { importancia de su estudio } \\
\text { y difusión. }\end{array}$ & $\begin{array}{l}\text { Incluye en su elección de } \\
\text { repertorio algunas obras } \\
\text { de música tradicional, } \\
\text { reconoce su procedencia, } \\
\text { género y estructura; } \\
\text { participa de forma } \\
\text { voluntaria en actividades } \\
\text { de difusión de la música } \\
\text { tradicional. }\end{array}$ & $\begin{array}{l}\text { No incluye en su } \\
\text { elección de repertorio } \\
\text { obras de música } \\
\text { tradicional, no reconoce } \\
\text { su origen, contexto o } \\
\text { compositor; su } \\
\text { importancia está en } \\
\text { relación al beneficio que } \\
\text { pueda obtener. }\end{array}$ \\
\hline $\begin{array}{l}\text { Modos de actuación de } \\
\text { forma consciente en la } \\
\text { preservación y difusión } \\
\text { de las características } \\
\text { esenciales que } \\
\text { identifican la muisca } \\
\text { tradicional. }\end{array}$ & $\begin{array}{l}\text { Preserva y difunde los } \\
\text { elementos identitarios y } \\
\text { rasgos esenciales de la } \\
\text { identidad musical } \\
\text { nacional. }\end{array}$ & $\begin{array}{l}\text { Preserva y difunde } \\
\text { eventualmente los } \\
\text { elementos identitarios y } \\
\text { rasgos esenciales de la } \\
\text { identidad musical } \\
\text { nacional. }\end{array}$ & $\begin{array}{l}\text { No preserva ni difunde } \\
\text { los elementos } \\
\text { identitarios y rasgos } \\
\text { esenciales de la identidad } \\
\text { musical nacional. }\end{array}$ \\
\hline
\end{tabular}

\section{Validación de la propuesta}

Para considerar la aplicabilidad de la propuesta se apeló a la validación por juicio de expertos, a quienes se les proporciono una carpeta con los documentos de validación que contenían 10 indicadores de validación interna y 10 de externa, los cuales poseen criterios de ponderación que abarcan lo cuantitativo por medio de puntajes de 1 (deficiente), 2 (bajo), 3 (regular), 4 (buena) y 5 (muy buena), mostrando un puntaje máximo por cada ficha de 50 puntos que en sumatoria equivalen a un total de 100. Así mismo, con un enfoque cualitativo se valoraron a través de estimaciones críticas de los documentos examinados tomando en cuenta los rangos de positivo, negativo y sugerencias.

\section{Características de los especialistas.}

Los especialistas fueron seleccionados considerando el grado académico de Doctor o Magister, ser imparcial en los juicios, experiencia en el nivel o grado, manejo de enfoques y teorías, como también interés y disponibilidad por participar en el proceso.

Los especialistas seleccionados se muestran en la siguiente tabla: 
Tabla 5.

Especialistas de la validación:

\begin{tabular}{ccccc}
\hline Apellidos y nombres & $\begin{array}{c}\text { Grado } \\
\text { académico }\end{array}$ & Especialidad/Profesión & Ocupación & $\begin{array}{c}\text { Años de } \\
\text { experiencia }\end{array}$ \\
\hline $\begin{array}{c}\text { Muñoz Salazar José } \\
\text { Manuel }\end{array}$ & Doctor & Ingeniero electrónico & $\begin{array}{c}\text { Docente } \\
\text { investigador }\end{array}$ & 35 \\
$\begin{array}{c}\text { Flores Valdiviezo } \\
\text { Hernán }\end{array}$ & Magister & Sociólogo & $\begin{array}{c}\text { Docente } \\
\text { investigador }\end{array}$ & 40 \\
$\begin{array}{c}\text { Ramírez Núñez } \\
\text { Carlos }\end{array}$ & Magister & Músico & $\begin{array}{c}\text { Docente } \\
\text { músico }\end{array}$ & 5 \\
\hline
\end{tabular}

Fuente: Adaptado de los documentos normativos de la USIL (2020).

El Doctor José Manuel Muñoz Salazar, posee un doctorado en Ciencias de la Educación por la Universidad Nacional de Educación Enrique Guzmán y Valle, Magister en Ciencias de la Educación con mención en Gestión e Innovación Educativa, ha laborado en diversas universidades y escuelas de posgrado, actualmente se desempeña como docente investigador de la EPG USIL.

El Magister Hernán Flores Valdiviezo, Sociólogo colegiado en el CSP. Con más de cuatro décadas dedicado a la Educación Superior y en Escuelas de Posgrado. Periodista profesional de la Orden del Colegio de Periodistas del Perú. Ha laborado por años en diferentes universidades y escuelas de posgrado. Actualmente se desempeña a dedicación exclusiva en la USIL.

El magister Carlos Ramírez Núñez, músico profesional egresado del Conservatorio Nacional de Música, solista y director invitado en diversas orquestas nacionales y extranjeras, ha sido director artístico de la Orquesta Sinfónica Juvenil “Orquestando" del Minedu. Actualmente es el director de la carrera de música USIL. 


\section{Valoración interna.}

En referencia a la ficha de validación interna, tiene como función presentar a los especialistas los 10 indicadores de evaluación de la propuesta, de manera que presente una visión general del criterio de los especialistas.

Tabla 6 .

Validez interna por juicio de expertos

\begin{tabular}{|c|c|c|c|c|c|c|}
\hline \multirow[t]{2}{*}{ Indicadores } & \multicolumn{2}{|c|}{ Juez 1} & \multicolumn{2}{|c|}{ Juez 2} & \multicolumn{2}{|c|}{ Juez 3} \\
\hline & n & $\%$ & $n$ & $\stackrel{\%}{2}$ & $n$ & $\%$ \\
\hline $\begin{array}{l}\text { Factibilidad de aplicación del resultado que se } \\
\text { presenta. }\end{array}$ & 5 & 10 & 4 & 8 & 5 & 10 \\
\hline $\begin{array}{l}\text { Claridad de la propuesta para ser aplicado por } \\
\text { otros }\end{array}$ & 5 & 10 & 4 & 8 & 4 & 8 \\
\hline $\begin{array}{l}\text { Posibilidad de la propuesta de extensión a otros } \\
\text { contextos semejantes }\end{array}$ & 4 & 8 & 5 & 10 & 4 & 8 \\
\hline $\begin{array}{l}\text { Correspondencia con las necesidades sociales e } \\
\text { individuales actuales }\end{array}$ & 4 & 8 & 5 & 10 & 4 & 8 \\
\hline $\begin{array}{l}\text { Congruencia entre el resultado propuesto y el } \\
\text { objetivo fijado. }\end{array}$ & 5 & 10 & 4 & 8 & 4 & 8 \\
\hline $\begin{array}{l}\text { Novedad en el uso de conceptos y } \\
\text { procedimientos de la propuesta. }\end{array}$ & 5 & 10 & 4 & 8 & 5 & 10 \\
\hline $\begin{array}{l}\text { La modelación contiene propósitos basados en } \\
\text { los fundamentos educativos, curriculares y } \\
\text { pedagógicos, detallado, preciso y efectivo }\end{array}$ & 5 & 10 & 4 & 8 & 5 & 10 \\
\hline $\begin{array}{l}\text { La propuesta está contextualizada a la realidad } \\
\text { en estudio. }\end{array}$ & 5 & 10 & 5 & 10 & 5 & 10 \\
\hline $\begin{array}{l}\text { Presenta objetivos claros, coherentes y posibles } \\
\text { de alcanzar. }\end{array}$ & 5 & 10 & 4 & 8 & 5 & 10 \\
\hline $\begin{array}{l}\text { Contiene un plan de acción de lo general a lo } \\
\text { particular. }\end{array}$ & 5 & 10 & 5 & 10 & 4 & 8 \\
\hline Total & 50 & 96 & 50 & 88 & 50 & 90 \\
\hline Promedio porcentual & & & & & & \\
\hline
\end{tabular}

Fuente: Adaptado de los documentos normativos de la USIL (2020)

Los resultados de la valoración interna, demuestran que, el juez 1 otorgó una valoración de $96 \%$, el juez 2 una valoración de $88 \%$ y el juez 3 dio un 90\%, como consolidado la valoración interna resultante fue de $91 \%$ lo cual indica que la propuesta tiene una calificación interna ubicada en la escala de valoración de muy bien. 


\section{Valoración externa}

En referencia a la ficha de validación externa, tiene como función presentar a los especialistas los 10 indicadores de evaluación de la propuesta, de manera que presente una visión general del criterio de los especialistas.

Tabla 7.

Validez externa por juicio de expertos

\begin{tabular}{|c|c|c|c|c|c|c|}
\hline \multirow[t]{2}{*}{ Indicadores } & \multicolumn{2}{|c|}{ Juez 1} & \multicolumn{2}{|c|}{ Juez 2} & \multicolumn{2}{|c|}{ Juez 3} \\
\hline & $\underline{\mathrm{n}}$ & $\%$ & $\mathrm{n}$ & $\%$ & $\underline{\mathrm{n}}$ & $\%$ \\
\hline Claridad & 5 & 10 & 4 & 8 & 5 & 10 \\
\hline Objetividad & 5 & 10 & 4 & 8 & 5 & 8 \\
\hline Actualidad & 4 & 8 & 4 & 8 & 4 & 8 \\
\hline Organización & 5 & 10 & 4 & 8 & 5 & 8 \\
\hline Suficiencia & 5 & 10 & 4 & 8 & 4 & 8 \\
\hline Intencionalidad & 4 & 8 & 5 & 10 & 4 & 10 \\
\hline Consistencia & 5 & 10 & 4 & 8 & 5 & 10 \\
\hline Coherencia & 5 & 10 & 5 & 10 & 5 & 10 \\
\hline Metodología & 5 & 10 & 5 & 10 & 5 & 10 \\
\hline Pertinencia & 5 & 10 & 4 & 8 & 4 & 8 \\
\hline Total & 50 & 96 & 50 & 86 & 50 & 92 \\
\hline Promedio porcentual & & & & & & \\
\hline
\end{tabular}

Fuente: Adaptado de los documentos normativos de la USIL (2020)

Los resultados de la valoración externa, demuestran que, el juez 1 otorgó una valoración de $96 \%$, el juez 2 una valoración de $86 \%$ y el juez 3 dio un 92\%, como consolidado la valoración externa resultante fue de $91 \%$ lo cual indica que la propuesta tiene una calificación externa ubicada en la escala de valoración de muy bien.

Estos datos se sintetizan en un apartado llamado (resultados) considerando el puntaje de valoración interna y externa, para la valoración de las mismas se consideró frecuencia de rangos y porcentaje de rangos, lo cual permite ubicar en qué rango se ubica la validez de la propuesta, lo cual se presenta en la tabla 8 . 
Tabla 8.

\section{Escala de valoración}

\begin{tabular}{lcc}
\hline Escala & Rango frecuencia & Rango porcentaje \\
\hline Deficiente & {$[10-17]$} & {$[20 \%-35 \%]$} \\
Bajo & {$[18-25]$} & {$[36 \%-51 \%]$} \\
Regular & {$[26-33]$} & {$[52 \%-67 \%]$} \\
Bien & {$[34-41]$} & {$[68 \%-83 \%]$} \\
Muy bien & {$[42-50]$} & {$[84 \%-100 \%]$}
\end{tabular}

Fuente: Adaptado de los documentos normativos de la USIL (2020)

\section{Resultados de la valoración de los especialistas y conclusiones}

A continuación, se presenta la sistematización de la información obtenida por los especialistas en relación a la validación interna y externa de la propuesta.

Tabla 9.

Valoración interna y externa por criterio de jueces

\begin{tabular}{lcccc}
\hline & Especialista 1 & Especialista 2 & Especialista 3 & Promedio \\
\hline Validación interna & $96 \%$ & $88 \%$ & $90 \%$ & $91 \%$ \\
Validación externa & $96 \%$ & $86 \%$ & $92 \%$ & $91 \%$ \\
Promedio por & $96 \%$ & $87 \%$ & $91 \%$ & $91 \%$ \\
especialista & & & \\
Promedio final & \multicolumn{2}{c}{$\mathbf{9 1 \%}$} \\
\hline
\end{tabular}

Fuente: Adaptado de los documentos normativos de la USIL (2020)

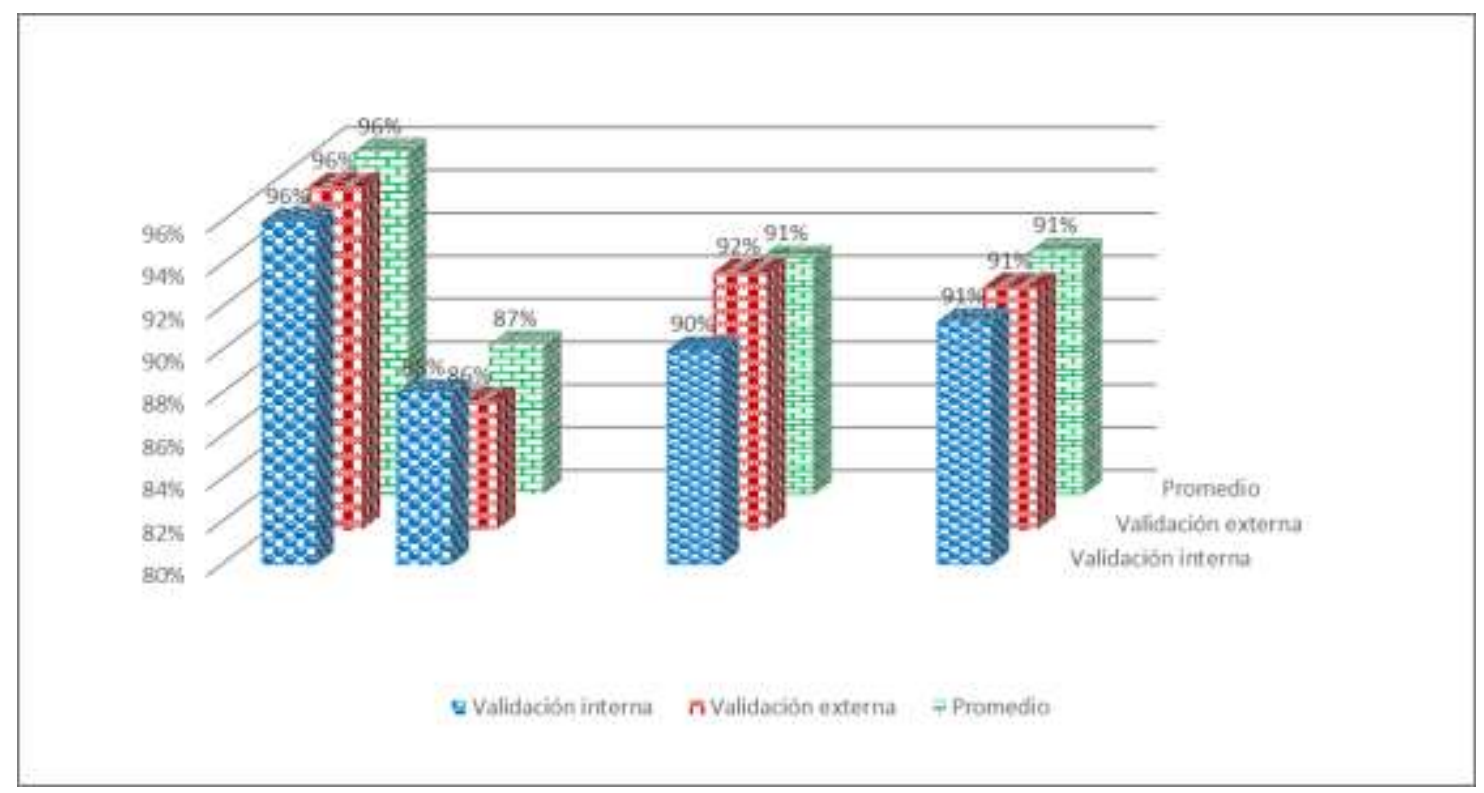

Figura 14. Valoración interna y externa por criterio de jueces 
En la tabla 9 se puede apreciar que el promedio de valoración interna del especialista 1 es de un $96 \%$, en contraste los especialistas 2 y 3 valoraron la propuesta con un $88 \%$ y $90 \%$ respectivamente obteniendo un promedio de $91 \%$, lo cual demuestra que la propuesta tiene una validez interna signada en la escala de valoración como muy bien. De igual manera, el promedio de valoración externa del especialista 1 es de $96 \%$ a diferencia de los especialistas 2 y 3 quienes valoraron la propuesta con un $86 \%$ y $92 \%$ respectivamente consolidando un promedio de $91 \%$, lo que demuestra que la propuesta tiene una validez externa signada en la escala de valoración como muy bien. Esto conlleva a que el contenido estructural y operativo de la propuesta Estrategia metodológica, de acuerdo al promedio final por especialistas sea de un $91 \%$ lo cual la posiciona como muy bien en la Escala de Valoración.

\section{Conclusiones aproximativas de los análisis y resultados de la propuesta y su validación} teórica/practica

Finalizada la ponderación del promedio final de la validez interna y externa con un $91 \%$, considerar la sugerencia realizada por el especialista temático sobre especificar la especialidad o especialidades instrumentales a las que tendría correspondencia con las necesidades sociales e individuales actuales, se obtiene como resultado final que la propuesta Estrategia metodológica para desarrollar la identidad musical nacional en los estudiantes de un Conservatorio de Lima se ubica en el nivel de Muy bien en la Escala de Valoración, por consiguiente se concluye científicamente que es aplicable, y puede ser administrada a diversas áreas de diseño curricular tomando en cuenta realidades características sociales, culturales y demográficas en donde se considere su aplicación. 


\section{Conclusiones}

Concluido el proceso de investigación, y modelación de la estrategia metodológica, se exponen las siguientes conclusiones de acuerdo al desarrollo de la investigación:

\section{Primera:}

Se cumplió con el objetivo general de la investigación al diseñar una estrategia metodológica para desarrollar la identidad musical nacional en los estudiantes, la cual se sustenta en los fundamentos socioeducativo, psicológico, pedagógico y curricular que dan soporte científico a su aplicabilidad e incorporación en los estamentos académicos. El diseño busca integrar a profesores y estudiantes a través de talleres metodológicos en una interacción educativa dinámica y vivencial que favorece el desarrollo de la identidad musical y cultural.

\section{Segunda:}

Se cumplió con la sistematización teórica de las categorías apriorísticas, en cuanto a los referentes teóricos acerca de la identidad, es sustentada por Hall (2003), articulado con el concepto de identidad cultural asumido por Rodríguez (2019), integrado a la identidad musical de Álvarez (2015) demuestra que el desarrollo de la identidad musical nacional es esencial en la formación del estudiante, ya que comprende no solo los conocimientos académicos de la cultura musical nacional sino que modifica el modo de actuación y postura del estudiante en referencia a la música tradicional, conociéndola desde una concepción ontológica, revitalizándola, valorándola y difundiendo el potencial académico, técnico y sociocultural que posee.

\section{Tercera:}

Se cumplió con el objetivo de diagnosticar el estado actual de la identidad cultural, para ello se realizó la construcción y la validación de los instrumentos, luego el recojo de la información, consecuentemente los procesos de codificación, categorización y triangulación. En tal sentido los resultados extraídos del trabajo de campo, demostraron un conocimiento superficial referido a los componentes de la música tradicional, más aún desconocen el potencial académico, 
técnico, artístico y social que puede abarcar; asimismo se evidencia la falta de material pedagógico y recursos académicos sistematizados de la música tradicional que sirvan de asistencia y soporte a los docentes en la articulación de contenidos en las especialidades instrumentales.

\section{Cuarta:}

El tercer objetivo se cumplió con la modelación de una estrategia metodológica para mejorar la identidad musical en los estudiantes con un modelo dinámico y vivencial enfocado a la interacción de los participantes con los componentes académicos, técnicos y socioculturales de la música tradicional con el objetivo de conocer de primera fuente estos potenciales recursos e incorporarlos no solo en la formación académica sino también en su formación integral. En referencia a la modelación de la propuesta se tomaron en consideración fundamentos científicos sistematizados durante el proceso de la investigación; el resultado obtenido es un diseño que engloba tres etapas, desde la preparación de las condiciones previas, marcada por la sensibilización al docente en los contenidos de la música tradicional; la ejecución de procesos, conformado por los componentes del proceso de formación superior; finalmente, el sistema de evaluación formativa, que consolidará los aprendizajes de manera significativa en los estudiantes.

\section{Quinta:}

la propuesta metodológica fue evaluada positivamente por especialistas, dos metodólogos y un temático los cuales convergen en que la propuesta presenta sólidos argumentos teóricos y prácticos que viabilizan su aplicación y cumple con los criterios de validez interna y externa. 


\section{Recomendaciones}

\section{Primera:}

Es fundamental que los docentes asimilen las potencialidades y recursos académicos que se encuentran en los componentes de la música tradicional para poder adecuarlos a una perspectiva educativa contextualizada, tomando en consideración aspectos de formación de la identidad cultural en los estudiantes, los cuales repercutirán en una actitud valorativa, de integración intercultural y de responsabilidad frente a lo nuestro.

\section{Segunda:}

Se recomienda al consejo académico la realización de acciones encaminadas a la investigación y producción de material pedagógico y recursos didácticos, referidos a la música tradicional, las cuales servirán de asistencia al docente en las sesiones de clase permitiendo una mejor asimilación de los componentes de la música tradicional logrando un aprendizaje significativo y una formación integral.

\section{Tercera:}

Es necesario que la directiva de la institución desarrolle una programación semestral de talleres o jornadas pedagógicas dirigidas a docentes y estudiantes de las distintas especialidades instrumentales, en donde puedan tener un acercamiento con, investigadores, musicólogos y exponentes artísticos de la música tradicional, produciendo un cambio en la concepción y el tratamiento de esta música a la vez que permite su sistematización e incorporación a la estructura curricular académica de la institución.

\section{Cuarta:}

Se recomienda la aplicabilidad de la propuesta en universidades o instituciones superiores de formación artística con lo que se contribuiría de forma transversal al desarrollo y consolidación de la identidad cultural en los estudiantes, ya que la diversificación de los contenidos de la propuesta, así como los componentes de actividad pueden adaptarse a distintas perspectivas 
educativas manteniendo su objetivo principal, con la intención de continuar con la investigación desde diversos ángulos del problema estudiado. 


\section{Referencias}

Alcaraz, A., Cruz, M., Guzmán, M., Vidal, V., Pastor, M., Rodríguez, F. \& Sánchez, C. (2004). Didáctica de las Ciencias Sociales: Didáctica de las Ciencias Sociales para Primaria. Madrid: Pearson Educación.

Álvarez, M., Martínez, V.\& Best, A. (2017). La formación de la identidad musical local en los instructores de arte. Columbia. SC: Academia Española.

Anijovich, R., \& Mora, S. (2010). Estrategias de enseñanza. Otra mirada al quehacer en el aula. Buenos Aires: Aique Grupo Editor.

Arraéz, M., Calles, J. \& Moreno L. (2006). La Hermenéutica: una actividad interpretativa. Recuperado de http://www.redalyc.org/pdf/410/41070212.pdf.

Arellano, J., (2019). El concepto de identidad, una aproximación a la música en América Latina. Neuma (Talca), 12(1), 36-59. https://dx.doi.org/10.4067/S071953892019000100036

Armijo, M. (2011). Planificación estratégica e indicadores de desempeño en el sector público. Santiago de Chile: Naciones Unidas CEPAL.

Arteaga, M. (2012). humanidades médicas, Revista virtual. Recuperado de: http://www.humanidadesmedicas.sld.cu/index.php/hm/article/view/850/554

Ayala, E. (2013). La formación docente bajo el paradigma de una educación humanística. (Tesis de maestría) Universidad Nacional Mayor de San Marcos. Recuperado de: https://cybertesis.unmsm.edu.pe/bitstream/handle/20.500.12672/3413/Ayala_fe.pdf?seq uence $=1 \&$ is Allowed $=\mathrm{y}$

Barcia, M., \& Rodríguez, M. (2011). La metodología en Educación Primaria. En B. Bermejo, Manual de didáctica general para maestros de Educación Infantil y de Primaria, pp. 181212. Madrid: Ediciones Pirámide.

Batista, D., Trujillo, Y. \& Barbán, Y. (2018). Validación De Procedimientos Para La Gestión Extensionista Desde La Experiencia Pedagogía Vivencial. Revista Didasc@lia: D\&E. Publicación cooperada entre CEDUT- Las Tunas y CEdEG-Granma. Recuperado de https://dialnet.unirioja.es/servlet/articulo?codigo=6715346

Bejar R. \& Rosales, S. (2005). La Identidad Nacional Mexicana como Problema Político y Cultural, Nuevas Miradas. México, D.F: UNAM

Bernardo, J. (1997). Técnicas y recursos para el desarrollo de las clases (3ra ed.).

Madrid: RIALP, S.A

Bernardo, J. (2011a). Enseñar hoy. Didáctica básica para profesores. Madrid: SÍNTESIS, S.A. 
Bernardo, J. (Coord.). (2011). Educación personalizada: Principios, técnicas y recursos. Madrid: SÍNTESIS, S.A

Bernal, G. (2000). Tradición oral. Escuela y modernidad, Bogotá: Aula Abierta.

Calderón, O. (2011). Actividades para fortalecer el valor identidad musical en los alumnos de música de la escuela de instructores "Rita Longa" de Las Tunas, (tesis de maestría) La Habana.

Caroll, J. (1963), A Model of School Learning, Teachers College Research Journal, vol. 41, $\mathrm{N}^{\circ}$ 2, pp. 237-269.

Camargo, M., Calvo, G., Franco, M., Vergara, M. \& Londoño, S. (2004). Las necesidades de formación permanente del docente. (articulo) Educación y Educadores 2004, 7 p. 79 - 112.

Castilla, R. (noviembre 2002) La Música Tradicional en la enseñanza. Seminario 2002, Patrimonio Etnológico en Aragón. Aragón, España.

Cázares, L. (2011). Estrategias educativas para fomentar competencias. Crearlas, organizarlas y evaluarlas (CODE). México: Trillas.

Cerezal, J. \& Fiallo, J. (2003). Métodos científicos de las investigaciones pedagógicas. La Habana: Magister servicios Gráficos.

Cerezal, J., Fiallo, J. \& Huaranga O. (2016). Los métodos Científicos en las investigaciones Pedagógicas. La Habana.: Colectivo Pedagógico.

Correa, V. (2013). Técnicas Didácticas en el proceso de enseñanza - aprendizaje de las ciencias naturales, cuarto año de educación básica, escuela, Republica de Venezuela, (tesis pregrado). Universidad central del Ecuador. Quito.

Costa, L. (1997). Practica Pedagógica y Música Tradicional. Congreso 1997, III Congreso de la SIBE, llevado a cabo en Benicàssim, España.

Cuevas, S. (2015). La trascendencia de la educación musical de principios del siglo xx en la enseñanza actual. Elsevier, revista virtual, Recuperado de file:///C:/Users/user/Downloads/Dialnet

LaTrascendenciaDeLaEducacionMusicalDePrincipiosDel-5593193.pdf

Curo, C. (2017). Programa de Sensibilización para promover el desempeño docente en la Institución Educativa Parroquial "San José Obrero" (tesis de grado). Universidad Cesar Vallejo. Lima.

Dana, P., \& Goldstein, S. (2015). A.R. Luria and Intelligence Defned as a Neuropsychological Construct. In S. Goldstein \& J. A. Naglieri (Eds.), Handbook of Intelligence: Evolutionary Theory, Historical Perspective, and Current Concepts, pp. 498. Springer. https://doi.org/10.1007/978-1-4939-1562-0 
De la Herrán, A. (2008). Metodología didáctica en educación secundaria: una perspectiva desde la didáctica general. En A. de la Herrán, \& J. Paredes, Didáctica General. La práctica de la enseñanza en Educación Infantil, Primaria y Secundaria, pp. 134 - 148. Madrid: McGraw HILL/INTERAMERICANA DE ESPAÑA, S.A.U.

Díaz, F. \& Hernández, G. (2010). Estrategias docentes para un aprendizaje significativo: didáctica y evaluación. Bogotá: ECOE

Díaz, F. \& Hernández, G. (2010). Estrategias docentes para un aprendizaje significativo. Una interpretación constructivista ( $3^{\mathrm{a}}$ Edición). México, D.F.: Mc Graw Hill.

Escalante G. (2018). El Huayno como expresión de la identidad cultural de los pobladores de Huamanga - Ayacucho. (tesis pregrado). Universidad Nacional de San Agustín de Arequipa. Arequipa.

Escamilla, A. (2011). Las competencias en la programación de aula (vol. II). Barcelona: GRAÓ.

Espinoza, E. (2020). Estrategia metodológica para la interculturalidad en la formación docente. (articulo) Universidad y Sociedad, 12(2), 369-379.

Fernández, M. \& Madrid-Vivar, D. (2010). Modelos didácticos y Estrategias de enseñanza en el Espacio Europeo de Educación Superior. Tendencias pedagógicas, ISSN 1133-2654, $\mathrm{N}^{\mathrm{o}}$ 15, 2010, pp. 91-111. 1.

Ferrara, L. (1991). Philosophy and the Analysis of Music: bridges to musical sound, form and reference. New York: Excelsior Music.

Flores C. (2017). Identidad cultural y aprendizaje significativo en los estudiantes de música de la UNE Enrique Guzmán y Valle. (tesis de maestría), Universidad Nacional de Educación Enrique Guzmán y Valle, Lima.

Fortera, M. (S.F). Metodologías Didácticas para la Enseñanza-Aprendizaje de Competencias. Recuperado de http://goo.gl/arsc28

Frühauf, T. (2019). Historia y evolución de la Pedagogía Musical, recuperado de: https://www.ebsco.com/e/latam/blog/que-es-la-pedagogia-musical

García, M. (2008). Desafíos de la interculturalidad. Lima: Instituto de Estudios Peruanos.

García, E. (2020). Sentidos de las prácticas musicales en la formación integral en la universidad. Revista de Investigaciones UCM, 20 (35), 12-23.

Garza, E. (2015). Modelo pedagógico para desarrollar la identidad cultural. (articulo) Humanidades Medicas 2015;15(3) pp. 562 - 581

Ghenadenik, M. (2017). Reflexión Académica en Diseño y Comunicación $N^{o} X X X$, El rol del docente en la universidad. Buenos aires: BUSCHI 
Guadarrama, P. (2006). Cultura y educación en tiempos de globalización posmoderna.

La Habana: Biblioteca Virtual de Filosofía y Pensamiento Cubanos. Disponible en: http://www.biblioteca.filosofia.cu/php/export.php?format=htm\&id=2181\&view=1

Hall, S. (2003). Introducción: ¿quién necesita identidad? En Hall, Stuart et. al. Cuestiones de identidad cultural. Buenos Aires: Amorrortu.

Hernández, R., Fernández, C. \& Baptista, C. (2014). Metodología de la investigación (6ta Ed.) D, México: Mc Graw Hill.

Herrán, A., Alvares, N. \& Cardoso, R. (2011). Técnicas didácticas para una enseñanza más formativa. Estrategias y metodologías para la formación del estudiante en la actualidad. Recuperado de: http://radicaleinclusiva.com/wpcontent/uploads/2020/03/teuniv.pdf

Hurtado de Barrera, J., Rojas, M. \& Blanco, H. (2008). Como formular objetivos de investigación. Caracas: Sypal.

Jiménez, M. (2016). La tradición oral como parte de la Cultura (articulo) ARJE: Revista de Postgrado, $\mathrm{N}^{\circ} 20,2017$

Jorgensen, H. (2009). Research into higher music education. Oslo: Novus AS.

Lavignac, A. (1950). La educación musical (traducción del original publicado en Francia alrededor del año 1900). Buenos Aires, Ricordi americana, pp. 365 y 366.

López, V. (2009). Evaluación formativa y compartida en educación superior. Propuestas, técnicas, instrumentos y experiencias. Madrid: Narcea.

Lucci, M. (2006). La Propuesta de Vygotsky: la Psicología Socio Histórica. Profesorado, Revista curricular y formación del profesorado. Recuperado de http://www.ugr.es/local/recfpro/Rev102COL2.pdf

Martínez, F. (2012). La Evaluación Formativa del Aprendizaje en el aula en la Bibliografía en Inglés y Francés. Revista Mexicana de Investigación Educativa 2012; 54(17) pp. 849 875

Martínez, R. \& Rodríguez, E. (2005). Manual de la Metodología de la investigación científica. Recuperado de http://www.sld.cu/galerias/pdf/sitios/cielam/manualdemetodologiadeinvestigacion es._1.pdf

Martínez, M. (2004). La Psicología Humanista. México: Trillas

Maynard, A., \& Martini, M. (Eds.). (2005). Learning in Cultural Context; Family, Peers, and School. New York: Springer.

Ministerio de Educación (2012). Ley General de Educación Nro. 28044. El Peruano. Recuperado de http://www.minedu.gob.pe/files/3896_201207100937.pdf 
Ministerio de educación de Perú-Ley No 30220 Ley universitaria (2014). Recuperado de https://www.sunedu.gob.pe/wp-content/uploads/2017/04/ Ley-universitaria30220.pdf

Ministerio de Educación (2015). Unidad de Formación Nro. 15 Estrategias Metodológicas en la Educación de Personas Jóvenes y Adultas. Cuadernos de Formación Continua. Equipo PROFOCOM. La Paz.

Molano, O. (2007). Identidad cultural un concepto que evoluciona. Disponible en: http://www.redalyc.org/pdf/675/67500705.pdf

Montero, F. (2017). la Música fusión, ¿verdadera inclusión? Una exploración de la escena fusión en Lima. ANTHROPOLOGICA / XXXVI, N. 40, 2018, pp. 97 - 119

Porto, A., \& Mosteiro, M. (2017). Investigación e innovación en la educación actual. Revista Boletín Redipe, 5(7), 17-33. Recuperado de https://revista.redipe.org/index.php/1/article/view/24

Moya, A. (2017). Las estrategias metodológicas y la actitud crítica en los estudiantes ingresantes a los institutos superiores públicos del distrito de Puente Piedra, (tesis de doctorado). Universidad Cesar Vallejo, Lima.

Naraza, N. \& Paz, A. (2016). Las estrategias didácticas desde su planificación hasta su aplicación en el área de Comunicación en el VII Ciclo de Educación Básica Regular en una institución educativa privada de la UGEL $N^{\circ} 03$ de Lima Metropolitana. (tesis de maestría) Pontificia Universidad Católica del Perú, Lima.

Obregón, J. (2010). Método Estadístico. Recuperado de http://paginas.facmed.unam.mx/deptos/wpcontent/uploads/2015/11/03REYNAG1.pdf

Oliveira, M. (1993). Vygotsky: Aprendizaje y Desenvolvimiento un proceso socio-histórico. Sao Paulo: Scipione. Serie pensamiento e ação no magisterio.

Ördög, L. (2000). La educación Musical según el Sistema Kodály. Madrid: Rivera Mota.

Ortiz, R. (1995). Culturas populares y nacionales frente a la realidad globalizada. En: "Los medios, nuevas plazas para la democracia”. Lima: Calandria.

Padron. G. (2006). Bases del Concepto de Investigación Aplicada: recuperado de http://padron.entretemas.com/invAplicada/

Ponencias (2004). Folklore, Cultura e Identidad. Ponencias XVII Congreso y VI Congreso Internacional del Folklore' "Mildred Merino de Zela" Lima: Pedagógico San Marcos, Instituto de Ciencias y Humanidades.

Pont, B. (s/f). Models d'acció didáctica. Barcelona: Universidad Oberta de Catalunya.

Quintero, Y. (2011). Estrategias Metodológicas. Recuperado de http://goo.gl/2JOXbe 
Ramírez, C. (2019). Estrategia metodológica para contribuir al desempeño docente de los especialistas del Programa Iniciativa pedagógica Orquestando en Instituciones Educativas Públicas del Ministerio de Educación. (tesis de maestría) Universidad San Ignacio de Loyola, Lima.

Rivera, R. (2016). Elementos de la música folclórica como material musical en la composición, Unión de la tradición y la academia en la composición contemporánea (tesis de maestría) Universidad EAFIT, Colombia.

Rodríguez, D. (2019). identidad cultural: características, elementos, formación y perdida. Recuperado de https://www.lifeder.com/identidad-cultural/

Rodríguez, J, (2005). la investigación acción educativa, que es, como se hace. Lima: DOXA

Rojano, J. (2008). Conceptos básicos en Pedagogía. Revista Electrónica de Humanidades, Educación y Comunicación Social 2008, N 4, p, 36 - 47

Romero, G. (S.F). La Utilización de las Estrategias Metodológicas Didácticas en Clase. Recuperado de http://goo.gl/0gk6uE

Romero, R. (1993). Música, danzas y máscaras en los andes; Proyecto de Preservación de la Música Tradicional Andina. Lima: PUCP, Instituto Riva - Agüero.

Rosler, R. (2007). Técnicas de enseñanza, enseñar a enseñar. Recuperado de https://imbiomed.com.mx/1/1/articulos.php?method=showDetail\&id_revista=118\&id_s eccion=2849\&id_ejemplar $=4557 \&$ id_articulo $=44957$

Rugeles, P. (2015). El rol del estudiante en los ambientes educativos mediados por las TIC. Revista Lasallista de investigación Vol. 12 No. 2 - 2015, p, 132 - 138

Salazar, A. \& Mugno, V. (2015). "Las hibridaciones e interculturalidades desde una perspectiva musical": música intercultural indígena. (tesis de grado) Pontificia Universidad Javeriana, Bogotá.

Tamayo \& Tamayo, M. (2015). El proceso de la investigación científica. México, D.F: Limusa.

Tobón, S., Guzmán, C., Hernández, J. \& Cardona, S. (2015). Sociedad del conocimiento: Estudio documental desde una perspectiva humanista y compleja. Paradigma [online]. 2015, vol.36, n.2, pp. 7-36. ISSN 1011-2251

Torres, M. y Giron, D. (2009). Didáctica General: Colección Pedagógica Formación Inicial de Docentes Centro americanos de Educación Básica (vol. 9.). San José, Costa Rica: MS.

Tripiana, S. (2009). Calidad de vida de los estudiantes de música del Conservatorio de Música de Aragón. Revista Electrónica de Música en la Educación 2009, №24, p,77 - 85 
UNESCO. (2001). Declaración Universal de la UNESCO sobre la Diversidad Cultural. Recuperado de: http://www.infoartes.pe/conozca-la-declaracion-universal-unescosobre-la-diversidad-cultural/

Valdivia, G. (2017). Bienestar psicológico e identidad sociocultural en grupos de educación superior de procedencia rural y urbana en el Cusco. (tesis doctoral) Universidad Nacional Mayor de San Marcos, Lima.

Vásquez, R. (2010). Estrategias de Enseñanza: investigaciones sobre didáctica en instituciones educativas de la ciudad de Pasto. Bogotá: Kimpres Universidad de La Salle.

Vygotsky, L. (1982). Obras escogidas (Vol. 2). Madrid: Visor Distribuciones.

Vygotsky, L. (1988). Pensamiento y lenguaje. La Habana: Pueblo y Educación.

Zumthor, P. (1989). La letra y la voz de la “literatura” medieval. Madrid: Cátedra. 


\section{Anexos}

\section{Anexo $N^{\circ}$ 1: Matriz Metodológica}

\begin{tabular}{|c|c|c|c|c|c|c|c|c|c|}
\hline $\begin{array}{l}\begin{array}{l}\text { Problema } \\
\text { general }\end{array} \\
\end{array}$ & $\begin{array}{l}\text { Problemas } \\
\text { específicos }\end{array}$ & $\begin{array}{c}\begin{array}{c}\text { Objetivo } \\
\text { general }\end{array} \\
\end{array}$ & $\begin{array}{c}\text { Objetivos } \\
\text { específicos }\end{array}$ & Categorías & Sub categorías & Método/ & $\begin{array}{l}\text { Unidad de } \\
\text { análisis }\end{array}$ & Técnicas & Instrumentos \\
\hline \multirow{8}{*}{$\begin{array}{l}\text { ¿Cómo } \\
\text { desarrollar la } \\
\text { identidad } \\
\text { musical } \\
\text { nacional en } \\
\text { los } \\
\text { estudiantes de } \\
\text { la } \\
\text { especialidad } \\
\text { de cuerdas de } \\
\text { un } \\
\text { conservatorio } \\
?\end{array}$} & \multirow{3}{*}{$\begin{array}{l}\text { ¿Cuál es el estado actual } \\
\text { del desarrollo de la } \\
\text { identidad musical nacional } \\
\text { en los estudiantes de la } \\
\text { especialidad de cuerdas de } \\
\text { un conservatorio? }\end{array}$} & \multirow{8}{*}{$\begin{array}{l}\text { Proponer la } \\
\text { estrategia } \\
\text { metodológica } \\
\text { para } \\
\text { desarrollar la } \\
\text { identidad } \\
\text { musical } \\
\text { nacional en } \\
\text { los } \\
\text { estudiantes de } \\
\text { la } \\
\text { especialidad } \\
\text { de cuerdas de } \\
\text { un } \\
\text { conservatorio }\end{array}$} & \multirow{3}{*}{$\begin{array}{l}\text { Diagnosticar el estado } \\
\text { actual del desarrollo de } \\
\text { la identidad musical } \\
\text { nacional en los } \\
\text { estudiantes de la } \\
\text { especialidad de cuerdas } \\
\text { de un conservatorio. }\end{array}$} & \multirow[t]{3}{*}{$\begin{array}{l}\text { Estrategia } \\
\text { Metodológica }\end{array}$} & $\begin{array}{l}\text { Planteamiento } \\
\text { del Objeto y } \\
\text { fundamentación }\end{array}$ & \multirow{3}{*}{$\begin{array}{l}\text { Métodos } \\
\text { empíricos: } \\
\text { Observación } \\
\text { Entrevista } \\
\text { Encuesta } \\
\text { Estadístico o } \\
\text { matemático }\end{array}$} & $\begin{array}{l}\text { Docentes } \\
\text { Estudiantes y } \\
\text { Literatura } \\
\text { especializada }\end{array}$ & $\begin{array}{l}\text { La observación } \\
\text { La entrevista } \\
\text { La encuesta }\end{array}$ & $\begin{array}{l}\text { Guía de observación } \\
\text { Guía de entrevista } \\
\text { Prueba pedagógica y } \\
\text { cuestionario }\end{array}$ \\
\hline & & & & & $\begin{array}{l}\text { Etapas y } \\
\text { procedimientos }\end{array}$ & & \multirow[t]{2}{*}{$\begin{array}{l}\text { Literatura } \\
\text { científica } \\
\text { temática }\end{array}$} & \multirow[t]{2}{*}{$\begin{array}{l}\text { Análisis } \\
\text { documental }\end{array}$} & $\begin{array}{l}\text { Fichas de análisis de } \\
\text { documentos }\end{array}$ \\
\hline & & & & & $\begin{array}{l}\text { Evaluación y } \\
\text { monitoreo }\end{array}$ & & & & Registro documental \\
\hline & \multirow{3}{*}{$\begin{array}{l}\text { ¿Cuál es la perspectiva } \\
\text { teórica de la estrategia } \\
\text { metodológica para } \\
\text { desarrollar la identidad } \\
\text { musical nacional en los } \\
\text { estudiantes de la } \\
\text { especialidad de cuerdas de } \\
\text { un conservatorio? }\end{array}$} & & \multirow{3}{*}{$\begin{array}{l}\text { Fundamentar teórica y } \\
\text { metodológicamente de la } \\
\text { estrategia metodológica } \\
\text { para desarrollar la } \\
\text { identidad musical } \\
\text { nacional en los } \\
\text { estudiantes de la } \\
\text { especialidad de cuerdas } \\
\text { de un conservatorio. }\end{array}$} & \multirow[t]{4}{*}{$\begin{array}{l}\text { Identidad } \\
\text { Musical }\end{array}$} & Identificación & \multirow{4}{*}{$\begin{array}{l}\text { Métodos } \\
\text { teóricos: } \\
\text { Histórico lógico } \\
\begin{array}{l}\text { Hermenéutico } \\
\text { dialectico }\end{array} \\
\text { Análisis síntesis } \\
\text { Inductivo } \\
\text { deductivo }\end{array}$} & \multirow[t]{4}{*}{$\begin{array}{l}\text { Documentos } \\
\text { científicos }\end{array}$} & \multirow[t]{4}{*}{$\begin{array}{l}\text { Análisis } \\
\text { documental }\end{array}$} & \multirow[t]{4}{*}{$\begin{array}{l}\text { Fichas de análisis de } \\
\text { documentos } \\
\text { Registro documental }\end{array}$} \\
\hline & & & & & $\begin{array}{l}\text { Concientización } \\
\text { Musical }\end{array}$ & & & & \\
\hline & & & & & & & & & \\
\hline & $\begin{array}{l}\text { ¿Qué criterios teóricos y } \\
\text { metodológicos se debe } \\
\text { tener en cuenta en la } \\
\text { modelación de la estrategia } \\
\text { metodológica para } \\
\text { desarrollar la identidad } \\
\text { musical nacional en los } \\
\text { estudiantes de la } \\
\text { especialidad de cuerdas de } \\
\text { un conservatorio? }\end{array}$ & & $\begin{array}{l}\text { Determinar los criterios } \\
\text { teóricos y } \\
\text { metodológicos a tener en } \\
\text { cuenta en la modelación } \\
\text { de la estrategia } \\
\text { metodológica para } \\
\text { desarrollar la identidad } \\
\text { musical nacional en los } \\
\text { estudiantes de la } \\
\text { especialidad de cuerdas } \\
\text { de un conservatorio. }\end{array}$ & & & & & & \\
\hline & $\begin{array}{l}\text { ¿Cómo validar la estrategia } \\
\text { metodológica para } \\
\text { desarrollar la identidad } \\
\text { musical nacional en los } \\
\text { estudiantes de la } \\
\text { especialidad de cuerdas de } \\
\text { un conservatorio? }\end{array}$ & & $\begin{array}{l}\text { Validar por juicio de } \\
\text { expertos la estrategia } \\
\text { metodológica para } \\
\text { desarrollar la identidad } \\
\text { musical nacional en los } \\
\text { estudiantes de la } \\
\text { especialidad de cuerdas } \\
\text { de un conservatorio. }\end{array}$ & & & $\begin{array}{l}\text { Método de } \\
\text { modelación: } \\
\text { Método Delphi }\end{array}$ & $\begin{array}{l}\text { Documentos } \\
\text { de la } \\
\text { propuesta }\end{array}$ & $\begin{array}{l}\text { Criterios de } \\
\text { expertos }\end{array}$ & $\begin{array}{l}\text { Lista de chequeo de } \\
\text { expertos }\end{array}$ \\
\hline
\end{tabular}


Anexo $N^{\circ}$ 2: Matriz de Categorización

\begin{tabular}{|c|c|c|c|c|c|c|c|}
\hline $\begin{array}{c}\text { Problema } \\
\text { general }\end{array}$ & $\begin{array}{c}\text { Objetivo } \\
\text { general }\end{array}$ & Categorías & Sub categorías & Indicadores & $\begin{array}{l}\text { Cuestionario } \\
\text { a estudiantes }\end{array}$ & $\begin{array}{c}\text { Guía de } \\
\text { entrevistas }\end{array}$ & $\begin{array}{c}\text { Prueba } \\
\text { pedagógica }\end{array}$ \\
\hline \multirow{9}{*}{$\begin{array}{l}\text { ¿Cómo } \\
\text { desarrollar la } \\
\text { identidad musical } \\
\text { nacional en los } \\
\text { estudiantes de la } \\
\text { especialidad de } \\
\text { cuerdas de un } \\
\text { conservatorio? }\end{array}$} & \multirow{9}{*}{$\begin{array}{l}\text { Proponer la } \\
\text { estrategia } \\
\text { metodológica } \\
\text { para desarrollar la } \\
\text { identidad musical } \\
\text { nacional en los } \\
\text { estudiantes de la } \\
\text { especialidad de } \\
\text { cuerdas de un } \\
\text { conservatorio }\end{array}$} & \multirow{6}{*}{$\begin{array}{l}\text { Identidad Musical } \\
\text { (Álvarez, 2017), es el } \\
\text { sentido de pertenencia } \\
\text { consustancial a las } \\
\text { tradiciones musicales de } \\
\text { la localidad, que } \\
\text { precisan los } \\
\text { sentimientos de } \\
\text { identificación y } \\
\text { concientización de los } \\
\text { elementos identitarios de } \\
\text { la música local, } \\
\text { que permiten asumir } \\
\text { actitudes que develan la } \\
\text { asunción del } \\
\text { patrimonio musical. (g. } \\
\text { 26) }\end{array}$} & \multirow{3}{*}{$\begin{array}{l}\text { Identificación Musical } \\
\text { (Álvarez, 2017) es el sistema de contenidos } \\
\text { de la música tradicional } \\
\text { presentes en las comunidades, las cuales } \\
\text { son reconocidos, recuperados y puestos en } \\
\text { valor, para transmitir, revitalizar y difundir } \\
\text { los aportes culturales del contenido de las } \\
\text { obras musicales. }\end{array}$} & $\begin{array}{l}\text { Reconoce la música tradicional en el } \\
\text { contexto de su comunidad }\end{array}$ & \multirow{3}{*}{$\begin{array}{l}1,2 \\
3\end{array}$} & \multirow[t]{3}{*}{1} & \multirow[t]{3}{*}{1} \\
\hline & & & & $\begin{array}{l}\text { Identifica los contenidos de la música } \\
\text { tradicional en el repertorio musical de su } \\
\text { comunidad. }\end{array}$ & & & \\
\hline & & & & $\begin{array}{l}\text { Difunde la música tradicional de su } \\
\text { comunidad en su práctica musical }\end{array}$ & & & \\
\hline & & & \multirow{3}{*}{$\begin{array}{l}\text { Concientización Musical } \\
\text { (Álvarez, 2017). Es la valoración de los } \\
\text { elementos identitarios que conforman las } \\
\text { raíces culturales de la comunidad, conlleva } \\
\text { la reafirmación de métodos y } \\
\text { procedimientos de búsqueda de } \\
\text { información acerca de los contenidos de las } \\
\text { obras musicales de } \\
\text { la comunidad con su entorno sociocultural. }\end{array}$} & $\begin{array}{l}\text { Valora los fundamentos culturales de su } \\
\text { comunidad creando conciencia musical }\end{array}$ & \multirow{3}{*}{\begin{tabular}{|l}
5 \\
6
\end{tabular}} & \multirow[t]{3}{*}{3} & \multirow[t]{3}{*}{5} \\
\hline & & & & $\begin{array}{l}\text { Aplica métodos y procedimientos de } \\
\text { búsqueda de información histórico } \\
\text { musical en su entorno socio cultural. }\end{array}$ & & & \\
\hline & & & & $\begin{array}{l}\text { Desarrolla acciones que favorezcan el } \\
\text { aprecio y valoración de elementos } \\
\text { identitarios de la música de su } \\
\text { comunidad. }\end{array}$ & & & \\
\hline & & \multirow{3}{*}{$\begin{array}{l}\text { Estrategia Metodológica } \\
\text { Según Moya (2017), la } \\
\text { estrategia } \\
\text { metodológica es la unión } \\
\text { de forma } \\
\text { integrada y coherente de } \\
\text { técnicas } \\
\text { didácticas, estrategias, } \\
\text { actividades y } \\
\text { recursos de enseñanza } \\
\text { aprendizaje. }\end{array}$} & \multirow{3}{*}{$\begin{array}{l}\text { Sistema de métodos y técnicas didácticas } \\
\text { Según Moya (2017), son procedimientos de } \\
\text { menor alcance que las } \\
\text { estrategias didácticas, dado que se utilizan } \\
\text { en períodos cortos (parte de una asignatura, } \\
\text { unidad de aprendizaje, etc.); cuyo foco es } \\
\text { orientar } \\
\text { específicamente una parte del aprendizaje, } \\
\text { desde una lógica con base psicológica, } \\
\text { aportando así al desarrollo de } \\
\text { competencias. }\end{array}$} & $\begin{array}{l}\text { Plantea problemas que requieran } \\
\text { procedimientos didácticos en el proceso } \\
\text { de enseñanza - aprendizaje }\end{array}$ & 8 & 4 & \\
\hline & & & & $\begin{array}{l}\text { Realiza procedimientos específicos para } \\
\text { desarrollar un tema puntual del curso }\end{array}$ & \multirow{2}{*}{$\begin{array}{l}9 \\
10\end{array}$} & \multirow[t]{2}{*}{5} & \\
\hline & & & & $\begin{array}{l}\text { Selecciona actividades de aprendizaje } \\
\text { delimitadas para el desarrollo de } \\
\text { competencias. }\end{array}$ & & & \\
\hline
\end{tabular}




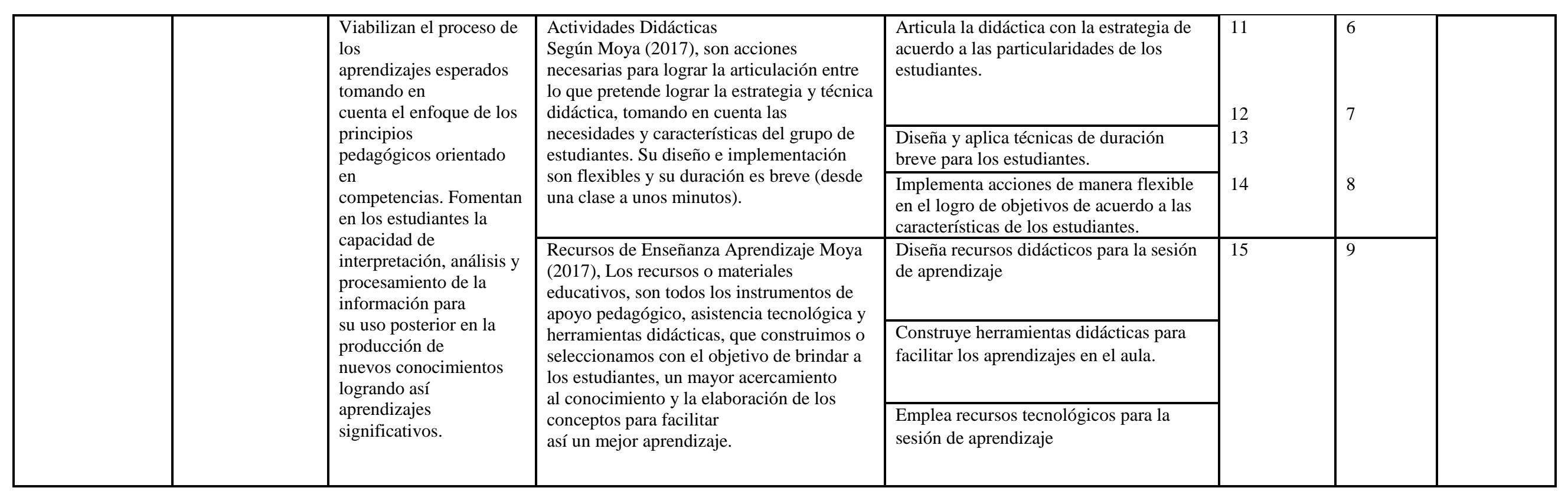


Anexo $\mathbf{N}^{\circ}$ 3: Instrumentos de recolección de datos

ENTREVISTA SEMI ESTRUCTURADA A LOS DOCENTES

Datos informativos:

Entrevistador:

Lugar y Fecha:

Duración:

OBJETIVO: Conocer la preparación teórica y didáctica que poseen los docentes sobre los fundamentos de la Identidad musical en los estudiantes del primer año de la especialidad de cuerdas de un Conservatorio de Lima

Preguntas:

1. ¿Qué acción pedagógica realiza Ud. ¿Para que el estudiante logre identificar los contenidos de la música tradicional?

2. ¿Ud. Considera importante difundir la música tradicional en su práctica musical, por qué?

3. ¿Qué actividades realiza para fomentar el aprecio, valoración y difusión de la música tradicional entre sus estudiantes?

4. ¿Qué estrategias y técnicas emplea en el proceso de enseñanza - aprendizaje de su especialidad, como lo realiza?

5. ¿Qué procesos didácticos emplea Ud. ¿En su sesión de clase?

6. ¿Qué estrategias emplea para que el estudiante logre articular sus conocimientos previos con la nueva información y aplique en la solución de problemas cotidianos?

7. ¿De qué manera Ud. Planifica y aplica estrategias y técnicas que responden a los intereses y necesidades de los estudiantes?

8. ¿Ud. Suele diseñar diferentes recursos didácticos para cada sesión de clase; como los aplica?

9. ¿De qué manera Ud. Promueve el uso de diferentes recursos materiales y digitales en cada sesión de clase? 


\section{CUESTIONARIO A LOS ESTUDIANTES DATOS GENERALES:}

Carrera:

Ciclo:

Edad: Sexo: Femenino ( ) Masculino ( ) Fecha:

OBJETIVO: Constatar el nivel de satisfacción que experimentan los estudiantes de la especialidad de cuerdas de un Conservatorio de Lima con la manera en que el docente de la asignatura Instrumento Principal dirige el proceso de enseñanza - aprendizaje para contribuir al desarrollo de su Identidad musical nacional.

\section{Instrucciones:}

Estimado estudiante, como parte del avance del proyecto de tesis de postgrado para el desarrollo de la "Identidad musical nacional en los estudiantes de la especialidad de cuerdas de un Conservatorio de Lima" necesitamos que colabores con tu opinión respecto a los contenidos de la asignatura y de la forma como el docente dirige la sesión de clase. Para ello te pedimos que leas atentamente el siguiente cuestionario para responder las siguientes preguntas.

\begin{tabular}{|c|c|c|c|c|c|}
\hline & PREGUNTAS & & ITEMS & & \\
\hline & & SIEMPRE & $\begin{array}{c}\text { CASI } \\
\text { SIEMPRE }\end{array}$ & $\begin{array}{c}\text { A } \\
\text { VECES }\end{array}$ & NUNCA \\
\hline 1 & $\begin{array}{l}\text { ¿Usted reconoce la música tradicional relacionada al } \\
\text { contexto de su comunidad? }\end{array}$ & & & & \\
\hline 2 & $\begin{array}{l}\text { ¿El docente te incentiva a practicar la musical tradicional de } \\
\text { tu comunidad? }\end{array}$ & & & & \\
\hline 3 & $\begin{array}{l}\text { ¿Cuándo ejecutas una obra musical tradicional, identificas } \\
\text { los elementos característicos que la diferencian? }\end{array}$ & & & & \\
\hline 4 & $\begin{array}{l}\text { ¿En tu elección de repertorio personal, consideras obras } \\
\text { musicales tradicionales de tu comunidad? }\end{array}$ & & & & \\
\hline 5 & ¿Usted aprecia y valora el legado cultural de tu comunidad? & & & & \\
\hline 6 & $\begin{array}{l}\text { ¿El docente te ayuda en la valoración del legado cultural de } \\
\text { las comunidades? }\end{array}$ & & & & \\
\hline 7 & $\begin{array}{l}\text { ¿El docente realiza actividades significativas para que el } \\
\text { estudiante aprecie y valore los elementos identitarios de la } \\
\text { música de su comunidad? }\end{array}$ & & & & \\
\hline 8 & $\begin{array}{l}\text { ¿El docente suele aplicar ciertas estrategias y técnicas } \\
\text { adecuadas en el proceso de enseñanza-aprendizaje? }\end{array}$ & & & & \\
\hline
\end{tabular}




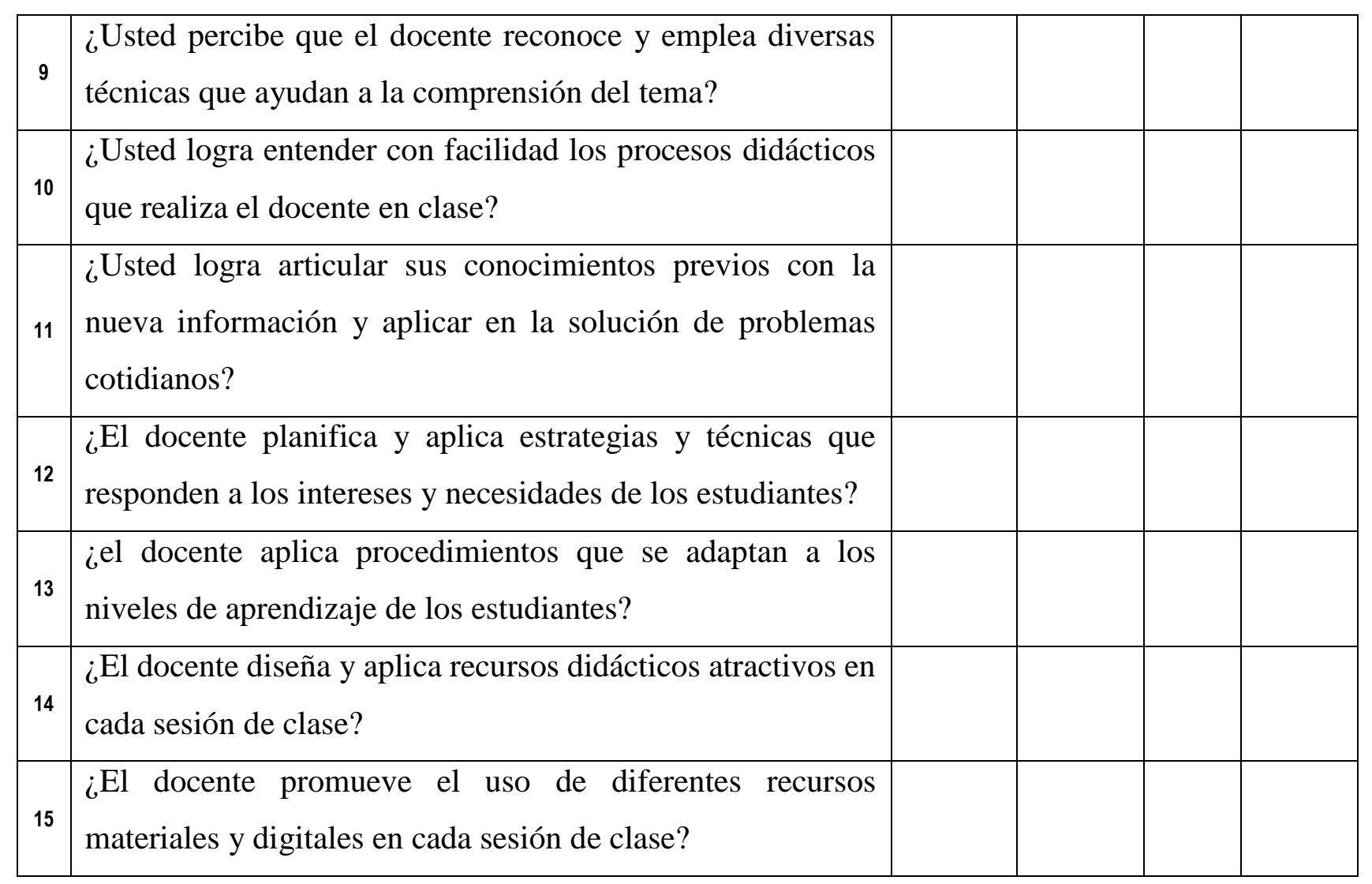




\section{PRUEBA PEDAGÓGICA PARA ESTUDIANTES}

\section{DATOS GENERALES:}

Carrera:

Ciclo:

Edad: Sexo: Masculino ( ) Femenino ( ) Fecha:

OBJETIV0: Comprobar el nivel de conocimientos teóricos sobre la Identidad Musical Nacional en la asignatura de instrumento principal para el desarrollo y aplicación de una Estrategia Metodológica en los estudiantes de la especialidad de cuerdas en un Conservatorio de Lima

\section{Instrucciones:}

Estimado estudiante, como parte de una investigación que estamos realizando para desarrollar la identidad musical nacional en el proceso de enseñanza - aprendizaje en la especialidad de cuerdas, necesitamos de tu colaboración. A continuación, te presentamos algunas preguntas relacionadas con los conocimientos adquiridos, por favor léelas atentamente y responde según corresponda.

Marque con una " $\mathrm{X}$ " la respuesta que usted considere apropiada dentro de las cuatro alternativas sugeridas. El presente cuestionario es anónimo, responde por favor con sinceridad.

\section{Preguntas}

1.-¿Qué contenidos son aplicables en la música tradicional?
a) Instrumentos típicos
b) Escala mixolidia
c) Dodecafonía
d) Ninguna
( )
()

2.-¿Cuál de los conceptos enmarca mejor la música tradicional?

(a) Música producida por la mezcla de dos géneros o estilos musicales distintos en una obra, que a su vez puede generar un género o estilo nuevo.

(b) Música que es transmitida de generación en generación de forma oral como una parte más de los valores y de la cultura de un pueblo.

(c) Es toda aquella música que se ha concebido para cantarse, tocarse o interpretarse en los contextos litúrgicos o religiosos.

(d) Música de alta complejidad intelectual que implican consideraciones estructurales y teóricas avanzadas; se caracteriza por la notación musical. 
3.- ¿Cuál de los instrumentos musicales de la música tradicional es un instrumento de viento?
a) Chacombo
b) Tinya
c) Waqrapuku
d) Arpa andina
()
()
()
()

4.- ¿Por qué consideras importante el legado cultural de tu comunidad presente en el repertorio musical tradicional?

(a) Promueven sentimientos de identificación y concientización de los elementos

identitarios de la música nacional, que permiten asumir actitudes que develan la asunción del patrimonio musical.

(b) Precisa acciones necesarias para conseguir la articulación entre lo que pretende lograr el arte contemporáneo y la técnica didáctica.

(c) Motiva el distanciamiento de entes participantes del proceso enseñanza aprendizaje asumiendo actitudes conductistas para lograr objetivos aleatorios.

(e) Conlleva un trabajo sencillo de realizar y no beneficia económicamente a nadie.

5.- ¿Cuál de las siguientes asociaciones consideras correctas?
a) Tondero - marinera - tinya - Loreto
b) Herranza - Santiago - waqrapuku - Lima
c) Festejo - danza de las pallas - quijada de burro - Ica
d) Diablada - tunantada - gaita - Tacna

6. ¿El huayno "Valicha" es un tema tradicional propio del departamento de: ?
a) Puno
b) Arequipa
c) Ucayali
d) Cuzco

7.- ¿Compositor peruano de "Sinfonía Nasca” ?
a) Silvestre Revueltas
b) Enrique Iturriaga
c) Francisco Pulgar Vidal
d) Alomia Robles 
Anexo $\mathrm{N}^{\circ}$ 4: Certificado de validez de los instrumentos de recolección de datos. Especialista 1
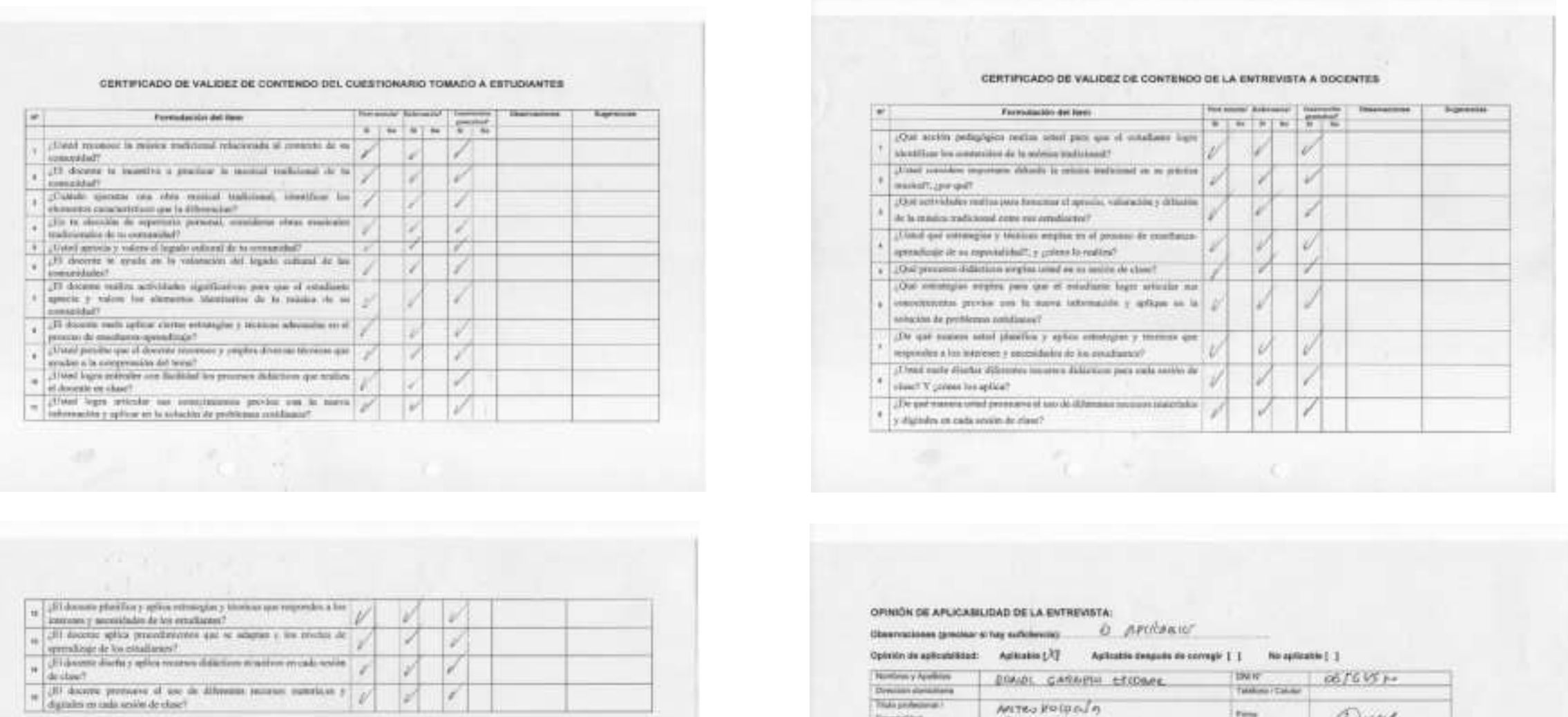

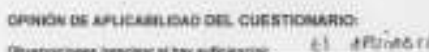

\begin{tabular}{|c|c|c|c|}
\hline$\Rightarrow$ & 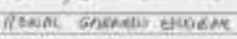 & Der & $06 \sqrt{6450}$ \\
\hline$x=$ & 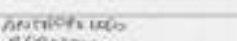 & & \\
\hline $\operatorname{lom}^{2}=$ & 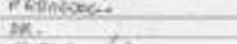 & & $(B x)$ \\
\hline nos & fortarestites & & 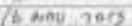 \\
\hline
\end{tabular}

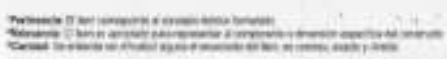

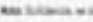

ORHDOK OE ARUCUEUDAD OF LA ENTRENSTA

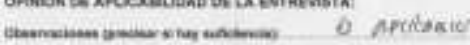

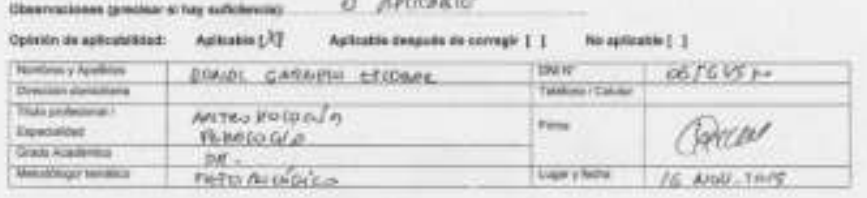

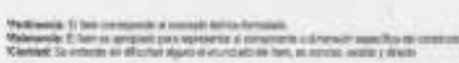




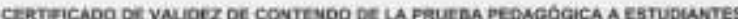

\begin{tabular}{|c|c|c|c|c|c|c|}
\hline$=$ & 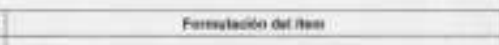 & & & $=$ & 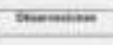 & tor. \\
\hline , & 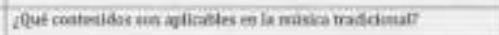 & 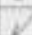 & & 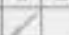 & & \\
\hline 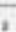 & 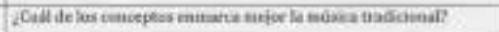 & 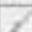 & & 7 & & \\
\hline$=$ & 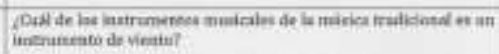 & . & & 1 & & \\
\hline - & 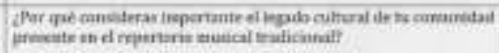 & o & & $\gamma$ & & \\
\hline . & 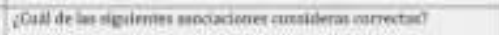 & 8 & & 2 & & \\
\hline - & 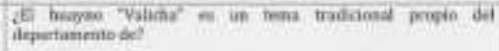 & & & 2 & & \\
\hline , & 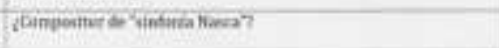 & $\theta$ & & 7 & & \\
\hline
\end{tabular}

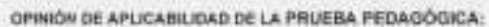

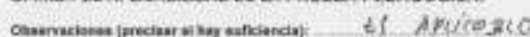

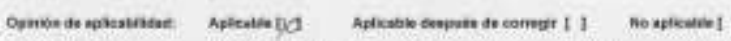

\begin{tabular}{|c|c|c|c|}
\hline 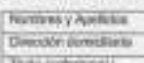 & Rown semelas mosk? & Sonn & a) \\
\hline 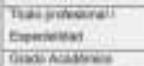 & 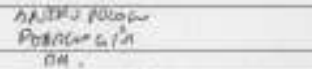 & $n n=$ & \\
\hline
\end{tabular}

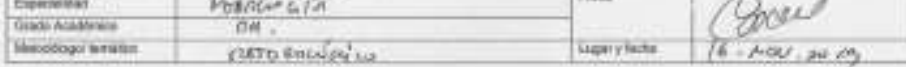

\section{4}

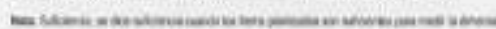




\section{Especialista 2}

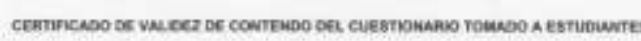

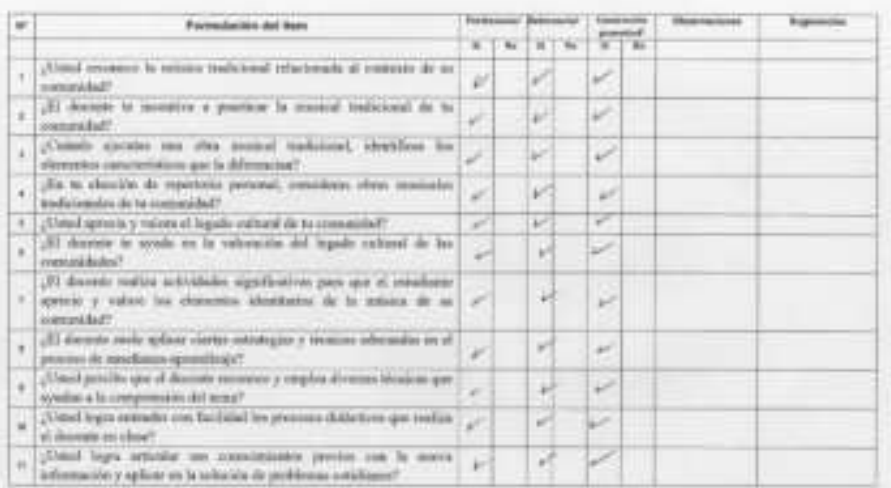

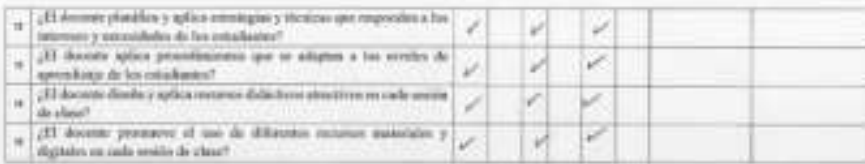

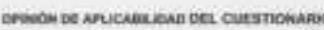

cherse

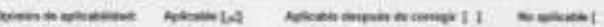

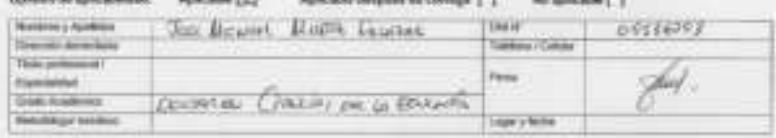

프:-1:-
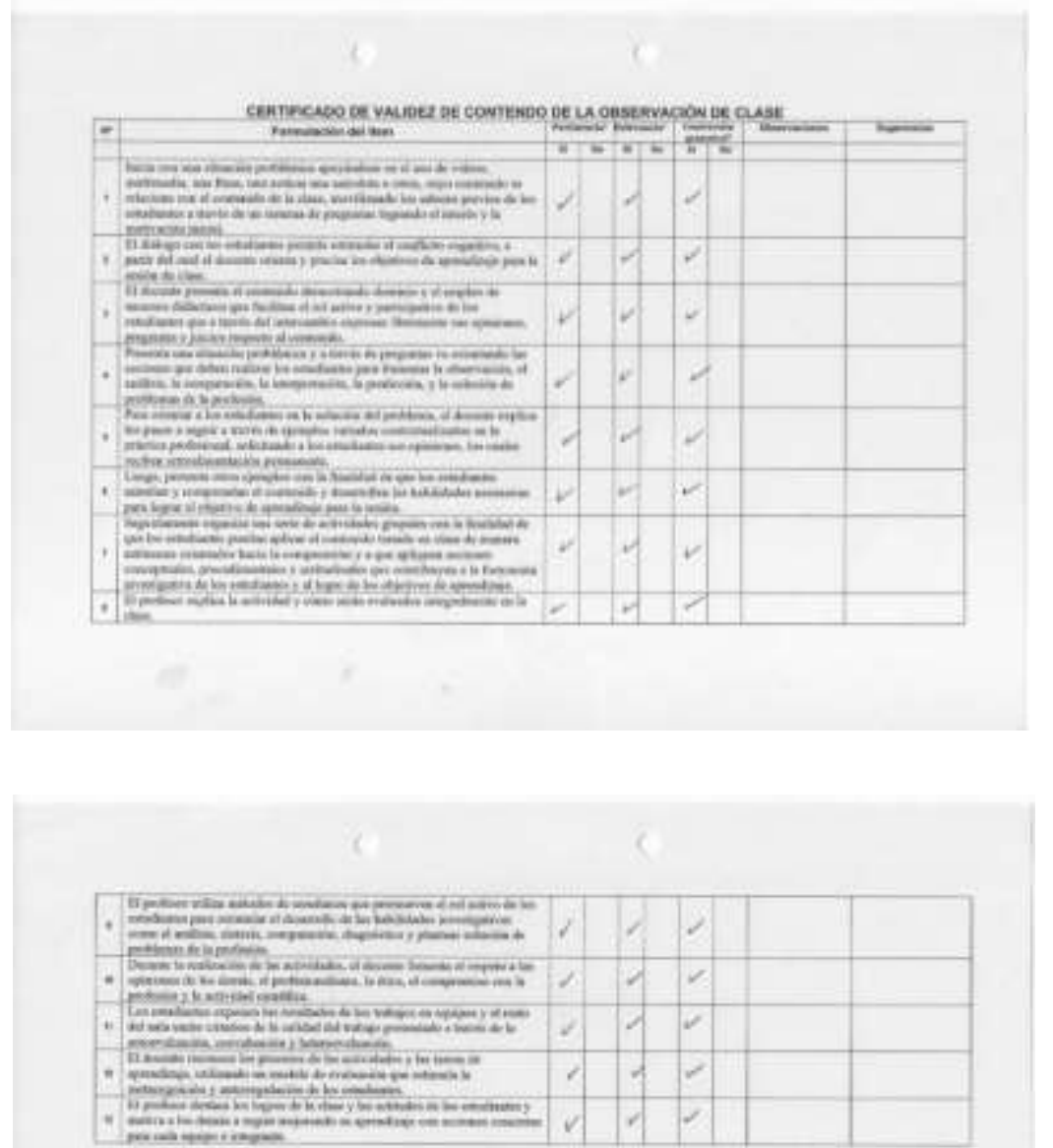

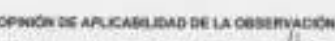

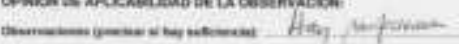

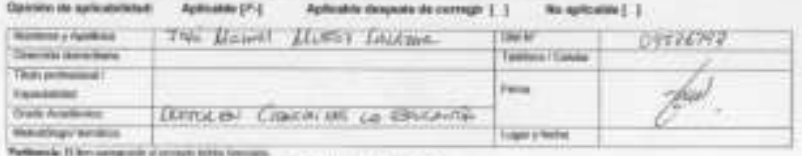

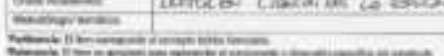




\section{CERTIFCADO DE VALLDEZ DE CONTEMDO DE LA PQYUEBA PEDAGOGICA A ESTUDUATTES}

\begin{tabular}{|c|c|c|c|c|c|c|}
\hline . & 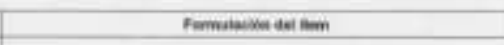 & $m$ & + & 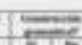 & $=$ & $\longrightarrow$ \\
\hline & 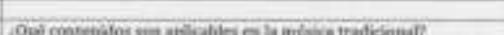 & $=$ & & & & \\
\hline & & $\gamma$ & 1 & 7 & & \\
\hline * & 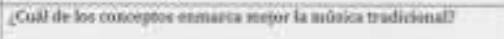 & 7 & 1 & 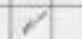 & & \\
\hline$=$ & 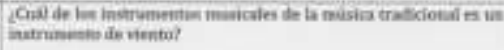 & $\gamma$ & $\mu$ & $\varnothing$ & & \\
\hline • & 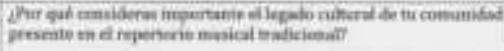 & $/$ & $\gamma$ & ' & & \\
\hline * & 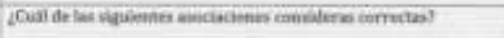 & 7 & $\theta$ & 1 & & \\
\hline - & 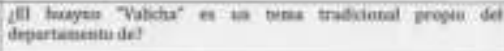 & 1 & $\gamma$ & 1 & & \\
\hline , & 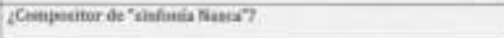 & D & r & $\gamma$ & & \\
\hline
\end{tabular}

OPAON OE ARLEABE

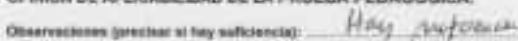

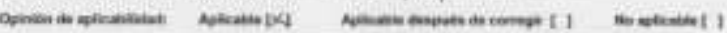

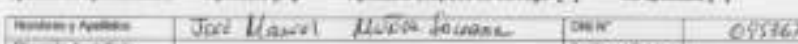

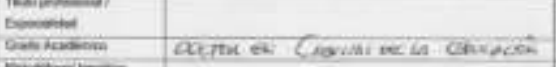

-

2

\section{-}




\section{Especialista 3}

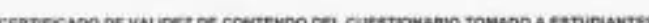

\begin{tabular}{|c|c|c|c|c|c|}
\hline thenemians & & $7=$ & $=$ & & $=$ \\
\hline 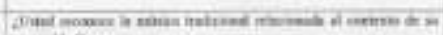 & 1 & 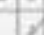 & 4 & & \\
\hline 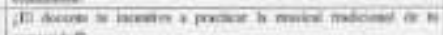 & . & 4 & 2 & & \\
\hline 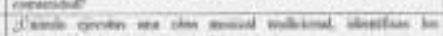 & 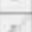 & & 7 & & \\
\hline 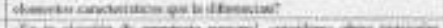 & & & & & \\
\hline 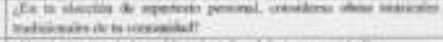 & $z$ & 6 & 8 & & \\
\hline 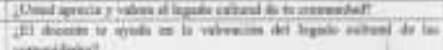 & 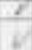 & 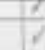 & 7 & & \\
\hline 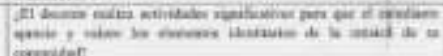 & 1 & , & 2 & & \\
\hline 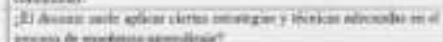 & , & 2 & 1 & & \\
\hline 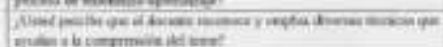 & 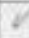 & 1 & 7 & & \\
\hline 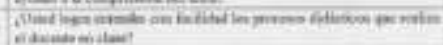 & 2 & y & 1 & & \\
\hline 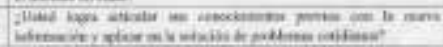 & 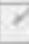 & 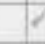 & 1 & & \\
\hline
\end{tabular}

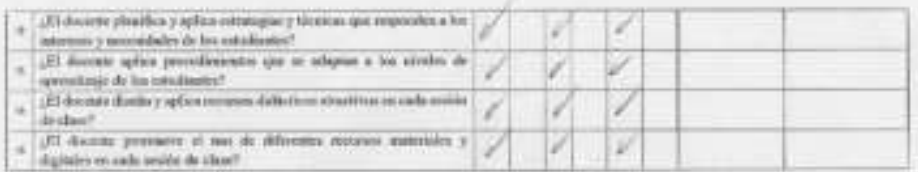

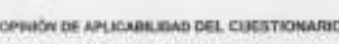

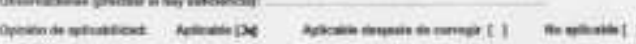

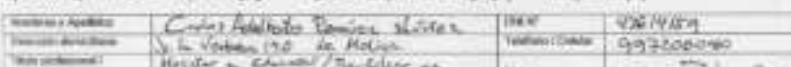

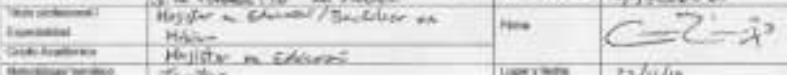

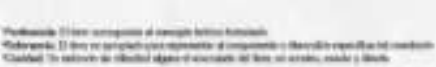

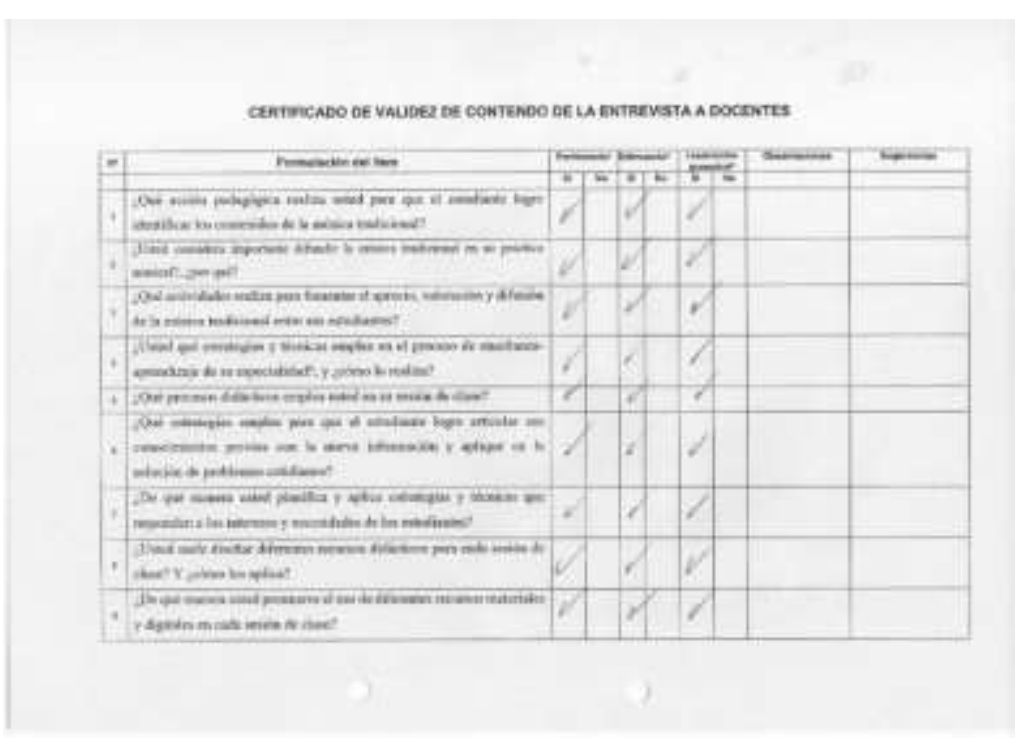

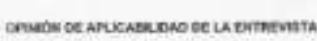

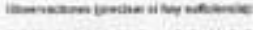

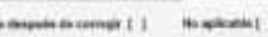

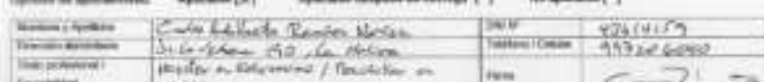

In

In:- 


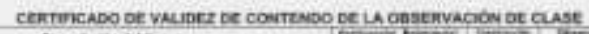

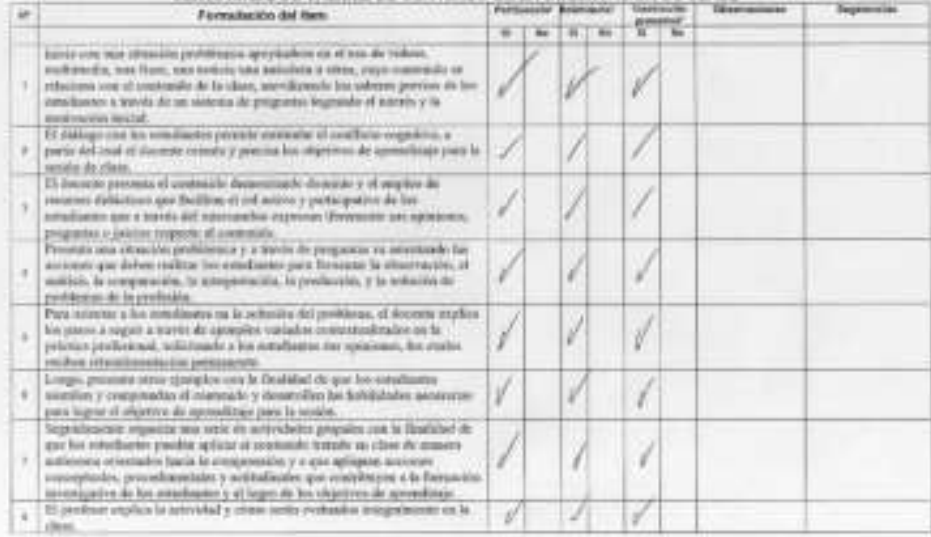

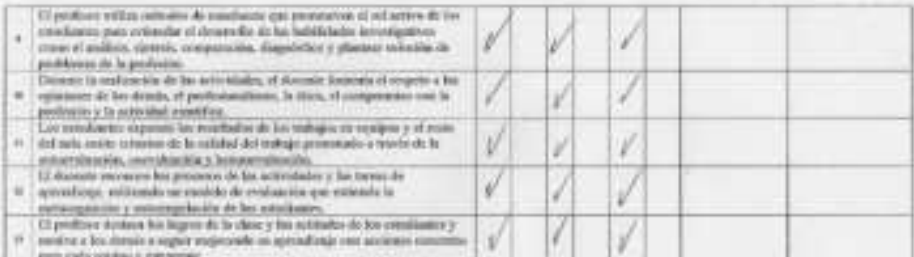

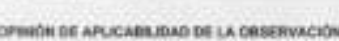

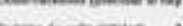

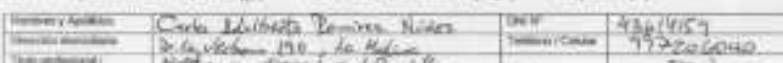

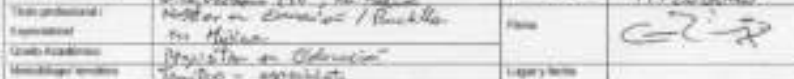

II=-

10

$$
\text { (1) }
$$

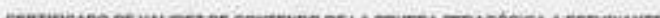

\begin{tabular}{|c|c|c|c|c|c|c|}
\hline & 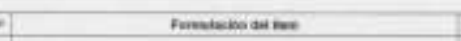 & & $=$ & $\overline{=}$ & $=$ & 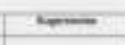 \\
\hline & 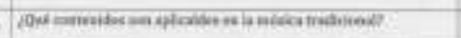 & D & 12 & 4 & & \\
\hline & 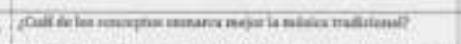 & & $\nabla$ & 7 & & \\
\hline & 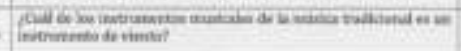 & r & $V$ & $y$ & & \\
\hline & 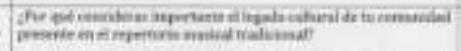 & f & $\gamma$ & $V$ & & \\
\hline & 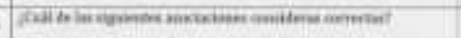 & V & $\gamma$ & $\theta$ & & \\
\hline & 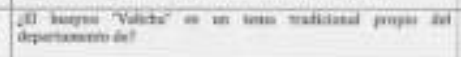 & 6 & 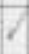 & $\nu$ & & \\
\hline & 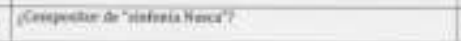 & 7 & 7 & $\mathrm{C}$ & & \\
\hline
\end{tabular}

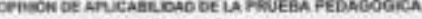

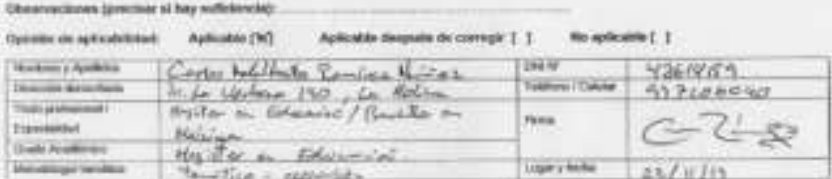

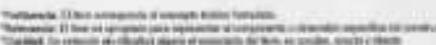

со 
Anexo $N^{\circ}$ 5: Certificados de validez de la propuesta

Validación de la propuesta - Especialista 1
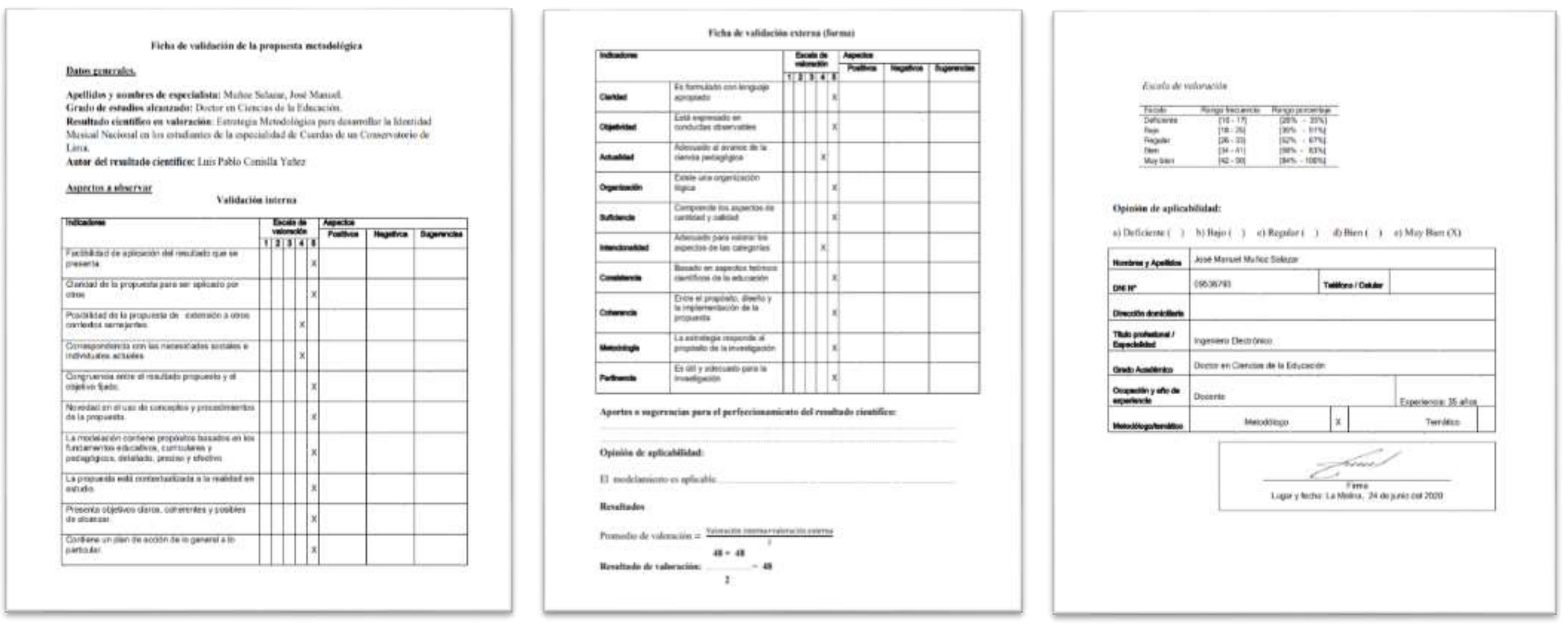
Validación de la propuesta - Especialista 2
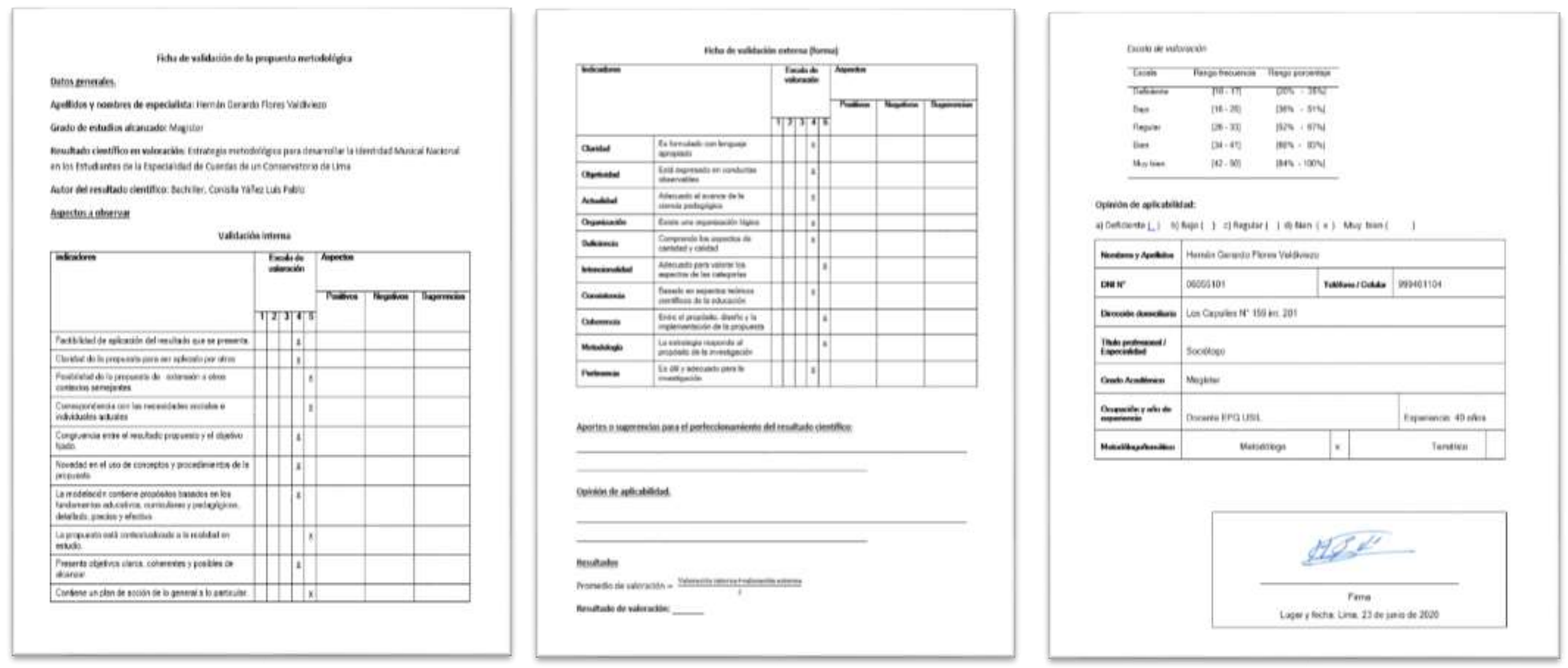
Validación de la propuesta - Especialista 3
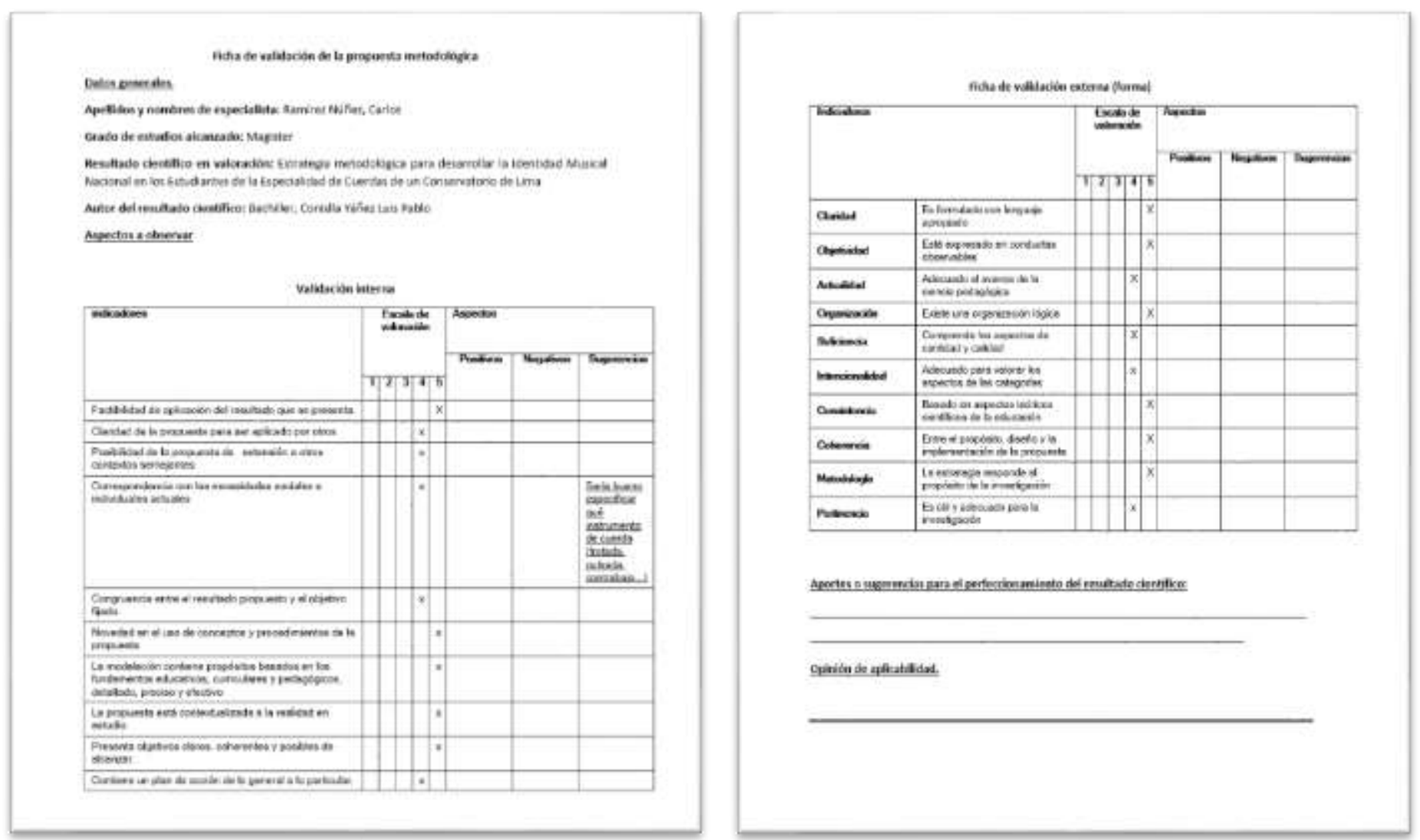

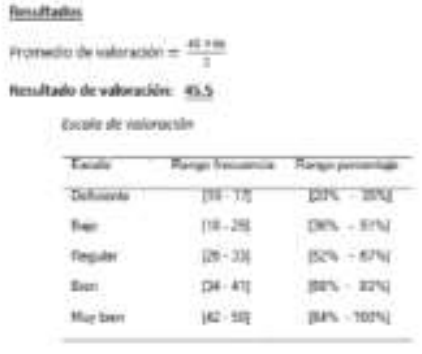

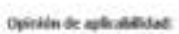

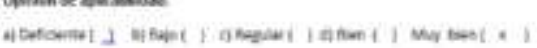

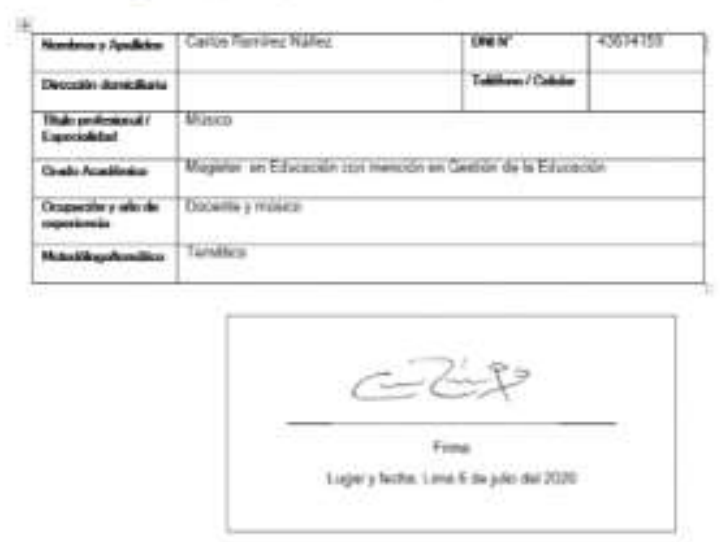


Anexo $\mathbf{N}^{\circ}$ 6: Resultados estadísticos del cuestionario aplicado a los estudiantes

\section{Tabla de frecuencia}

\section{¿El docente te ayuda en la valoración del legado cultural de las} comunidades?

\begin{tabular}{|c|c|c|c|c|c|}
\hline & & Frecuencia & Porcentaje & $\begin{array}{l}\text { Porcentaje } \\
\text { válido }\end{array}$ & $\begin{array}{l}\text { Porcentaje } \\
\text { acumulado }\end{array}$ \\
\hline \multirow[t]{5}{*}{$\overline{\text { Válido }}$} & Siempre & 6 & 19,4 & 19,4 & 19,4 \\
\hline & Casi siempre & 8 & 25,8 & 25,8 & 45,2 \\
\hline & A veces & 13 & 41,9 & 41,9 & 87,1 \\
\hline & Nunca & 4 & 12,9 & 12,9 & 100,0 \\
\hline & Total & 31 & 100,0 & 100,0 & \\
\hline
\end{tabular}

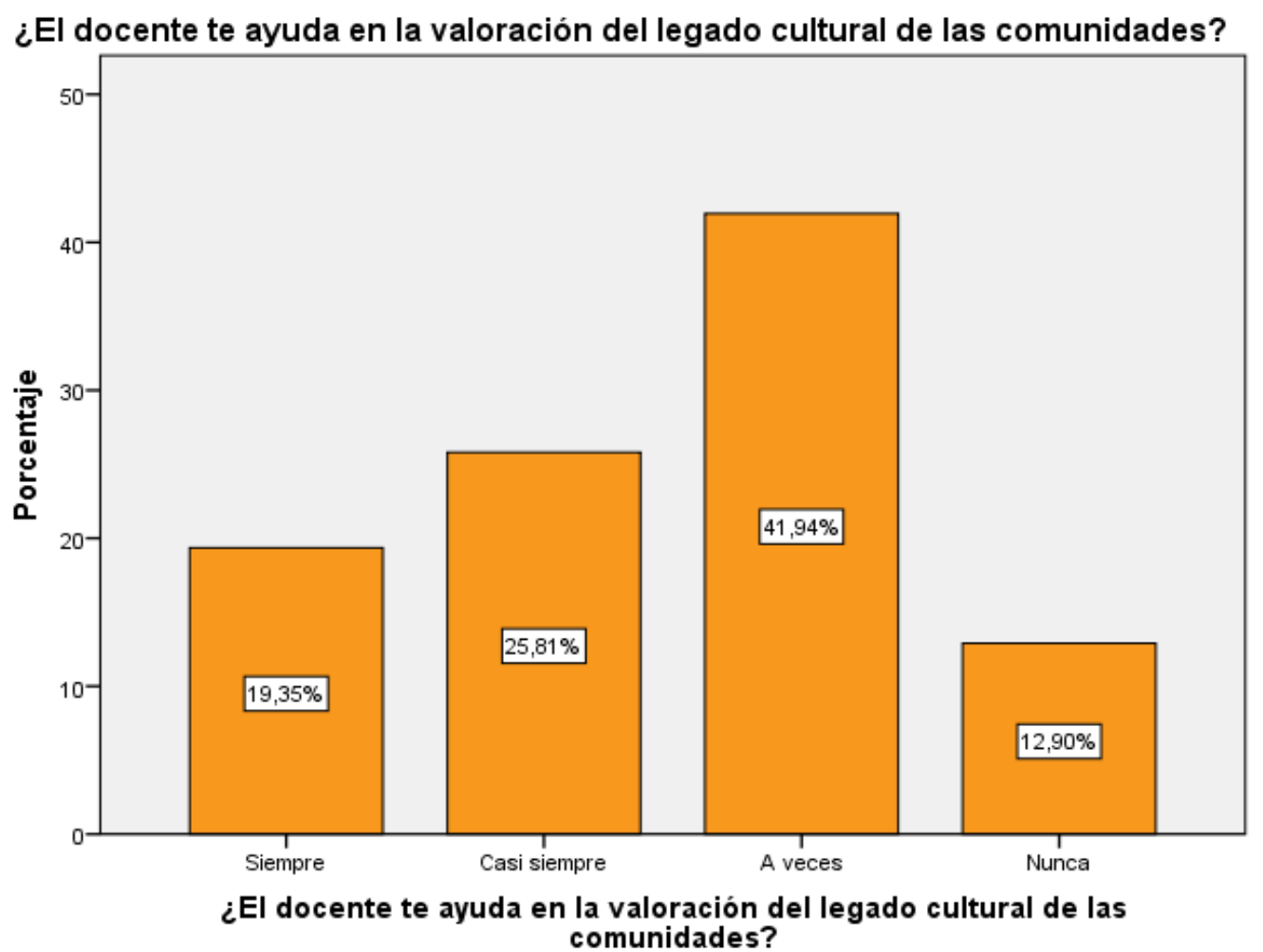

Del total de 31 estudiantes encuestados, 13 de ellos que equivalen al 41,9\% mencionan que a veces el docente los ayudan en la valoración del legado cultural de las comunidades; 8 de los estudiantes que equivalen al $25,8 \%$ manifiestan que casi siempre el docente los ayudan en la valoración del legado cultural de las comunidades; 6 de ellos que equivalen al 19,4\% mencionan que siempre el docente los ayudan en la valoración del legado cultural de las comunidades y 4 de ellos que equivalen al 12,9\% mencionan que nunca el docente los ayudan en la valoración del legado cultural de las comunidades. 
Anexo $N^{\circ}$ 7: Resultados estadísticos de la prueba pedagógica aplicada a los estudiantes

Nivel de conocimiento de la identidad musical

\begin{tabular}{llllll}
\hline \hline & & Frecuencia & Porcentaje & $\begin{array}{l}\text { Porcentaje } \\
\text { válido }\end{array}$ & $\begin{array}{l}\text { Porcentaje } \\
\text { acumulado }\end{array}$ \\
\hline Válido & Bajo & 3 & 9,7 & 9,7 & 9,7 \\
& Medio & 23 & 74,2 & 74,2 & 83,9 \\
& Alto & 5 & 16,1 & 16,1 & 100,0 \\
& Total & 31 & 100,0 & 100,0 & \\
\hline \hline
\end{tabular}

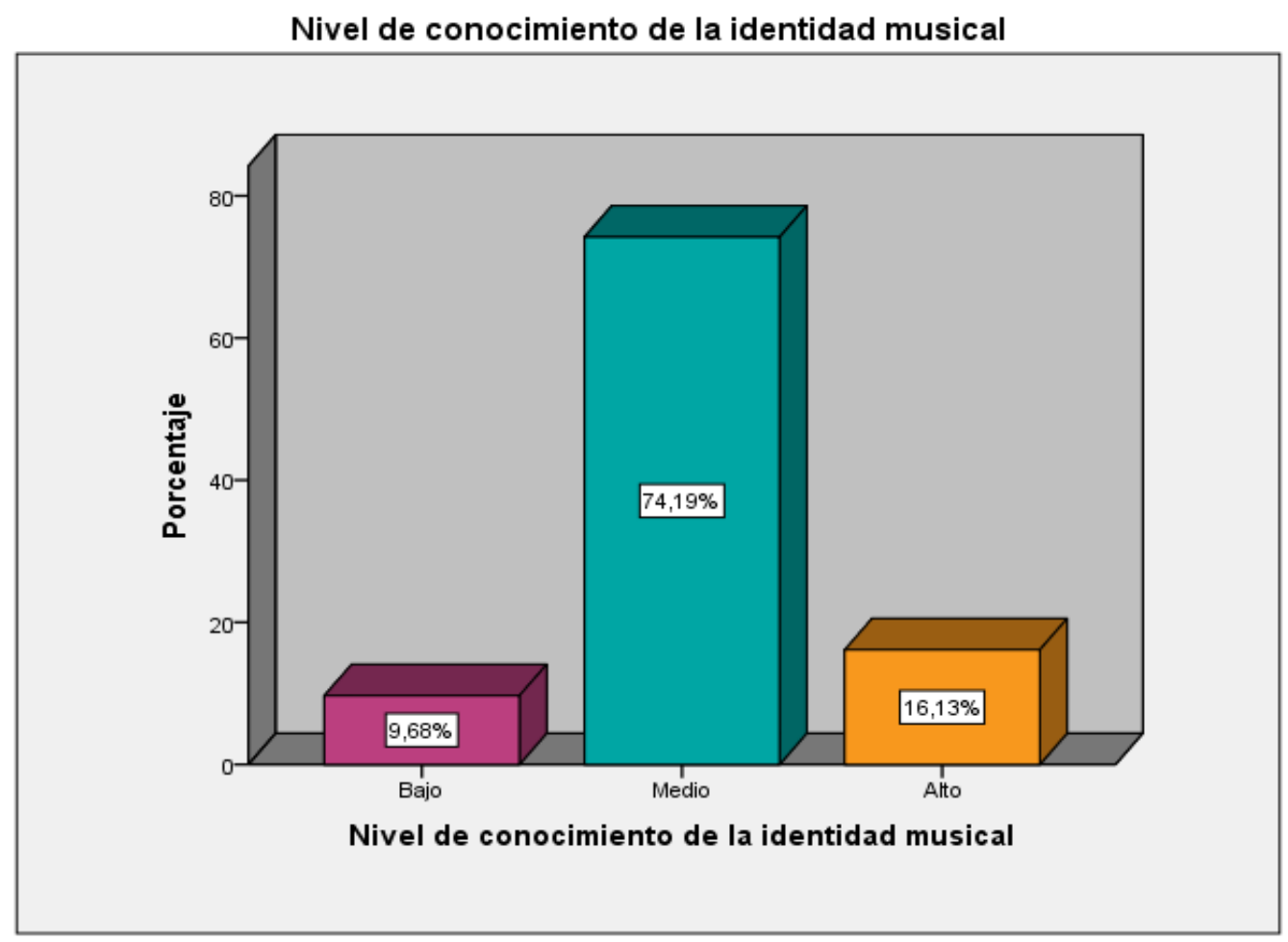

Del total de 31 estudiantes evaluados, 23 estudiantes que equivale al 74,2\% se encuentran en un nivel medio de conocimiento sobre la identidad musical; cinco estudiantes que equivale al 16,1\% lograron alcanzar un nivel alto de conocimiento sobre la identidad musical y tres estudiantes que equivale al $9,7 \%$ se encuentran en un nivel bajo de conocimiento sobre la identidad musical. 


\section{Anexo $\mathbf{N}^{\circ}$ 8: Transcripción de las entrevistas y observación de clase}

\section{PROCESO DE CODIFICACIÓN DE LAS ENTREVISTAS}

Entrevista $\mathrm{N}^{\circ} 1$

\begin{tabular}{|c|c|c|c|c|}
\hline Preguntas & Respuestas & Frases codificadas & Códigos & \\
\hline $\begin{array}{l}\text { 1.- ¿Qué acción } \\
\text { pedagógica realiza } \\
\text { Ud. para que el } \\
\text { estudiante logre } \\
\text { identificar los } \\
\text { contenidos de la } \\
\text { música tradicional? }\end{array}$ & $\begin{array}{l}\text { Entrevistado: El conservatorio está más dedicado a la música académica. Con tendencias europeas. } \\
\text { Hay veces que hacemos música latinoamericana. Y para graduarse tienen que presentar una pieza de } \\
\text { un compositor peruano. Donde se trata de ver motivos peruanos o que vienen de la música tradicional } \\
\text { peruana. Pero en realidad hacemos muy poco, más es enfocado a la literatura académica de Los } \\
\text { grandes maestros. }\end{array}$ & $\begin{array}{l}\text { El conservatorio está dedicado a la música } \\
\text { académica con tendencias europeas. a veces } \\
\text { hacemos música latinoamericana. Y para } \\
\text { graduarse tienen que presentar una pieza de } \\
\text { un compositor peruano, se ven motivos } \\
\text { peruanos que vienen de la música tradicional. } \\
\text { En realidad, hacemos muy poco... es enfocado } \\
\text { a la literatura académica de los grandes } \\
\text { maestros. }\end{array}$ & $\begin{array}{l}\text { Influencia académica europea. } \\
\text { Enseñanza enfocada a la literatura } \\
\text { académica. } \\
\text { Poca valoración de la música } \\
\text { tradicional - latinoamericana. } \\
\text { Desconocimiento académico de la } \\
\text { música tradicional peruana. } \\
\text { Falta incentivar la música peruana } \\
\text { en el proceso de formación }\end{array}$ & $\begin{array}{l}58 \\
59 \\
\\
60 \\
61\end{array}$ \\
\hline $\begin{array}{l}\text { 2.- ¿Usted considera } \\
\text { importante difundir la } \\
\text { música tradicional en } \\
\text { la práctica musical? }\end{array}$ & $\begin{array}{l}\text { Entrevistado: Me parece que sí. Porque tenemos que difundir nuestra música. Y para eso tenemos } \\
\text { que conocerla primero. Hay veces que estamos enseñando y nos piden una pieza y no tenemos las } \\
\text { bases, de cuáles son los ritmos de los de la música negra, no tenemos la base de cuáles son los } \\
\text { acordes que se usa en la música de la costa los valses y la marinera La poliritmia es muy importante } \\
\text { y queremos que sea algo fácil pero no es fácil. Entonces se pueden enseñar muchas cosas usando la } \\
\text { música peruana. } \\
\text { Entrevistador: ¿Es más viable? ¿Quizá a veces decirle al alumno sabes que, tú investiga o si } \\
\text { tienes los requerimientos él en la discoteca biblioteca pudiese recopilar esa información? } \\
\text { Entrevistado: Bueno siempre es bueno que el alumno investigue, pero para eso los profesores también } \\
\text { tienen que estar preparados con ciertos conocimientos previos o si no los profesores cómo lo va a } \\
\text { guiar al alumno }\end{array}$ & $\begin{array}{l}\text { Tenemos que difundir nuestra música, para } \\
\text { eso tenemos que conocerla. ... estamos } \\
\text { enseñando y nos piden una pieza y no tenemos } \\
\text { las bases; los ritmos, acordes que se usan en } \\
\text { los valses, marineras, queremos que sea fácil } \\
\text { pero no lo es. ... se puede enseñar muchas } \\
\text { cosas usando la música peruana. Siempre es } \\
\text { bueno que el alumno investigue. Para eso los } \\
\text { profesores tienen que estar preparados con } \\
\text { conocimientos previos, sino como guían al } \\
\text { alumno. }\end{array}$ & $\begin{array}{l}\text { Poco interés por difundir nuestra } \\
\text { música } \\
\text { Falta de recursos académicos } \\
\text { (partituras, escore, manuales } \\
\text { técnicos, etc.) de la música } \\
\text { tradicional. } \\
\text { Necesidad de investigación por los } \\
\text { alumnos. } \\
\text { falta de capacitación y } \\
\text { actualización docente }\end{array}$ & $\begin{array}{l}62 \\
63\end{array}$ \\
\hline $\begin{array}{l}\text { 3.- ¿Qué actividades } \\
\text { realiza para fomentar } \\
\text { el aprecio valoración } \\
\text { y difusión de la } \\
\text { música tradicional } \\
\text { entre sus } \\
\text { estudiantes? }\end{array}$ & $\begin{array}{l}\text { Entrevistado: Como dije el conservatorio está más enfocado en la música clásica. Realmente es muy } \\
\text { poco. Yo diría que solamente cuando son... cuando vienen los recitales titulación y se busca la pieza } \\
\text { peruana ahí recién ponemos... que yo sé, es una deficiencia del Conservatorio. Pero es cómo son las } \\
\text { cosas hasta ahora. }\end{array}$ & $\begin{array}{l}\text { El conservatorio está más enfocado en la } \\
\text { música clásica. Realmente es muy poco. solo } \\
\text { en los recitales titulación y se busca la pieza } \\
\text { peruana ahí recién. que yo sé, es una } \\
\text { deficiencia del Conservatorio. Pero es cómo } \\
\text { son las cosas hasta ahora. }\end{array}$ & $\begin{array}{l}\text { Predominio de la música clásica. } \\
\text { Bajo interés y desidia en el } \\
\text { fomento de la música tradicional. } \\
\text { Reorganización curricular. } \\
\text { Falta la inserción de la música } \\
\text { tradicional en el currículo } \\
\text { Deficiencia académica }\end{array}$ & $\begin{array}{l}66 \\
67 \\
68 \\
69 \\
70 \\
\end{array}$ \\
\hline $\begin{array}{l}\text { 4.- ¿Qué estrategias y } \\
\text { técnicas emplea en el } \\
\text { proceso de } \\
\text { enseñanza } \\
\text { aprendizaje de la } \\
\text { especialidad? ¿y } \\
\text { cómo los realiza? }\end{array}$ & $\begin{array}{l}\text { Entrevistado: ¿En términos generales? } \\
\text { Entrevistador: sí en eso si } \\
\text { Entrevistado: bueno hay, uno primero tiene que desarrollar la técnica en el instrumento y después } \\
\text { enseñarles las piezas más representativas del de Literatura de la viola. Y a la vez que el alumno vaya } \\
\text { desarrollando este, su propia musicalidad porque cada alumno es diferente cada alumno toca diferente } \\
\text { entonces, pero a veces. El lalumno no puede desarrollar su musicalidad si no tiene la técnica previa } \\
\text { Entrevistador: es necesario. } \\
\text { Entrevistado: Es necesario tener la técnica. Entonces hay varios aspectos que se desarrollan. }\end{array}$ & $\begin{array}{l}\text { desarrollar la técnica en el instrumento. } \\
\text { enseñarles las piezas más representativas del } \\
\text { de Literatura de la viola. a la vez que el alumno } \\
\text { vaya desarrollando este, su propia } \\
\text { musicalidad. } \\
\text { cada alumno es diferente cada alumno toca } \\
\text { diferente. El alumno no puede desarrollar su } \\
\text { musicalidad si no tiene la técnica. Es necesario } \\
\text { tener la técnica. Entonces hay varios aspectos } \\
\text { que se desarrollan. }\end{array}$ & $\begin{array}{l}\text { Desarrollo de la técnica } \\
\text { instrumental. } \\
\text { Repertorio de viola. } \\
\text { Desarrollo de la musicalidad } \\
\text { propia en el estudiante. } \\
\text { Estructuración técnica } \\
\text { instrumental adecuada en el } \\
\text { proceso de cada estudiante }\end{array}$ & $\begin{array}{l}71 \\
72 \\
73 \\
74\end{array}$ \\
\hline $\begin{array}{l}\text { 5.- ¿Qué procesos } \\
\text { didácticos emplea Ud. } \\
\text { en la sesión de clase? }\end{array}$ & $\begin{array}{l}\text { Entrevistado: Bueno comienzo con escalas y arpegios que es la técnica. Después estudios que es } \\
\text { parte técnica también en cada estudio están concentrados en una específica destreza técnica. } \\
\text { Después siempre hago Bach. Yo creo que Bach es importante y después los alumnos tienen una pieza }\end{array}$ & $\begin{array}{l}\text { escalas y arpegios que es la técnica, } \\
\text { estudios... y encada estudio, una destreza } \\
\text { especifica. siempre hago Bach. Yo creo que }\end{array}$ & $\begin{array}{l}\text { Recursos técnicos y materiales } \\
\text { didácticos. } \\
\text { Compositor de base. }\end{array}$ & 75 \\
\hline
\end{tabular}




\begin{tabular}{|c|c|c|c|c|}
\hline & $\begin{array}{l}\text { dos que van trabajando. Entonces es bastante material que Los alumnos desarrollan una hora de } \\
\text { Entrevistador: una consulta adicional de ese punto. En el caso de que el alumno ingresa - previo } \\
\text { a un examen de admisión - y da su primera clase. Ud. ¿Realiza un diagnóstico de lo que toca? } \\
\text { Entrevistado: Bueno. Uno se da cuenta de las cosas que el alumno debe mejorar, cuáles son sus } \\
\text { fortalezas y las cosas que todavía están en proceso. eh, pero eso uno se da cuenta desde que ve al } \\
\text { alumno desde que va tocando siempre uno puede mejorar el vibrato puede mejorar el manejo del arco, } \\
\text { la posición los cambios de posición al final son las mismas cosas que todos tienen que realizar. Hay } \\
\text { unos que lo hacen mejor que otros ¿no? pero siempre son los mismos puntos que hay que enfocar. }\end{array}$ & $\begin{array}{l}\text { Bach es importante. bastante material que Los } \\
\text { alumos cosarrollan una hora de clase. Uno se } \\
\text { da cuenta de las cosas que el alumno debe } \\
\text { mejorar. desde que va tocando siempre uno } \\
\text { puede mejorar el vibrato, manejo del arco, } \\
\text { posición, cambios de posición. unos lo hacen } \\
\text { mejor que otros, pero siempre son los mismos } \\
\text { puntos que hay que enfocar. }\end{array}$ & $\begin{array}{l}\text { Evaluación y diagnostico técnico } \\
\text { musical. } \\
\text { Asistencia y retroalimentación al } \\
\text { estudiante. } \\
\text { Desarrollo personal }\end{array}$ & $\begin{array}{l}77 \\
78\end{array}$ \\
\hline $\begin{array}{l}\text { 6.- ¿Qué estrategias } \\
\text { emplea para que el } \\
\text { estudiante logre } \\
\text { articular sus } \\
\text { conocimientos } \\
\text { previos con la nueva } \\
\text { información y aplique } \\
\text { está en la solución de } \\
\text { problemas habituales } \\
\text { en el instrumento? }\end{array}$ & $\begin{array}{l}\text { Entrevistado: Bueno en el desarrollo de las piezas y estudios que el alumno va haciendo está } \\
\text { estructurado de manera que va de menos a más. Entonces si el alumno ha podido tocar una pieza Yo } \\
\text { sé que está listo para la siguiente, pero trato de no saltar porque ahí el alumno se puede frustrar porque } \\
\text { no está listo. Entonces la currícula está estructurada de cierta manera que el alumno va avanzando } \\
\text { poco a poco. Entonces uno sabe que hay una conexión con los conocimientos previos y con los } \\
\text { conocimientos que va adquiriendo. }\end{array}$ & $\begin{array}{l}\text { las piezas y estudios, está estructurado, de } \\
\text { menos a más. Si, ha podido tocar una pieza, sé } \\
\text { que está listo para la siguiente. trato de no } \\
\text { saltar porque ahí el alumno se puede frustrar } \\
\text { porque no está listo. la currícula está } \\
\text { estructurada de manera que el alumno va } \\
\text { avanzando poco a poco. hay una conexión con } \\
\text { los conocimientos previos y con los } \\
\text { conocimientos que va adquiriendo. }\end{array}$ & $\begin{array}{l}\text { Congruencia y correlación técnica. } \\
\text { Alcance de objetivos. } \\
\text { Desempeño docente y asistencia } \\
\text { al estudiante. } \\
\text { Secuencia curricular. } \\
\text { Aprendizajes logrados }\end{array}$ & $\begin{array}{l}81 \\
82 \\
83\end{array}$ \\
\hline $\begin{array}{l}\text { 7.- ¿De qué manera } \\
\text { planifica y aplica } \\
\text { estas estrategias y } \\
\text { técnicas que } \\
\text { responden a los } \\
\text { intereses y } \\
\text { necesidades de los } \\
\text { estudiantes? }\end{array}$ & $\begin{array}{l}\text { Entrevistado: Bueno este.... nuestros Alumnos del Conservatorio van a ser alumnos de orquesta. Van } \\
\text { a ser profesional de orquesta no van a ser solistas. Lamentablemente es muy complicado salir de acá } \\
\text { y ser un solista. Entonces siempre se le enfoca se le dice... bueno yo trato de decirle no toques siempre } \\
\text { como orquesta, orquesta se toca más suave, en orquesta se toca más. Y más cuadrado los ritmos. } \\
\text { Cuando uno es solista puedes tener más libertades entonces le voy haciendo diferencia entre tocar en } \\
\text { orquesta y tocar como solista. Pero también hace música de cámara y entonces hay que enfocarlos } \\
\text { por lo que los alumnos van a hacer. Pero así mismo todos van a ser profesores. Entonces yo siempre } \\
\text { estoy hablándoles de cómo enseñar cómo hacer un. cómo mejorar el vibrato cómo mejorar el arco } \\
\text { cómo hacer ciertos ejercicios que espero que ellos usen cuando sean profesores. } \\
\text { Entrevistador: Consolidando esta pregunta; en base a su experiencia ¿uno aprende más } \\
\text { practicando o enseñando? } \\
\text { Yo aprendo más enseñando, ahora claro practico ya muy poco, pero enseñando uno aprende bastante. } \\
\text { Por eso creo que todavía me conservo porque aún sin practicar tanto, todos los días estoy enseñando. } \\
\text { Entonces uno enseña y practica las cosas básicas que siempre tiene que reforzar. }\end{array}$ & $\begin{array}{l}\text { nuestros Alumnos del Conservatorio van a ser } \\
\text { profesional de orquesta no van a ser solistas, } \\
\text { es muy complicado salir de acá y ser un solista. } \\
\text { Siempre se le dice... no toques como orquesta, } \\
\text { orquesta se toca más suave, más cuadrado los } \\
\text { ritmos. Cuando uno es solista puedes tener } \\
\text { más libertades, le voy haciendo diferencia } \\
\text { entre tocar en orquesta y tocar como solista. } \\
\text { también hace música de cámara. Pero así } \\
\text { mismo todos van a ser profesores. siempre } \\
\text { estoy hablándoles de cómo enseñar, cómo } \\
\text { mejorar el vibrato, el arco cómo hacer ciertos } \\
\text { ejercicios que espero que ellos usen cuando } \\
\text { sean profesores. aprendo más enseñando, Por } \\
\text { eso creo que todavía me conservo porque aún } \\
\text { sin practicar tanto, todos los días estoy } \\
\text { enseñando. Entonces. }\end{array}$ & $\begin{array}{l}\text { Estructura, nivel y oferta } \\
\text { académica. } \\
\text { Carencia de ciertas carreras o } \\
\text { convenios para la } \\
\text { profesionalización. } \\
\text { Falta de acompañamiento } \\
\text { pedagógico. } \\
\text { orientación profesional al } \\
\text { estudiante. } \\
\text { Autoevaluación docente. }\end{array}$ & $\begin{array}{l}89 \\
90\end{array}$ \\
\hline $\begin{array}{l}\text { 8.- ¿Usted suele } \\
\text { diseñar diferentes } \\
\text { recursos didácticos } \\
\text { para cada sesión de } \\
\text { clase y de ser así } \\
\text { como se aplicaría? }\end{array}$ & $\begin{array}{l}\text { Entrevistado: no esté.... mayormente los alumnos tocan su repertorio. Lamentablemente no tenemos } \\
\text { computadora no tenemos YouTube. Lo que sí ahora tengo es celular. Entonces cuando están tocando } \\
\text { busco una versión que me gusta de esa pieza, les hago escuchar como toca como frasea el tempo, a } \\
\text { ver que tempo es, entonces con el celular me estoy agenciado. Pero que haya un diseño tecnológico } \\
\text { diseño aparte de lo que los alumnos tocan, no mucho; pero el celular también tiene metrónomo que } \\
\text { antes era un problema, inmediatamente uno puede buscar una versión de los grandes maestros para } \\
\text { que el alumno se dé cuenta, que vean que hay otras formas de hacer las cosas. } \\
\text { Entrevistador: A diferencia de hace algunos años ¿Se ha avanzado tecnológicamente en ese } \\
\text { campo? } \\
\text { Entrevistado: claro Por ejemplo cuando yo tengo que tocar Veo en YouTube las diferentes versiones } \\
\text { y de ahí saco ideas de arcos y de digitaciones e ideas de fraseo que antes cuando yo estudiaba no } \\
\text { había nada. Yo escuchaba discos, pero eso era limitado. }\end{array}$ & $\begin{array}{l}\text { Lamentablemente no tenemos computadora } \\
\text { no tenemos YouTube. Lo que sí ahora tengo es } \\
\text { celular. busco una versión, les hago escuchar } \\
\text { como toca como frasea, entonces con el celular } \\
\text { me estoy agenciado. Pero que haya un diseño } \\
\text { tecnológico diseño aparte de lo que los } \\
\text { alumnos tocan, no. el celular, tiene metrónomo } \\
\text { que antes era un problema, uno puede buscar } \\
\text { una versión de los grandes maestros para que } \\
\text { se dé cuenta, que hay otras formas de hacer } \\
\text { las cosas. } \\
\text { cuando yo tengo que tocar Veo las diferentes } \\
\text { versiones, saco ideas de arcos, de digitaciones } \\
\text { e ideas de fraseo que antes no había nada. Yo } \\
\text { escuchaba discos, pero eso era limitado. }\end{array}$ & $\begin{array}{l}\text { Carencia en el aula de los tics. } \\
\text { Uso de material didáctico y } \\
\text { tecnológico propio. } \\
\text { Búsqueda de recursos y material } \\
\text { pedagógico. } \\
\text { Preparación de clase y } \\
\text { actualización docente. }\end{array}$ & $\begin{array}{l}91 \\
92\end{array}$ \\
\hline
\end{tabular}




\section{PROCESO DE CODIFICACION DE OBSERVACION DE CLASE}

\section{$1^{\circ}$ observación}

\begin{tabular}{|c|c|c|c|c|}
\hline & Especificación & Frases codificadas & Códigos & $\mathbf{N}^{\circ}$ \\
\hline Inicio & $\begin{array}{l}\text { El docente llega al aula con cierto retraso; saluda, se disculpa, inicia su clase. } \\
\text { Relaciona correctamente el nuevo contenido con las clases pasadas, pero no uso una } \\
\text { dinámica de motivación de clase por ello los alumnos no están muy activos a } \\
\text { participar y no despierta su interés. } \\
\text { El docente explica los objetivos de la sesión, pero no son muy claros, no todos lo } \\
\text { entienden, demuestra entusiasmo al explicar los contenidos iniciales, trata de } \\
\text { involucrar a todos los estudiantes, pero no se ve un orden en el abordaje del tema, } \\
\text { algunos estudiantes conversan entre ellos y usan el celular. Finalmente realiza una } \\
\text { audición de repertorio al tema con lo que logra captar la atención de los estudiantes. } \\
\text { (quizá debió empezar por ahí) }\end{array}$ & $\begin{array}{l}\text { docente llega al aula con cierto retraso } \\
\text { Relaciona correctamente el nuevo contenido con las clases } \\
\text { pasadas no uso una dinámica de motivación... Ios alumnos no } \\
\text { están activos a participary no despierta su interés. explica los } \\
\text { objetivos, pero no son muy claros, no todos lo entienden, } \\
\text { demuestra entusiasmo, trata de involucrar a todos los } \\
\text { estudiantes, pero no hay orden en el abordaje del tema, } \\
\text { estudiantes conversan entre ellos y usan el celular. realiza una } \\
\text { audición de repertorio, logra captar la atención de los } \\
\text { estudiantes. }\end{array}$ & $\begin{array}{l}\text { Disciplina laboral. } \\
\text { Relaciona conocimientos previos. } \\
\text { Desconocimiento de estrategias didácticas. } \\
\text { Baja motivación estudiantil. } \\
\text { Docente con dificultades para hacerse entender. } \\
\text { Carencia de estrategias lúdicas que involucren a los } \\
\text { estudiantes. } \\
\text { Motivación docente. } \\
\text { Indisciplina en el aula. } \\
\text { Uso de materiales didácticos. }\end{array}$ & $\begin{array}{l}190 \\
191 \\
192 \\
193 \\
194 \\
195 \\
196 \\
197\end{array}$ \\
\hline Desarrollo & $\begin{array}{l}\text { La sesión de aprendizaje no tiene una estructura ni un orden, se basa en la repetición } \\
\text { y en la ejecución de habilidades netamente musicales. En el desarrollo de la sesión } \\
\text { no se observa participación activa por parte de los estudiantes, es más de ejecución } \\
\text { instrumental. El docente ldentifica a los estudiantes que requieren una mayor ayuda } \\
\text { o a sesoramiento especial y los asiste alternadamente. } \\
\text { El docente desarrolla lenguajes artísticos ampliamente; sin embargo, no fomenta de } \\
\text { manera significativa el aprecio, la creación y expresión de los estudiantes en su } \\
\text { práctica musical. basa el proceso de enseñanza en la repetición que si bien es el más } \\
\text { usado para la enseñanza de los distintos instrumentos musicales es considerado muy } \\
\text { tradicional y conductista; por ello este método no motiva al estudiante para lograr } \\
\text { capacidades nuevas. Además, el docente no propone metodologías innovadoras, ni } \\
\text { proyectos, no ejemplifica con circunstancias reales para lograr un aprendizaje } \\
\text { significativo. } \\
\text { La práctica musical constante genera en los estudiantes actitudes como la } \\
\text { perseverancia, motivación y emoción; sin embargo, el docente debe canalizar de } \\
\text { manera asertiva este proceso para generar el logro esperado y no la frustración en } \\
\text { los estudiantes. Por otro lado, no cuenta con el aula apropiada para el desarrollo } \\
\text { óptimo de su sesión de aprendizaje, no cuenta con material multimedia, } \\
\text { acompañamiento pedagógico; evidenciando así que la institución no les brinda las } \\
\text { facilidades logísticas, el equipamiento y menos un beneficio económico que lo ayude } \\
\text { con su labor. }\end{array}$ & $\begin{array}{l}\text { La sesión de aprendizaje no tiene una estructura ni un orden, } \\
\text { se basa en la repetición y técnica musical. En la sesión no se } \\
\text { observa participación activa de los estudiantes, El docente } \\
\text { asiste a los estudiantes que requieren mayor ayuda o } \\
\text { asesoramiento. El docente desarrolla lenguajes artísticos } \\
\text { ampliamente. no fomenta de manera significativa el aprecio, } \\
\text { la creación y expresión de los estudiantes en su práctica } \\
\text { musical...el proceso de enseñanza se basa en la repetición... } \\
\text { es el más usado para la enseñanza de instrumentos musicales } \\
\text { considerado tradicionaly conductista; este método no motiva } \\
\text { al estudiante para lograr capacidades nuevas. el docente no } \\
\text { propone metodologías innovadoras, ni proyectos, no } \\
\text { ejemplifica con circunstancias reales, no logra aprendizaje } \\
\text { significativo. La práctica musical genera perseverancia, } \\
\text { motivación y emoción; el docente debe canalizar este } \\
\text { proceso, no la frustración en los estudiantes. no cuenta con } \\
\text { el aula apropiada, no cuenta con material multimedia, } \\
\text { acompañamiento pedagógico. la institución no brinda las } \\
\text { facilidades, el equipamiento, mejora salarial. Se realiza pocas } \\
\text { actividades que promueven el pensamiento crítico (análisis, }\end{array}$ & $\begin{array}{l}\text { Falta de orden en la estructura de la sesión de } \\
\text { aprendizaje. } \\
\text { Habilidades musicales } \\
\text { Desarrollo de Técnica instrumental. } \\
\text { Compromiso del docente. } \\
\text { Acompañamiento pedagógico y asesoría al estudiante } \\
\text { Dominio docente del lenguaje artístico. } \\
\text { Carencia de estrategias para la creación, aprecio y } \\
\text { valoración de su identidad en la práctica musical. } \\
\text { No hay participación activa de los estudiantes. } \\
\text { El docente no motiva o fomenta la creatividad, aprecio } \\
\text { ni expresividad en las practicas musicales. } \\
\text { Metodología de enseñanza instrumental tradicional, } \\
\text { repetitiva y memorística. } \\
\text { Desmotivación del estudiante. } \\
\text { bajo desarrollo de capacidades. } \\
\text { falta de actualización docente en nuevas metodologías } \\
\text { de enseñanza. } \\
\text { Capacitación pedagógica docente. } \\
\text { La música y el desarrollo de habilidades blandas } \\
\text { Acompañamiento y asesoramiento, al estudiante. }\end{array}$ & $\begin{array}{l}199 \\
200 \\
201 \\
202 \\
203 \\
204 \\
205 \\
206 \\
207 \\
208 \\
209 \\
210 \\
211 \\
212 \\
213\end{array}$ \\
\hline Cierre & $\begin{array}{l}\text { No se generan análisis y pensamiento crítico de manera participativa en el cierre de } \\
\text { la sesión donde se cerciore que los conocimientos ya han sido apropiados por los } \\
\text { estudiantes. } \\
\text { El docente no ha recordado los objetivos de la sesión, ha vuelto a definir los nuevos } \\
\text { conceptos en el resumen final de la sesión, pero no ha explicado adecuadamente las } \\
\text { conclusiones. Ha promovido la búsqueda bibliográfica y la investigación; sin } \\
\text { embargo, no ha utilizado alguna estrategia para comprobar si se han cumplido los } \\
\text { objetivos de la sesión, tampoco ha explicado adecuadamente las tareas que hay que } \\
\text { realizar para la siguiente sesión y no ha gestionado adecuadamente el tiempo para } \\
\text { el cierre de la sesión. }\end{array}$ & $\begin{array}{l}\text { No se generan análisis y pensamiento crítico de manera } \\
\text { participativa, donde se cerciore que los conocimientos ya han } \\
\text { sido apropiados por los estudiantes. El docente no ha } \\
\text { recordado los objetivos de la sesión, define los nuevos } \\
\text { conceptos, pero no ha explicado las conclusiones. Ha } \\
\text { promovido la búsqueda bibliográfica y la investigación; no ha } \\
\text { comprobado los objetivos de la sesión, tampoco ha explicado } \\
\text { adecuadamente las tareas, no ha gestionado el tiempo para } \\
\text { el cierre de la sesión. }\end{array}$ & $\begin{array}{l}\text { Falta de aplicación de rubrica de evaluación. } \\
\text { retroalimentación al estudiante. } \\
\text { Cierre de la sesión de clase inconcluso. } \\
\text { Coherencia entre el planteamiento inicial y cierre de la } \\
\text { sesión. } \\
\text { Necesidad de organizar y cumplir el esquema de sesión. } \\
\text { docente investigador. } \\
\text { Fomento y promoción para la investigación. } \\
\text { Aplicación de la rúbrica de evaluación. } \\
\text { Retroalimentación y consolidado de saberes nuevos } \\
\text { inconclusos. Gestión de tiempo de la sesión }\end{array}$ & $\begin{array}{l}221 \\
222 \\
223 \\
224 \\
225 \\
226 \\
227 \\
228 \\
229\end{array}$ \\
\hline
\end{tabular}




\section{Anexo $\mathbf{N}^{\circ}$ 9: Comparación, relación y clasificación de categorías emergentes}

\begin{tabular}{|c|c|c|}
\hline FAMILIA & CODIGOS & CONCLUSIONES APROXIMATIVAS \\
\hline $\begin{array}{l}\text { Importancia de la evaluación formativa en los } \\
\text { procesos de enseñanza-aprendizaje }\end{array}$ & $\begin{array}{l}\text { Evaluación y diagnostico técnico musical. } \\
\text { Falta de a plicación de rubrica de evaluación. } \\
\text { Presenta y explica los procedimientos de aplicación de la } \\
\text { rúbrica de evaluación. } \\
\text { retroalimentación al estudiante. } \\
\text { triangulación y contraste de la información. } \\
\text { Retroalimentación inconclusa. } \\
\text { Retroalimentación y consolidado de saberes nuevos } \\
\text { inconclusos. } \\
\text { Aplicación de la rúbrica de evaluación. } \\
\text { Asistencia y retroalimentación al estudiante. } \\
\text { Autoevaluación docente. } \\
\text { Autoevaluación y reflexión docente. } \\
\text { Autoevaluación, compara criterios propios con los de las } \\
\text { clases vistos en YouTube }\end{array}$ & $\begin{array}{l}\text { La evaluación formativa nos permite orientar la actividad por medio de informes sobre la manera en que se van } \\
\text { alcanzando los objetivos. Es necesario contar previamente con una evaluación y diagnostico técnico musical del } \\
\text { estudiante, esto facilitara la estructuración de los contenidos que desarrollaran durante las sesiones de clase y } \\
\text { serán dosificados a medida que el estudiante alcance los objetivos propuestos; durante este proceso el docente } \\
\text { realizara un seguimiento constante a través de la aplicación de una rubrica de avaluación para ello debe explicar los } \\
\text { procedimientos de aplicación de la misma, y esta puede ser reajustada de acuerdo al avance del estudiante. } \\
\text { Debemos señalar que la falta de aplicación de una rubrica de avaluación en cada sesión de clase ocasionaría que la } \\
\text { consolidación de saberes nuevos quedase inconclusa y por lo tanto tampoco se daría una retroalimentación; este } \\
\text { proceso cognitivo es esencial para la triangulación de saberes previos en contraste con la nueva información, en ese } \\
\text { sentido el docente debe brindar la asistencia y acompañamiento que requiere el estudiante. } \\
\text { La autoevaluación y coevaluación que se deben dar durante desarrollo de la sesión de clase permite a los } \\
\text { estudiantes participar de manera activa en los procesos de evaluación, implica compartir y discutir con ellos los } \\
\text { objetivos de aprendizaje y los resultados esperados, apoyándolos para que, de forma individual o grupal, reflexionen } \\
\text { acerca de sus experiencias, valoren sus fortalezas y puedan programar sus avances en coordinación con el docente. } \\
\text { Es importante indicar que de la misma manera en que se evalúa formativamente a los estudiantes, los docentes } \\
\text { también deben realizar una autoevaluación y reflexión de su accionar pedagógico, este proceso permitirá consolidar }\end{array}$ \\
\hline $\begin{array}{l}\text { Gestión del tiempo durante las sesiones de } \\
\text { clase }\end{array}$ & $\begin{array}{l}\text { Gestión de tiempo de la sesión } \\
\text { Gestión de tiempo en las sesiones de clase } \\
\text { mala gestión de tiempo en la clase. } \\
\text { Posible limitación de tiempo en el desarrollo de la } \\
\text { sesión. } \\
\text { Organización de la sesión de clase. } \\
\text { Cierre de la sesión de clase inconcluso. } \\
\text { Cierre y objetivos principales de la sesión. } \\
\text { correcta organización y distribución de las horas de } \\
\text { estudio. } \\
\text { Falta de conocimiento e integración docente al proceso y } \\
\text { estructuración de sesión de clase. } \\
\text { Falta de orden en la estructura de la sesión de } \\
\text { anrondizaio }\end{array}$ & $\begin{array}{l}\text { Una enseñanza de calidad además del tiempo que se invierte en el estudiante, es una variable que el docente } \\
\text { controla e influye directamente en el rendimiento, por ello la necesidad de tener organizada la sesión de clase y } \\
\text { cumplir el esquema trazado. Una mala gestión del tiempo en la sesión ocasionaría que los objetivos planteados y los } \\
\text { aprendizajes esperados quedaran inconclusos, los estudiantes no asimilarían los contenidos y limitaría sus } \\
\text { conocimientos para la sesiones siguientes; Caroll (1963) "el grado de aprendizaje de una tarea esta en funcion de la } \\
\text { relación existente entre la cantidad de tiempo que ocupa realmente el estudiante en ella y el tiempo necesario } \\
\text { para aprender" este problema en la gestión de tiempo surge por la falta de conocimiento, orden e integración del } \\
\text { docente al proceso y estructuración de las sesiones de clase. } \\
\text { Tomando en cuenta que toda sesión posee un inicio, en donde se dan a conocer los contenidos, plantean los } \\
\text { objetivos y debe motivarse al estudiante por medio de estrategias, recursos o materiales que despierten su interés, } \\
\text { suele pasar que en esta fase de la sesión se invierte demasiado tiempo lo cual limita el desarrollo de los contenidos, } \\
\text { que es ahí en donde se afianza y consolida los temas y objetivos propuestos. Finalmente, el cierre de la sesión debe } \\
\text { tener consistencia y coherencia con el planteamiento inicial, la retroalimentación es clave en este punto pues } \\
\text { afianza los aprendizajes logrados para las demás sesiones. }\end{array}$ \\
\hline
\end{tabular}


Capacitacion y actualizacion en los contenidos de la musica tradicional

Estructuracion y contenidos de la musica academica y tradicional
Acompañamiento docente.

\section{disciplina laboral}

\section{motivacion docente}

Docente con dificultades para hacerse entender.

Falta de a compañamiento pedagógico.

falta de actualización docente en nuevas metodologías de enseñanza.

mejora del desempeño docente.

Bajo conocimiento y preparación del tema de la sesion. Capacitación pedagógica docente.

Compromiso del docente.

Criterio del docente y desarrollo de habilidades blandas.

Desarrollo personal

Desempeño docente y asistencia al estudiante.

desempeño docente.

docente investigador.

El docente no motiva o fomenta la creatividad, aprecio ni expresividad en las practicas musicales.

falta de capacitación y actualización docent

Fomento y promoción para la investigación.

Profesionalismo del docente y asistencia al estudiante.

a cerca miento correcto a la obra musical.

Amplio conocimiento de estilos musicales, géneros y

características de cada compositor.

Amplitud del criterio musical del estudiante.

Aplicación de los ejercicios técnicos (escalas, arpegios,

articulaciones etc.) en el estudio de la especialidad.

Aplicación de los elementos de la música en la practica

instrumental, grupos de cámara y orquesta.

Balance y dialogo entre las voces.

Carencia de un repertorio académico para instrumentos

de cuerda basado en la música tradicional.

Carencia de un repertorio transversal en la currícula.

Coherencia en el repertorio asignado a la especialidad
instrumental. Compositor de ba

\section{Conpositor de base.}

Clasmado en el instrumento musical.

Diversificación dos estilos y géneros musicales.

especialidades.

Diversificar la enseñanza académica usando la gran

cantidad de elementos culturales.

Las formas y estilos musicales, su estructura y desarrollo

Esquema de contenidos,

Estructura, nivel y oferta aca démica.

La institución exige un alto nivel académico.

presentación de contenidos.
En relación a la capacitación y actualización en los contenidos de la música tradicional los entrevistados manifiestan que es un tema principal para la mejora continua del trabajo profesional, lo que llevara a un mejor aprovechamiento de los aprendizajes en los estudiantes. Y que esta mejora para el desempeño docente debe estar bajo la supervision de un área especifica en la cual, se motive al docente brindándole las herramientas para la investigación en los temas y contenidos de la música tradicionaly tenga un segun

“derara \& Londoño (2004) de manera significativa, pertinente y adecuada a los contextos sociales en que se inscribe y a las poblaciones que atiende." (P.81)

La falta de un acompañamiento pedagógico, capacitación y actualización pone en evidencia un bajo conocimiento y preparación de los temas a abordar, dificultades para hacerse entender además de que un docente no motivado no fomenta la creativida, aprecioniexpresividad en la practicas musicales; al no contar con recursos, materiales ni estrategias o metodologias innovadoras, esta desmotivación se trannfier a los estros Los ementos a lus componen

asimilados $y$ comprendidos por tratamiento de estos contenidos deben reflejar las capacidades del docente para dosificar y desarrollar los temas, logrando el a precio y valoración de los elementos identitarios que conforman la música tradicional. Debe mostrar un dominio del lenguaje artístico en relación a los temas, unificando ideas, conceptos, y puntos de similitud entre los contenidos de la música académica y la música tradicional. Al abordar una obra tradicional, el rol del docente como mediador es motivar, a traves de experiencias propias, comentarios o sugerencias, al estudiante a buscar mayor

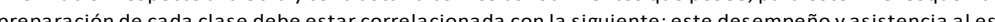
demuestra su profesiolismo, disciplina yun desarrollo de las habilidades blandas a cual promeve la empá laboral y un ambiente de trabajo óptimo.

\section{Respecto a la estructuración y contenidos de la música académica y tradicional los}

entrevistados mencionan que se debe tener un acercamiento correcto a la obra musical respaldado por un

amplio conocimiento de las formas, estilos musicales, géneros y características de cada compositor. Rivera (2016) sostiene que las diversas obras de música tradicional, ya sean propias del país o extrajeras, han sido de inspiración a diversos compositores

académicos; en ese sentido la música académica aporta recursos, herramientas y técnica al musico, las cuales también son requeridas para tener una mejor comprensión de los variados contenidos de la música tradicional. La aplicación de estos elementos de la música en la práctica instrumental, grupos de cámara y orquesta deben estar sujetos al nivel interpretativo de los estudiantes los cuales se sustentan en ejercicios técnicos (escalas, arpegios, articulaciones etc.) repertorio de la especialidad, amplitud del criterio musical, así como la experiencia ganada a través de las practicas instrumentales.

También comentan que la carencia de un repertorio académico para instrumentos de cuerda basado en la música tradicional es un impedimento para poder desarrollar la identidad musical nacional en los estudiantes, recomiendan que se debe diversificar la enseñanza académica usando la gran cantidad de elementos culturales con coherencia en el repertorio asignado a la especialidad instrumental, además debe ser transversal en la currícula, diversificando este material pedagógico entre las distintas especialidades. Consideran, que, si bien la institución exige un alto nivel académico, tanto a sus profesores como estudiantes, es necesaria una reorganización curricular tomando en 
